Universidade de São Paulo

FFCLRP - Departamento de Física

Pós-graduação em Física Aplicada à Medicina e Biologia

\title{
Vibroacustografia na avaliação tridimensional de artroplastia total de quadril
}

Hermes Arytto Salles Kamimura

Dissertação apresentada à Faculdade de Filosofia, Ciências e Letras de Ribeirão Preto da Universidade de São Paulo, como parte das exigências para a obtenção do título de Mestre em Ciências. Área: Física Aplicada à Medicina e Biologia.

Ribeirão Preto - SP

2011 
HERMES ARYTTO SALLES KAMIMURA

\section{Vibroacustografia na avaliação tridimensional de artroplastia total de quadril}

Dissertação apresentada à Faculdade de Filosofia, Ciências e Letras de Ribeirão Preto da Universidade de São Paulo, como parte das exigências para a obtenção do título de Mestre em Ciências.

Área de Concentração:

Física Aplicada à Medicina e Biologia.

Orientador:

Prof. Dr. Antonio Adilton Oliveira Carneiro

Versão corrigida

Versão original disponível na FFCLRP-USP

Ribeirão Preto - SP

2011 
Autorizo a reprodução e divulgação total ou parcial deste trabalho, por qualquer meio convencional ou eletrônico, para fins de estudo e pesquisa, desde que citada a fonte.

\section{FICHA CATALOGRÁFICA}

Kamimura, Hermes Arytto Salles.

Vibroacustografia na avaliação tridimensional de artroplastia total de quadril/ Hermes Arytto Salles Kamimura; orientador Prof. Dr. Antonio Adilton Oliveira Carneiro. Ribeirão Preto, 2011. 125 p.

Dissertação (Mestrado - Programa de Pós-graduação em Física Aplicada à Medicina e Biologia) - Faculdade de Filosofia, Ciências e Letras de Ribeirão Preto da Universidade de São Paulo.

1. artroplastia total de quadril. 2. implantes. 3. osso. 4. transdutores matriciais. 5. ultrassom. 6. vibroacustografia. 
Nome: Kamimura, Hermes Arytto Salles

Título: Vibroacustografia na avaliação tridimensional de artroplastia total de quadril

Dissertação apresentada à Faculdade de Filosofia, Ciências e Letras de Ribeirão Preto da Universidade de São Paulo, como parte das exigências para a obtenção do título de Mestre em Ciências.

Aprovado em:

\section{Banca Examinadora}

Prof. Dr. :

Instituição:

Julgamento:

Assinatura:

Prof. Dr. :

Instituição:

Julgamento:

Assinatura:

Prof. Dr. :

Instituição:

Julgamento:

Assinatura: 
Dedico este trabalho à Janette, minha mãe intercessora, ao Osamu, meu pai-herói, e às memórias de meus irmãos Marcelo e Márcio. 


\section{Agradecimentos}

Para a realização deste trabalho enfrentei uma jornada de trabalho intensa e desafiadora. Indispensavelmente, meu esforço foi impulsionado pela motivação e apoio de quem primeiramente agradeço, Deus.

Meus agradecimentos ao Prof. Dr. Antonio Adilton Oliveira Carneiro que durante este período de grandes descobertas não se limitou a me orientar, mas também me gratificou com grandes oportunidades de crescimento profissional e pessoal, além de me mostrar exemplos de dedicação e competência a serem seguidos.

Agradeço também aos meus familiares que me apoiaram durante toda minha trajetória até aqui. Em especial aos meus pais, Osamu e Janette, meus tios Eduardo, Manoela e Wellyene, minha sobrinha Mayna e cunhada Andreia, e meus primos Tomás e Luciano pelos seus conselhos.

Desde algum tempo meu interesse pela pesquisa científica tem aumentado e grandes culpados por isso são: meu tio Prof. Dr. Arlindo Kamimura, meu amigo Prof. Dr. Pedro de Lemos Menezes, o Prof. Dr. Carlos Alberto Pelá e o Prof. Dr. Marcelo Mulato, os quais agradeço imensamente pela inspiração que me forneceram e pela paciência que tiveram.

Agradeço a Aneta Chaloupková pelo apoio, incentivo e por ser minha grande surpresa na monótona Rochester.

Expresso meus agradecimentos ao Prof. Dr. Mostafa Fatemi pela supervisão do meu estágio acadêmico realizado na Mayo Clinic nos EUA, onde realizei parte da pesquisa relatada neste trabalho. Agradeço 
viii

também os Prof. Dr. James F. Greenleaf e Prof. Dr. Kai-Nan An pelo apoio nas discussões técnicas e pela disponibilização de seus laboratórios para minhas atividades de pesquisa.

O apoio técnico, bem como os momentos de descontração foram imprescindíveis para a execução deste trabalho e, portanto, agradeço os colegas do Brasil e dos EUA: Sérgio O. B. da Silva, José L. Aziane, Elcio A. Navas, Nilza M. L. Marino, Randall R. Kinnick, Thomas M. Kinter, Liao Wang, Arza Alizad e Jennifer L. Milliken.

Agradeço os amigos Theo Z. Pavan, André L. Baggio, Anderson B. de Melo, Isaias J. A. Soares, Silvio L. Vieira e Matthew W. Urban pelas discussões técnicas e auxílios nas simulações e processamentos de imagens. E também, a amiga Marina Berardi pela gentileza em corrigir a ortografia desta dissertação.

Nos momentos de cansaço encontrei energia extra para seguir em frente, através do apoio de grandes amigos que desde a minha adolescência me acompanham e torcem por mim. São eles: Sr. Paulo Hidaka, Sra. Rosalina Hidaka, Edgar Alencar, Cinthia Alencar, Marcelo Nakamura (Jiraia), Ricardo Hidaka (Ri), Sérgio Komatsu (Shi), Rodrigo Hidaka (Mazão), Stenner Hidaka (Nitchan), Enedino Silva (Nino), Bruno Bega, Douglas Steven (Bacon), Beatriz (Biazul), Érika Tanaka, Toshi Tanaka, Ricardo Duarte e Cintia Cinti.

Amigos mais recentes, porém de mesma importância em minha vida foram: Alexandre Bruno, Natália Noronha, Eduardo Ito (Edu), Gustavo Tukamoto (Tuka), Hugo Toledo (Eico), Marcos Vinícius Nakandakari (Sakê), Melina de Araújo (Mel), Rafael Araújo (Saddam), Rodrigo Sato (Tamagoxi), Rodrigo Tanaka (Buda), Tadeu Kubo, Fernanda Cavalcante, Stela Nardi (Caxinha), Elene Nardi, Gustavo Parra (Puddim), Leila Guidolin, Luiz C. Guidolin, Tiago Chaud, Danilo Toledo, Wilian (Pesado), Hugo Miguel (Monte), Igor Fiasqui (Perninha) e Lucas Del Lama (Mudinho) os quais agradeço pelos momentos de devaneios e longas discussões sobre Física e outros assuntos em bares e repúblicas.

Além disso, agradeço os demais companheiros de laboratório, 
Thiago Almeida, Marden Fagundes, Rogério Bulha, Marcelo de Pádua, Raimundo Nonato, Ebenézer Cavalcanti, Larissa Gatto, Tenysson de Lemos, Diego Thomaz cujas companhias foram indispensáveis para o meu crescimento profissional e pessoal.

Nos EUA, também tive o grande apoio de: Anne Suchomel, Alireza Rafsanjani, Aracelly Medina, Tatiana Biles, Natthan, Al-Batool, Yuko Miyabara, Rei Omi, Akira Goto, Jie Liang, Heng Zhao, Miguel Restrepo, que não só tiveram paciência em me ajudar na melhoria do meu inglês, como também tornaram minha vida muito mais fácil na gelada Rochester.

Agradeço o Conselho Nacional de Desenvolvimento Científico e Tecnológico (CNPq) e o National Institute of Health dos EUA, pelo apoio financeiro.

Este trabalho não somente me permitiu o crescimento profissional, como também me reservou maravilhosas surpresas que me fazem pessoalmente grato e realizado.

MUITO OBRIGADO A TODOS! 


\section{Resumo}

Kamimura, H.A.S Vibroacustografia na avaliação tridimensional de artroplastia total de quadril. 2011. Dissertação (Mestrado Programa de Pós-graduação em Física Aplicada à Medicina e Biologia) - Faculdade de Filosofia, Ciências e Letras de Ribeirão Preto da Universidade de São Paulo. 2011.

A vibroacustografia (VA) é uma técnica de imagem de alta resolução lateral $(<0,7 \mathrm{~mm})$, livre de speckles, não invasiva e que utiliza radiação não-ionizante, baseada no fenômeno de combinação não-linear de ondas de ultrassom $(\mathrm{MHz})$ que gera uma região focal estreita de baixa frequência $(\mathrm{kHz})$. Neste trabalho, propõe-se uma avaliação tridimensional baseada em imagens de VA da área descoberta de implantes, após o procedimento cirúrgico de artroplastia total de quadril (ATQ). A ATQ é uma técnica terapêutica de substituição de articulações do quadril por implantes, em pacientes com osteoartrose avançada. Atualmente, o acompanhamento pós-operatório é auxiliado pela análise de radiografia plana por raios-X. Contudo, esta técnica apresenta limitações na avaliação da estabilidade dos implantes, tais como: avaliação imprecisa da área, uma vez que, a radiografia plana trata o problema tridimensional como bidimensional; impossibilidade de visualização de algumas regiões do implante, devido ao sobreposicionamento das regiões numa imagem planar; restrição do uso de radiação ionizante na região da pelve em pacientes jovens. Devido à alta atenuação da onda de ultrassom incidindo sobre 
xii

objetos densos, a VA pode ser ajustada para adquirir imagens relativas, principalmente, à superfície destes. Uma correção da topologia baseada na geometria do implante é apresentada, a fim de se avaliar com precisão a área superficial na representação tridimensional da imagem de VA. A correção da topologia baseada em aquisições em modo-B também é apresentada, sendo útil na avaliação da forma de ossos ou nos casos em que a forma do objeto estudado é desconhecida. Além disso, é apresentado um estudo numérico da utilização de transdutores matriciais reconfiguráveis $(R C A$, do inglês reconfigurable array) para a formação de feixe em VA. Um estudo paramétrico da seleção de abertura, número de canais, número de elementos, distância focal e parâmetros de varredura eletrônica do feixe é apresentado para demonstrar a viabilidade e avaliar o desempenho da imagem de VA utilizando o RCA. A função de espalhamento de ponto do sistema foi calculada com base em métodos de espectro angular usando a aproximação de Fresnel para fontes retangulares. Foram discutidas as vantagens de transdutores bidimensionais e RCA, e aspectos relacionados à importância clínica da implementação do $R C A$ na VA, tais como resolução espacial, taxa de aquisição da imagem e implementação do RCA em máquinas comerciais. Conclui-se que: a aquisição de imagens por VA foi menos sensível ao ângulo de incidência das ondas de ultrassom do que por modo-B e apresentou alta resolução e alto contraste entre o osso e o implante, o que permitiu uma avaliação precisa da área exposta do implante; os transdutores RCA podem aprimorar a aquisição de imagens por VA, devido à sua resolução espacial similar à de transdutores confocais e à possibilidade de deflexão eletrônica do feixe (em inglês steering) nos planos de elevação e azimutal.

Palavras-chave: artroplastia total de quadril, implantes, osso, transdutores matriciais, ultrassom, vibroacustografia. 


\section{Abstract}

Kamimura, H.A.S Vibro-acoustography in the tridimensional evaluation of total hip arthroplasty. 2011. Thesis (Masters Physics Applied to Medicine and Biology Graduate Program) - Faculdade de Filosofia, Ciências e Letras de Ribeirão Preto da Universidade de São Paulo. 2011.

Vibro-acoustography (VA) is a high lateral resolution $(<0.7 \mathrm{~mm})$, speckle-free, non-ionizing and non-invasive image based on the nonlinear combination phenomenon of ultrasound waves $(\mathrm{MHz})$ that generates a narrow focus region of low frequency $(\mathrm{kHz})$. In this work, we propose a VA-based tridimensional evaluation of the exposed area of implants, after total hip arthroplasty (THA). THA is a therapeutic surgery procedure in which the hip joints are replaced by metal prostheses in patients with advanced osteoarthritis. Currently, the postoperative assessment of THA is performed by analyzing planar $\mathrm{X}$-ray radiographies. However, this technique presents limitations in the implant stability evaluation such as: inaccurate evaluation of the area, since the planar radiography reduces the tridimensional problem into a two-dimensional one; problems in the visualization of some regions of the implants due to the superimposition of the regions; limitations of using ionizing radiation in the pelvis region of young patients. Due to the high attenuation of the ultrasound wave into objects of high density, the VA image can be set to mainly acquire the surface information. Topological correction based on the geometry of 
xiv

the implant is presented in order to accurately evaluate the surface area in tridimensional representation of the VA image. The topological correction based on B-mode slices is also presented and is useful in the evaluation of bone shape or in cases which the shape of the object is unknown. Furthermore, it is presented a numerical study of the use of reconfigurable arrays (RCA) for VA beam formation. A parametric study of the aperture selection, number of channels, number of elements, focal distance and steering parameters is presented in order to show the feasibility and evaluate the performance of VA imaging based on RCA. The point-spread function of the system is calculated based on angular spectrum methods using the Fresnel approximation for rectangular sources. Advantages of two-dimensional and RCA arrays and aspects related to clinical importance of the RCA implementation in VA such as spatial resolution, image frame-rate, and commercial machine implementation are discussed. It is concluded that: the VA image is less sensitive to the wave incident angle than B-mode; the VA image presents high-resolution and high-contrast between bone and implant, which allowed an accurate evaluation of the uncovered area; RCA transducers improve the VA acquisition by producing spatial resolution similar to confocal transducers, and due to the possibility of steering in elevation and azimuthal planes.

Keywords: bone, implant, reconfigurable array, total hip arthroplasty, ultrasound, vibro-acoustography. 


\section{Lista de Abreviaturas}

AM Amplitude modulada (Amplitude modulated)

AP Anteroposterior (Antero-posterior)

ATQ Artroplastia total de quadril (Total hip arthroplasty)

DAC Desenho assistido por computador (CAD, Computer aided design)

DDQ Displasia do desenvolvimento de quadril (Dysplasia of hip development)

FFT Transformada rápida de Fourier (Fast Fourier Transform)

FWHM Largura à meia altura (Full-width at half-maximum)

K-K Kramers-Kronig (Kramers-Kronig)

OSTM Objeto simulador de tecido mole (Tissue-mimicking material)

PSF Função de espalhamento de ponto (Point spread function)

RCA Transdutor matricial reconfigurável (Reconfigurable array)

US Ultrassom (Ultrasound)

US 3D Ultrassom tridimensional (Tridimensional ultrasound)

VA Vibroacustografia (Vibro-acoustography) 


\section{Lista de Símbolos}

$\begin{array}{ll}A & \text { Área } \\ c & \text { Velocidade do som } \\ c_{0} & \text { Velocidade de fase da onda } \\ d & \text { Distância entre o topo do implante e o transdutor confocal } \\ D_{f} & \text { Distância focal } \\ d_{g} & \text { Espessura da camada de gordura } \\ d_{m} & \text { Espessura da camada de músculo } \\ d_{r} & \text { Coeficiente de arrasto } \\ E & \text { Densidade de energia } \\ f & \text { Frequência } \\ F & \text { Força de radiação } \\ F_{d} & \text { Componente dinâmica da força de radiação } \\ f_{R} & \text { Fator de correção das resoluções das imagens } \\ F_{Z} & \text { Zona focal } \\ H & \text { Altura total do transdutor retangular } \\ n & \text { Fator de dependência com a frequência do coeficiente } \\ & \text { de atenuação }\end{array}$


$N_{c} \quad$ Número de canais do transdutor

$N_{e} \quad$ Número de elementos do transdutor

$\vec{I} \quad$ Vetor intensidade

$\vec{I}_{0} \quad$ Vetor intensidade inicial

$\operatorname{Im}(x, y)$ Função que descreve a imagem nas direções $x$ e $y$

$J_{1} \quad$ Função de Bessel cilíndrica de primeira ordem

k Número de onda

p Pressão

$r \quad$ Raio da componente acetabular

$\vec{r} \quad$ Vetor posição

$R_{i} \quad$ Coeficiente de reflexão da intensidade acústica

$R_{l} \quad$ Resolução lateral

$R_{p} \quad$ Coeficiente de reflexão da pressão acústica

$R_{m B} \quad$ Resolução da imagem em modo-B

$R_{G} \quad$ Resolução geral, incluindo resolução da imagem de VA

e distanciamento entre as imagens de modo-B

$R_{V A} \quad$ Resolução da imagem de vibroacustografia

S Área superficial

$T_{p} \quad$ Coeficiente de transmissão da pressão acústica

$u_{0} \quad$ Velocidade da partícula na superfície do transdutor

v $\quad$ Velocidade da partícula

$v_{i} \quad$ Vértices de um triângulo $\left(v_{i}=\left(x_{i}, y_{i}, z_{i}\right)\right)$ 
W Largura total do transdutor retangular

$x, y, z \quad$ Componentes do sistema de coordenadas cartesianas

$Z_{0} \quad$ Impedância característica

$Z_{01} \quad$ Impedância característica do meio 1

$Z_{02} \quad$ Impedância característica do meio 2

$Z_{a} \quad$ Impedância acústica

$Z_{e} \quad$ Impedância específica

$\alpha \quad$ Coeficiente de atenuação total

$\alpha_{0}{ }^{\prime} \quad$ Fator de atenuação

$\alpha_{a} \quad$ Coeficiente de atenuação devido à absorção

$\alpha_{e} \quad$ Coeficiente de atenuação devido ao espalhamento

$\alpha_{g} \quad$ Coeficiente de atenuação da gordura

$\alpha_{m} \quad$ Coeficiente de atenuação do músculo

$\beta \quad$ Componente real da compressibilidade adiabática

$\Delta \omega \quad$ Diferença de frequência angular

$\Delta f \quad$ Diferença de frequência

$\theta \quad$ Ângulo genérico

$\theta_{i} \quad$ Ângulo de incidência

$\theta_{t} \quad$ Ângulo de transmissão

K Compressibilidade adiabática para ondas acústicas

$\lambda \quad$ Comprimento de onda

$\rho \quad$ Densidade do meio 
$\rho_{0} \quad$ Densidade no equilíbrio

$\phi_{i} \quad$ Funções de fase da onda $(\operatorname{com} i=1,2)$

$\Phi \quad$ Potencial de velocidade

$\xi_{0} \quad$ Função apodização

$\omega \quad$ Frequência angular $(\omega=2 \pi f)$

$\omega_{0} \quad$ Frequência angular central 


\section{Lista de Figuras}

1.1 Ilustração de artroplastia total de quadril. Modificado de: http://healthierchoices.ca/TestsAndProcedures_details. aspx?TP_id=10\&Type=1 (Acessado em: mar/2011). . . . . 2

1.2 Radiografias pélvicas AP de um homem de 29 anos (a) com displasia do quadril e (b) após artroplastia total de quadril de ambos os lados do quadril. Fonte: Spangehl et al. The Journal of Bone and Joint Surgery, 2001 [2]. . . . . . . . . 3

1.3 Radiografias AP (anteroposterior) de modelos pélvicos, simulando diferentes coberturas de componentes acetabulares em artroplastia total de quadril. . . . . . . . . . . . 4

2.1 Transdutor confocal de duas cerâmicas utilizado na aquisição em modo de VA. . . . . . . . . . . . . . . . 15

2.2 Mapa acústico do transdutor confocal simulado em Field II [38]. (a) Sagital na região focal $(7 \mathrm{~cm})$ e (b) plano azimutal. 15

2.3 Esquema simplificado mostrando sistema de excitação e detecção da VA. . . . . . . . . . . . . . . . . . 17

2.4 Esquema das conexões elétricas para os diferentes transdutores matriciais. (a) 1D; (b) 1,25D; (c) 1,5D; (d) 1,75D e (e) 2D. . . . . . . . . . . . . . . . . . 19

2.5 Imagens de osso de frango por VA utilizando transdutor confocal de foco fixo à aproximadamente $7 \mathrm{~cm}$, para diferentes distâncias entre transdutor e osso. . . . . . . 20 
xxii

3.1 Modelo ósseo de pelve masculina adulta feito de material esponjoso. . . . . . . . . . . . . . . . . . . 22

3.2 Componente acetabular metálica utilizada em artroplastia total de quadril. . . . . . . . . . . . . . . . . 23

3.3 Objeto simulador à base de gelatina de porco e leite evaporado, moldado no formato do modelo pélvico. . . . . 25

3.4 Modelo pélvico simulando artroplastia total de quadril composto de: pelve feita de Foam Cortical Shell, tecido mole à base de gelatina e leite evaporado, e componente acetabular. . . . . . . . . . . . . . . . . . . . . . . . 25

3.5 Tanque acústico preenchido com água desgaseificada e sistema de motores para realização de varreduras em modo de VA e modo-B. . . . . . . . . . . . . . . . . 26

3.6 Descrição do sistema de VA e montagem experimental para estudo de artroplastia total de quadril. O sistema mecânico de varredura controlado pelo computador permite o ajuste da posição do foco. . . . . . . . . . 28

3.7 (a) Equipamentos eletrônicos utilizados na geração de imagens por VA, de cima para baixo: fonte de alimentação e pré-amplificador para hidrofone, amplificador lock-in (não utilizado), filtro passa-banda, geradores de função e amplificador de potência. (b) Aparato experimental simulando ATQ dentro do tanque de água. . . . . . . . . 28

3.8 (a) Aparelho convencional de ultrassom GE modelo Vivid 7 utilizado para aquisições em modo-B do modelo pélvico. (b) Aparato experimental para aquisições em modo-B. . . . 30

3.9 Vetores formados pelas coordenadas da superfície 3D do implante. Geometricamente, o produto vetorial entre dois vetores representa a área do paralelogramo. . . . . . . . . . 35 
3.10Sistema de digitalização. (a) Ponta de prova em contato com a borda para digitalização de pontos escolhidos pelo usuário, (b) arranjo experimental para digitalização e (c) sistema de digitalização ótica NDI modelo Optotrak Certus ${ }^{\top \mathrm{TM}} .36$

4.1 Imagens de VA em diferentes posicionamentos do foco, com distâncias $d$ entre o transdutor e o topo do implante iguais a: (a) $6,3 \mathrm{~cm}$, (b) $5,8 \mathrm{~cm}$ e (c) $5,3 \mathrm{~cm}$. A Figura (d) mostra a combinação linear das imagens com igual ponderação.

4.2 Segmentação por contorno da imagem de VA para identificação da área descoberta do implante. (a) Imagem combinada de VA, (b) gradiente de magnitude, (c) região segmentada e (d) região segmentada destacada na imagem original. . . . . . . . . . . . . . . . . . .

4.3 Representação 3D da imagem de VA pelo método analítico de correção da topologia. (a) Topologia 3D definida pela equação da esfera com diâmetro de $57,1 \pm 0,05 \mathrm{~mm}$, igual ao do implante e (b) representação 3D da imagem de VA. .

4.4 Representação 3D da área descoberta do implante a partir de método analítico de reconstrução da topologia do implante e imagem adquirida por VA. (a) Representação 3D da área descoberta e (b) vista de topo da área descoberta. . . . . . . . . . . . . . . . . . . . . . .

4.5 (a) Representação analítica de semiesfera para a topologia do implante e (b) exemplo de possível desalinhamento da região exposta do implante na aquisição da imagem de VA (vista de cima). 
xxiv

4.6 Aquisição de imagem em modo-B fornecida pela máquina GE Vivid 7 mostrando a superfície do implante e a região óssea do modelo. (a) Imagem original, com escala de profundidade à esquerda da imagem (em amarelo) apresentada em centímetros e (b) visualização da mesma imagem processada no software Imagel, mostrando as superfícies do implante e do osso em amarelo com alta reflexão da onda ultrassônica. . . . . . . . . . . . . . . . . . . .46

4.7 Sequência de processamento aplicada nas 280 imagens adquiridas em modo-B para extração de superfície tridimensional. (a) Correção da resolução espacial e extração da região de interesse, (b) aplicação de $80 \%$ de threshold e filtro de média, (c) extração dos pixeis de maior valor e binarização da imagem, (d) ligação entre os pontos por interpolação linear e (e) construção da superfície tridimensional da região de interesse a partir das linhas extraídas do processo exemplificado em (d). . . .

4.8 Representação 3D da imagem de VA com correção da topologia a partir de imagens adquiridas em modo-B. (a) Topologia 3D a partir da aquisição de 280 imagens em modo-B da região de interesse e (b) representação 3D da imagem de VA.

4.9 Representação 3D da área descoberta do implante a partir de imagens adquiridas em modo-B e por VA. (a) Representação 3D da área descoberta e (b) vista de topo da área descoberta. . . . . . . . . . . . . . . . . . . . . . . .49 
4.10Processo de geração de superfície em software de CAD (Solidworks ${ }^{T M}$ ) baseado nos pontos digitalizados pelo sistema ótico (Optotrak Certus ${ }^{\top \mathrm{M}}$ ). (a) Pontos digitalizados em espaço tridimensional, (b) semicírculo gerado a partir dos pontos capturados sobre a borda do implante, (c) semiesfera representando o implante e linha de borda determinada pelos pontos adquiridos na borda osso/implante e (d) superfície descoberta do implante determinada a partir dos pontos digitalizados na borda entre osso e implante. . . . . . . . . . . . . . . . . . . . . 51

4.11Representação 3D de 280 aquisições em modo-B, também conhecida do inglês como $3 D B$-scan, da região do implante e região óssea adjacente. (a) Vista frontal e (b) vista em perspectiva. . . . . . . . . . . . . . . . 53

4.12 Perfis da região metálica obtidos pelo método analítico (em azul) e pelo método baseado em aquisições de modo-B (em vermelho). O método baseado em modo-B apresenta distorções, especialmente nas bordas laterais, causadas pelo espalhamento da onda ultrassônica pela superfície rugosa do implante. . . . . . . . . . . . . . . 54

4.13Curvas de nível da área descoberta. (a) Método analítico e (b) método baseado nas aquisições em modo-B. . . . . . . 54

5.1 Transdutor matricial reconfigurável com fontes retangulares $\left(x_{m}, y_{n}\right)$ situadas no plano de origem e um ponto de observação em $\left(x_{0}, y_{0}, z_{0}\right)$ no plano de observação numa distância $R_{m n} \ldots \ldots \ldots \ldots$. . . . . . . . . 60 
5.2 Aspectos para a definição da abertura: (a) canais, representados por iguais áreas mostrando os elementos ativados para cada canal; (b) regiões para cada frequência, áreas com frequência de excitação $\omega_{1}$ em vermelho e $\omega_{2}$ em verde; e (c) perfil de atraso temporal, no qual diferentes níveis representam atrasos na fase de ativação. As figuras (d), (e) e (f) mostram os respectivos aspectos para definição de abertura para $6 \mathrm{~mm}$ de deflexão eletrônica do foco na direção $x$. A variação no número de canais nas simulações foi de 32 à 128. Para permitir uma boa visualização foram representados apenas 8 canais neste esquema. . . . . . . . . . . . . . . . . . . .65

5.3 Parâmetros espaciais utilizados na avaliação do foco. A FWHM foi utilizada para definir a zona focal e a resolução lateral. A distância focal foi definida como a distância entre o transdutor e o ponto de máximo da força acústica. . . . . . 66

5.4 Variação da amplitude da força em relação às distâncias focais de 20, 30, 40 e $50 \mathrm{~mm}$ representadas em (a), (b), (c) e (d), respectivamente. O número de canais avaliados foram 32, 64, 96 e 128. O número de elementos foi fixado em $200 \times 200$. Todos os valores foram normalizados pelo valor máximo para todas as distâncias. . . . . . . . . . 68

5.5 Resoluções laterais para profundidades de foco em 20, 30 , 40 e $50 \mathrm{~mm}$ para 128 canais e $200 \times 200$ elementos. . . . 69

5.6 Mapas da PSF para 128 canais, distância focal ajustada para $20 \mathrm{~mm}$ e número de elementos variando de $50 \times 50$ à $200 \times 200 \ldots \ldots$. . . . . . . . . . . . . . 70

5.7 Perfil axial da PSF mostrando a distância focal efetiva para número de elementos variando de 50 × 50 à 200 × $200 . \ldots 71$ 
5.8 Mapas da PSF para distâncias focais de 20, 30, 40 e 50 mm, em (a), (b), (c) e (d), respectivamente. O número de canais foi ajustado para 128 , o número de elementos para $200 \times 200$ e o feixe foi deslocado na direção azimutal para valores de $x_{0}=0,3,6,9$ e $12 \mathrm{~mm} \ldots \ldots \ldots . \ldots 72$

5.9 Forças máximas normalizadas extraídas dos mapas da Figura 5.8 para distâncias focais esperadas em 20, 30, 40 e $50 \mathrm{~mm}$. . . . . . . . . . . . . . . . . . . . . . 73

5.10Variação da magnitude normalizada da componente de $\Delta \omega$ com $N_{c, 1}$ e localização focal variando de $x_{0}=0$ a $25 \mathrm{~mm}$

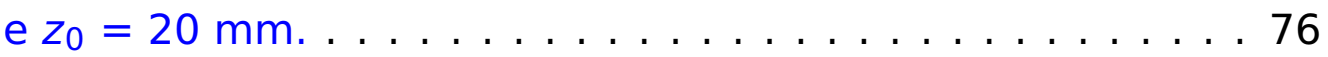

5.11Resultados da otimização da deflexão eletrônica do foco para diferentes posições focais. (a) Valores ótimos para $N_{c, 1}$ e (b) magnitude normalizada da componente de $\Delta \omega$ $\operatorname{com} N_{c, 1}=N_{c, 2}=64 \ldots \ldots \ldots \ldots \ldots \ldots$

5.12 Magnitude otimizada da componente de $\Delta \omega$ para diferentes posições focais. . . . . . . . . . . . . . . . . 77 
xxviii 


\section{Lista de Tabelas}

2.1 Nomenclatura para transdutores de ultrassom matriciais. . 18

3.1 Valores empíricos para velocidade do som, densidade e atenuação para diferentes tecidos para uma onda de $1 \mathrm{MHz} .24$

3.2 Ingredientes do objeto simulador de tecido mole simulando músculo esquelético e gordura. . . . . . . . . . . . . 24

4.1 Resultados das avaliações das áreas descoberta e coberta do implante pelos métodos ótico, analítico e baseado em imagens por modo-B. . . . . . . . . . . . . . 52

5.1 Parâmetros gerais para simulações do $R C A \ldots \ldots \ldots \ldots 3$

5.2 f-número para aberturas e distâncias focais utilizadas nas simulações. . . . . . . . . . . . . . . . . . . . 71

5.3 Resumo do desempenho geral do RCA para diferentes números de canais e elementos e diferentes distâncias focais. $D_{f}$ é a distância focal efetiva, $F_{z}$ a zona focal, $R_{l}$ a resolução lateral e $F_{n}$ a força normalizada. . . . . . . 74 
$x x x$ 


\section{Sumário}

Agradecimentos vii

Resumo xi

Abstract $\quad$ xii

$\begin{array}{ll}\text { Lista de Abreviaturas } & \text { xv }\end{array}$

Lista de Símbolos $\quad$ xvii

Lista de Figuras $\quad$ xxi

Lista de Tabelas $\quad$ xxix

1 Introdução 1

1.1 Motivação . . . . . . . . . . . . . . . . . . . . 2

1.2 Objetivos ...................... 6

1.3 Organização do trabalho . . . . . . . . . . . . . . 6

2 Fundamentação teórica 9

2.1 Atenuação da onda ultrassônica . . . . . . . . . . . . . . . . 9

2.2 Impedância acústica . . . . . . . . . . . . . . . . . . . . . . 11

2.3 Coeficientes de reflexão e de transmissão . . . . . . . . . . . . 13

2.4 Força de radiação acústica dinâmica . . . . . . . . . . . . . 13

3 Materiais e métodos 21

3.1 Modelo para representação de artroplastia total de quadril . . . . . . . . . . . . 22 
xxxii

3.1.1 Pelve e implante metálico . . . . . . . . . . . 22

3.1 .2 Tecido mole . . . . . . . . . . . . . . . . . . . 22

3.2 Aquisições . . . . . . . . . . . . . . . . 26

3.2.1 Modo de vibroacustografia . . . . . . . . . . . . . 27

3.2 .2 Modo-B . . . . . . . . . . . . . . . . . . . . . . . 29

3.3 Processamento de imagens . . . . . . . . . . . . . 29

3.3.1 Segmentação . . . . . . . . . . . . . . 30

3.3.2 Correção da topologia . . . . . . . . . . . . . . . 31

3.4 Avaliação da área superficial . . . . . . . . . . . . . . 34

4 Resultados e discussão 39

4.1 Imagens de vibroacustografia . . . . . . . . . . . . 39

4.2 Segmentação . . . . . . . . . . . . . . . . 41

4.3 Correção de topologia . . . . . . . . . . . . . . . . . 42

4.3.1 Método analítico . . . . . . . . . . . . . . . 42

4.3.2 Método baseado nas aquisições em modo-B . . . . . 45

4.4 Avaliação da área superficial . . . . . . . . . . . . 50

4.4.1 Método ótico . . . . . . . . . . . . . . . 50

4.4 .2 Por vibroacustografia . . . . . . . . . . . . 51

4.5 Discussão . . . . . . . . . . . . . . . . . . 51

5 Transdutor matricial reconfigurável para VA 57

5.0.1 Solução analítica para o campo acústico . . . . . . . 59

5.0 .2 Implementação numérica . . . . . . . . . . . 61

5.1 Algoritmo . . . . . . . . . . . . . . 63

5.1 .1 Descrição geral . . . . . . . . . . . . . . 63

5.1.2 Definição da abertura para o estudo numérico . . . . 64

5.1 .3 Análise da PSF . . . . . . . . . . . . . . . . . 66

5.1.4 Otimização da deflexão eletrônica do foco . . . . . . 66

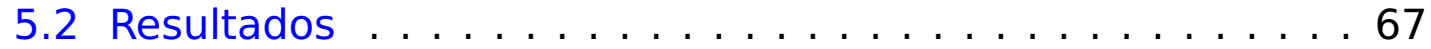

5.2.1 Análise espacial do foco . . . . . . . . . . . 67

5.2.2 Otimização da deflexão eletrônica do foco . . . . . . 75

5.3 Discussão . . . . . . . . . . . . . . . . . . . . . . . . . . 75 
xxxiii

6 Considerações finais $\quad 81$

6.1 Conclusões . . . . . . . . . . . . . . . . 81

6.2 Trabalhos Futuros . . . . . . . . . . . . . . . 82

$\begin{array}{ll}\text { Referências Bibliográficas } & 85\end{array}$ 
xxxiv 


\section{Capítulo}

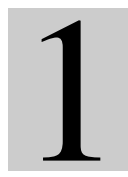

\section{Introdução}

A Artroplastia Total de Quadril (ATQ) é um procedimento terapêutico de reconstituição cirúrgica da articulação do quadril, cujo objetivo é aliviar a dor ou restaurar o movimento de pacientes com osteoartrose avançada [1]. A osteoartrose, ou osteoartrite, é a forma mais comum de artrite $^{1}$, caracterizada pela degeneração progressiva da articulação, acompanhada de aumento progressivo de dor, deformação e limitação de movimentos. Ocorre devido ao estresse mecânico da cartilagem articular sujeita a cargas exageradas por longo período de tempo, por problemas congênitos ou de desenvolvimento da cartilagem ou osso [2]. Nesse procedimento, duas próteses são implantadas: uma em substituição à cabeça do fêmur e outra posicionada na pelve, na região do acetábulo (esse implante é chamado de componente acetabular) (Figura 1.1).

A radiografia plana tem sido a principal técnica utilizada na avaliação de ATQ. Contudo, por se tratar de um problema tridimensional, a visualização plana prejudica o diagnóstico preciso da estabilidade do implante em ATQ [3]. Este trabalho propõe o uso da imagem de vibroacustografia [4] representada em três dimensões para uma avaliação mais precisa da estabilidade do implante. 0 trabalho foi realizado em parte no laboratório GIIMUS (Grupo de Inovação em Instrumentação Médica e Ultrassom, Universidade de São Paulo,

\footnotetext{
${ }^{1}$ Definição dada por DeCS - Descritores em Ciências da Saúde http://decs . bvs . $\mathrm{br} /$ (Acessado em: mar/2011)
} 


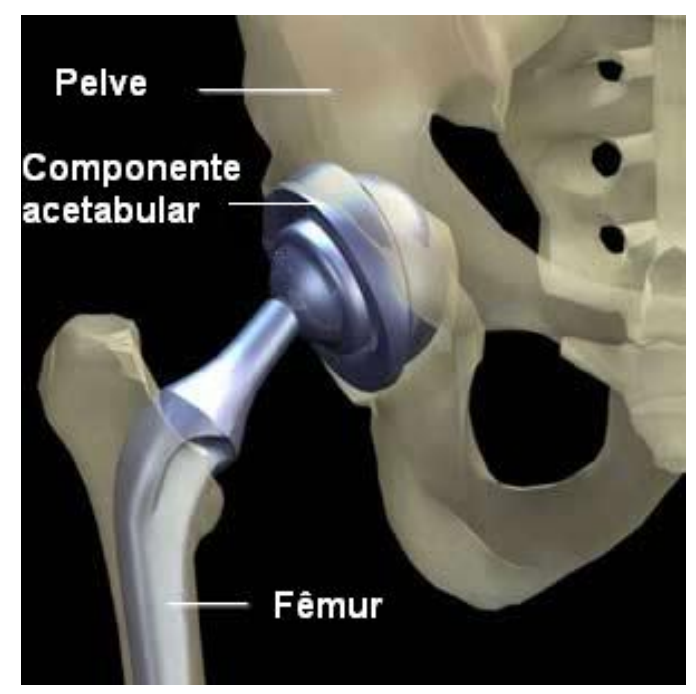

Figura 1.1: Ilustração de artroplastia total de quadril. Modificado de: http://healthierchoices.ca/TestsAndProcedures_details. aspx?TP_id=10\&Type=1 (Acessado em: mar/2011).

Ribeirão Preto, SP, Brasil) e em parte no laboratório de Ultrassom da Mayo Clinic (College of Medicine, Rochester, MN, EUA).

\subsection{Motivação}

A avaliação da área do implante coberta pelo acetábulo dentro da pelve ou, cobertura do implante, pode ser um importante fator prognóstico para a avaliação da estabilidade do implante. Em alguns casos, a componente acetabular pode não obter plena cobertura no acetábulo como, por exemplo, em: pacientes com displasia do desenvolvimento do quadril (DDQ) [5] (Figura 1.2(a)) e pacientes sob revisão [6]. Estudos prévios têm investigado a relação entre a taxa de perda e a medida da cobertura da componente acetabular, baseada em radiografias AP (anteroposterior) planas do quadril. As recomendações sobre a cobertura do implante variam entre 60 e $80 \%$ [7] [8] [9] [10]. Contudo, a cobertura mínima em três dimensões não é bem definida [11] e poderia ser utilizada como critério, durante o posicionamento da componente acetabular e a avaliação pós-operatória. Para se obter uma informação precisa da 


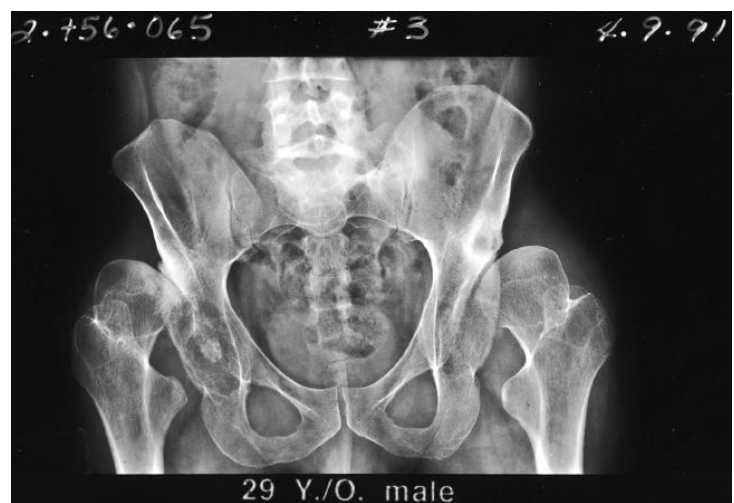

(a)

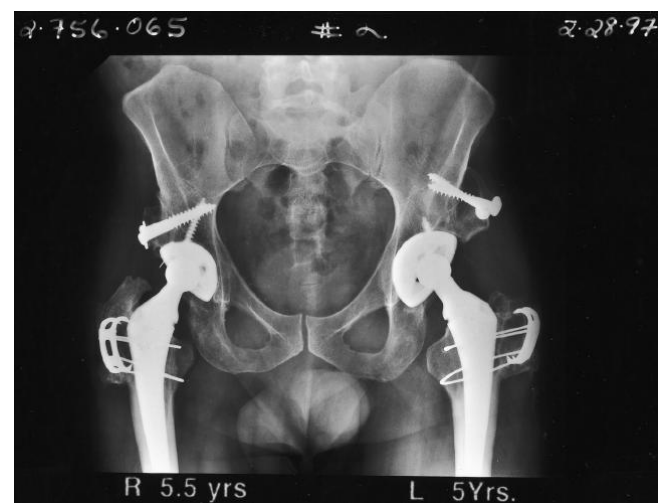

(b)

Figura 1.2: Radiografias pélvicas AP de um homem de 29 anos (a) com displasia do quadril e (b) após artroplastia total de quadril de ambos os lados do quadril. Fonte: Spangehl et al. The Journal of Bone and Joint Surgery, 2001 [2].

cobertura mínima da componente acetabular, uma técnica de geração de imagens tridimensionais é necessária para avaliação pós-cirúrgica.

Diversos estudos de acompanhamento pós-operatório têm sido realizados utilizando a radiografia plana [12] [13] [14]. Contudo, Spangehl et al. [3] apontaram as limitações relacionadas à visualização bidimensional da cobertura da componente acetabular, por se tratar de um problema tridimensional. A radiografia AP permite uma visualização parcial (lateral) da cobertura da componente acetabular. Em alguns casos, a visualização por radiografia AP leva a uma estimativa imprecisa da região descoberta do implante quando a deficiência da cobertura é posterior e/ou anterior (Figura 1.2(b)).

A Figura 1.3 mostra alguns exemplos de radiografias AP de modelos pélvicos com diferentes coberturas parciais das componentes acetabulares. As visualizações por radiografia plana permitem apenas a visualização lateral das coberturas dos implantes. A visualização das regiões anterior e posterior fica prejudicada por esta técnica.

Técnicas de ultrassom (US) têm sido amplamente utilizadas na avaliação de ossos [15] [16]. A geração de imagens por US pode ser útil no diagnóstico de fraturas em osso, não detectáveis por 


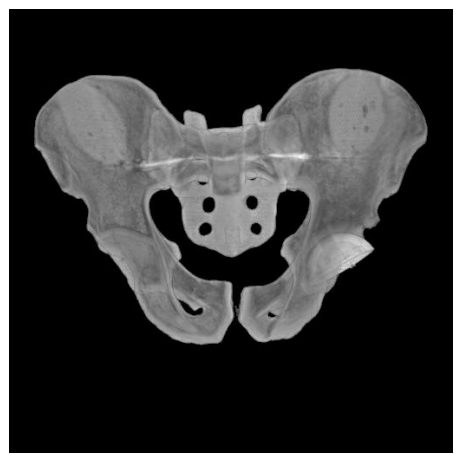

(a)

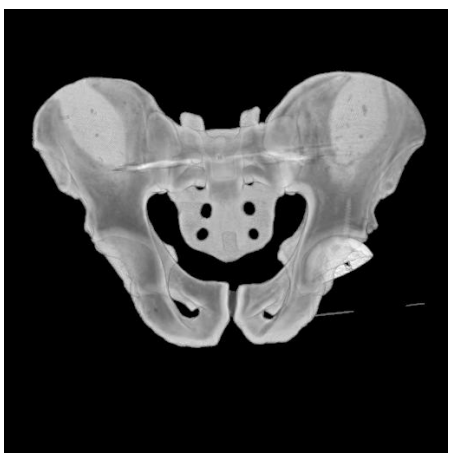

(b)

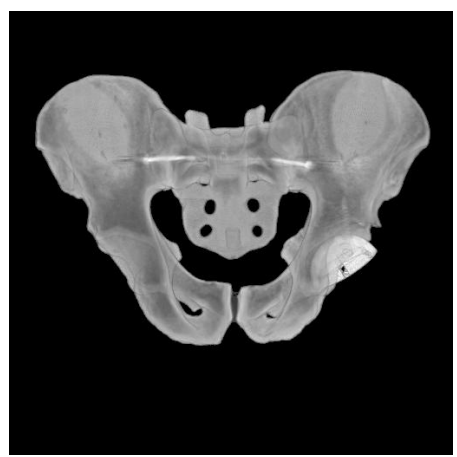

(c)

Figura 1.3: Radiografias AP (anteroposterior) de modelos pélvicos, simulando diferentes coberturas de componentes acetabulares em artroplastia total de quadril.

outras modalidades médicas de diagnóstico por imagem [17]. Barrat et al. [18] discutiram a viabilidade do uso da geração de imagens de ultrassom tridimensional (US 3D) para geração de imagens da superfície óssea de fêmur e pelve, em procedimentos cirúrgicos auxiliados por computador em casos de ATQ.

A vibroacustografia (VA) é uma técnica de imagem na qual dois feixes confocais de US com frequências ligeiramente diferentes $(\mathrm{MHz})$ geram uma excitação acústica de baixa frequência $(\mathrm{kHz})$, devido à força de radiação das ondas de interferência [4] [19] [20]. A baixa frequência é detectada por um hidrofone acoplado ao sistema. A excitação de baixa frequência focalizada fornece imagens livres de speckles e com alta resolução lateral (sub-milímetros). A técnica de VA tem se mostrado viável principalmente em avaliações de tecidos moles, tais como artérias [21] [22], mama [23] [24], tireóide [25] e próstata [26] [27] [28] [29]. Contudo, estudos apresentados por Callé et al. [30] também mostraram a viabilidade da técnica na geração de imagens de ossos, focalizando a estrutura trabecular de um calcâneo cortado. Renaud et al. [31] mostraram resultados preliminares da avaliação de fraturas no calcanhar através de técnicas de excitação por US, incluindo VA. Além disso, Alizad et al. [32] apresentaram uma análise espectral comparativa entre ossos fraturados e intactos. 
Uma grande vantagem da VA em comparação com imagens em modo-B é a baixa sensibilidade ao ângulo de incidência da onda. Um estudo comparativo de geração de imagens de sementes utilizadas em braquiterapia, entre as técnicas de VA e de pulso-eco, mostrou que a qualidade da imagem de VA foi muito menos afetada por variações de orientação das sementes de até 80 graus, do que nas imagens em modo-B [33]. O modo-B é altamente afetado pela variação do ângulo, visto que a formação da imagem nessa técnica é baseada na intensidade da onda refletida para o transdutor. Considerando uma interface plana entre dois meios com diferentes impedâncias acústicas, o ângulo de reflexão da onda dessa interface é igual ao ângulo de incidência. Nesse caso, quanto maior for o ângulo de incidência menor é a intensidade da onda refletida em direção ao transdutor. Na VA, um hidrofone é responsável por adquirir a resposta do tecido, devido à excitação de baixa frequência. A onda de baixa frequência se propaga em todas as direções e com muito menor atenuação do que ondas de alta frequência. Portanto, a orientação do objeto e a posição do hidrofone não é crítica em aquisições de imagens por VA. A baixa sensibilidade ao ângulo de incidência da imagem de VA é especialmente importante neste estudo, uma vez que a superfície do implante apresenta áreas de grande curvatura na região da borda e a região óssea adjacente ao implante pode apresentar grandes variações no seu formato.

A imagem gerada pela VA é bidimensional, contudo, representa o mapa acústico do volume coberto pelo foco do transdutor. Com isso, através de correções, é possível extrair informações ou representar o volume a partir da imagem bidimensional. Neste trabalho, propõe-se a representação tridimensional de imagens de VA para a avaliação da área superficial de implantes utilizados em artroplastia total de quadril. A avaliação tridimensional da área superficial tem o objetivo de alcançar resultados mais precisos do que os obtidos por avaliações bidimensionais utilizando radiografia plana por raios- $X$. 
Duas metodologias de correção da topologia para a representação tridimensional da imagem de VA são apresentadas: correção analítica baseada na geometria do implante e correção a partir de aquisições em modo-B baseadas em US 3D [34]. Adotou-se um método de digitalização ótica para se obter uma estimativa da área superficial da região de interesse e posterior comparação com os resultados da VA.

\subsection{Objetivos}

Este trabalho teve como principal objetivo explorar a técnica de vibroacustografia, com representação tridimensional, para avaliar a área superficial de implantes utilizados em artroplastia total de quadril. A modelagem de um transdutor planar multielementos para o aperfeiçoamento da aplicação de vibroacustografia em estudos biológicos foi um dos objetivos complementares deste trabalho.

\subsection{Organização do trabalho}

O Capítulo 2 descreve algumas características físicas das imagens de VA e modo-B que justificam este trabalho. Além disso, a VA é detalhada, mostrando características de resolução da imagem devido ao uso de transdutores confocais.

O Capítulo 3 descreve os métodos propostos neste trabalho para a avaliação de ATQ. São descritas as metodologias para aquisição de imagens por VA e US 3D. Duas metodologias são empregadas na representação tridimensional da imagem de VA. A área descoberta da componente acetabular é avaliada utilizando as representações tridimensionais da imagem de VA, além de um método de digitalização ótica para comparação dos resultados.

O Capítulo 4 mostra os resultados das aquisições de VA e modo-B, além de discutir o processamento das imagens para segmentação da região de interesse e avaliação da área superficial do implante. 
O Capítulo 5 apresenta um estudo numérico para implementação de transdutores matriciais 2D em VA e suas possíveis contribuições para a melhoria da técnica de VA. Além disso, propõe-se uma otimização da varredura eletrônica utilizando-se da flexibilidade de controle de canais possibilitada pelo uso desse modelo de transdutor.

O Capítulo 6 discute as principais vantagens dos métodos propostos, além das limitações físicas que poderiam dificultar a implementação clínica da técnica. Por fim, estudos futuros são propostos para validação da técnica na rotina clínica, implementação e modificações no protocolo para aquisição de imagens de VA utilizando o transdutor matricial 2D, e implementação dos métodos propostos em diferentes aplicações clínicas. 


\section{Capítulo}

\section{Fundamentação teórica}

As imagens de US representam o mapa das propriedades acústicas locais do meio, tais como densidade e compressibilidade. Elas são sujeitas a distorções devido a difração, atenuação, dispersão e inomogeneidades do meio. Com isso, as imagens de US trazem consigo não apenas informações geométricas do meio estudado, mas também informações quantitativas das propriedades mecânicas do mesmo.

Primeiramente, alguns dos fatores que alteram a resolução e o contraste das imagens baseadas em US serão descritos, justificando o uso da técnica para a aplicação neste trabalho. Além disso, é apontada a dependência com a frequência dos diversos fatores, com o intuito de discutir as principais diferenças entre as modalidades de VA e modo-B.

Em seguida, a técnica de VA é detalhada e uma breve apresentação é dada a respeito das características dos transdutores empregados nas modalidades de VA e modo-B.

\subsection{Atenuação da onda ultrassônica}

No estudo da propagação de ondas longitudinais em um meio atenuador, deve-se considerar a dependência com a frequência de propagação. A mudança da velocidade de fase de uma onda com a frequência é chamada de dispersão. A dispersão é causada pela absorção do meio e pode ser definida pela relação de Kramers-Kronig 
(K-K) que relaciona a dependência de frequência do coeficiente de atenuação com a dependência de frequência da velocidade de fase. As equações de K-K podem ser obtidas considerando a resposta linear de um meio acústico isotrópico, descrito pela forma generalizada da Lei de Hooke em conjunto com a relação de dispersão para a propagação do som no meio [35].

Para ondas acústicas, a partir da função complexa da compressibilidade, obtêm-se as equações de K-K definidas por:

$$
\kappa(\omega)=\beta(\omega)-i \alpha(\omega)=\frac{\omega}{c_{0}(\omega)}-i \alpha(\omega)
$$

sendo $c_{0}(\omega)$ a velocidade de fase da onda e $\alpha(\omega)$ o coeficiente de atenuação. As equações que relacionam essas duas grandezas podem ser expressas da seguinte forma [36]:

$$
\begin{gathered}
\alpha(\omega)=\frac{-2 \omega^{2}}{\pi} \int_{0}^{\infty}\left[\frac{1}{c_{0}\left(\omega^{\prime}\right)}-\frac{1}{c_{0}(\omega)}\right] \frac{d \omega^{\prime}}{\omega^{\prime 2}-\omega^{2}} \\
\frac{1}{c_{0}(\omega)}=\frac{2}{\pi} \int_{0}^{\infty}\left[\alpha\left(\omega^{\prime}\right)-\alpha(\omega)\right] \frac{d \omega^{\prime}}{\omega^{\prime 2}-\omega^{2}}
\end{gathered}
$$

$O$ coeficiente de atenuação é normalmente expresso em dB.cm ${ }^{-1} \mathrm{e}$ é dependente da frequência, temperatura e pressão. Uma aproximação para a dependência com a frequência na maioria dos tecidos biológicos é dada por

$$
\alpha=\alpha_{0}^{\prime}|\omega|^{n}
$$

sendo $\alpha_{0}^{\prime}$ o fator de atenuação e $n$ a dependência com a frequência.

A atenuação da onda mecânica contribui para o contraste e também para a resolução da imagem de US. A perda de energia da onda de US por absorção se dá pela conversão dessa em outras formas de energia, tais como calor, energia química ou luz [36]. Além disso, mudanças na compressibilidade e densidade do meio podem causar espalhamento da onda (principalmente por reflexão e refração). Basicamente, na 
imagem por pulso-eco, a onda refletida é utilizada para calcular a distância do objeto e a intensidade do pixel naquele local.

Para uma onda incidente com intensidade $\vec{I}_{0}$ dentro de um meio, as perdas por absorção e espalhamento contribuem para a perda total de intensidade da onda transmitida $\vec{I}(x)$, dada uma distância $x$ [36].

$$
\vec{I}(x)=\vec{I}_{0} e^{-2\left(\alpha_{e}+\alpha_{a}\right) x}=\vec{I}_{0} e^{-2 \alpha x}
$$

sendo $\alpha_{e}, \alpha_{a}$ e $\alpha$ respectivamente os coeficientes de atenuação por espalhamento, por absorção e total.

Bamber [37] relatou resultados experimentais para a atenuação versus frequências, característicos de alguns tecidos biológicos. Para uma onda de $3 \mathrm{MHz}$ propagando-se no osso do crânio, a atenuação é de aproximadamente $50 \mathrm{~dB} \cdot \mathrm{cm}^{-1}$. Com isso, a intensidade da onda ultrassônica é reduzida a 0,001\% em $1 \mathrm{~cm}$ de distância.

Dessa forma, os parâmetros de um aparelho de US (frequência, intensidade, contraste etc) podem ser ajustados para mostrar principalmente as informações relativas à superfície do osso ou do implante estudado. Além disso, as ondas acústicas de baixa frequência presentes na modalidade de VA são menos atenuadas que as de alta frequência presentes nas técnicas de US diagnóstico por imagem. Por esse motivo, a distância entre o foco do transdutor e o hidrofone se torna menos crítica. Contudo, deve-se considerar que a ondas de baixa frequência obtidas por essa técnica têm cerca de dez mil vezes menor amplitude que as ondas de alta frequência. Portanto, equipamentos para amplificação e tratamento do sinal são exigidos para uma viável aquisição do sinal.

\subsection{Impedância acústica}

O conceito de impedância é importante na caracterização da propagação da onda com mudança de meio cujos meios envolvidos apresentam diferentes propriedades acústicas. Neste estudo, a onda 
ultrassônica se propaga por diferentes meios, incluindo: água, objeto simulador de tecido mole, implante (liga metálica) e modelo ósseo.

Para uma onda harmônica de frequência angular $\omega$, em uma posição espacial $r$, a impedância acústica pode ser definida por

$$
Z_{a}(\vec{r}, \omega)=\frac{F(\vec{r}, \omega)}{v(\vec{r}, \omega)}
$$

sendo $F(\vec{r}, \omega)$ a força acústica total atuando sobre uma área específica e $v(\vec{r}, \omega)$ a velocidade da partícula.

Considerando a força por unidade de área ao invés de a força total atuando sobre uma área específica, define-se a impedância acústica específica por

$$
Z_{e}(\vec{r}, \omega)=\frac{p(\vec{r}, \omega)}{v(\vec{r}, \omega)}
$$

sendo $p(\vec{r}, \omega)=p_{0} \exp ^{-j k \vec{r}}$ o fasor de pressão e $k$ o número de onda.

A impedância acústica específica $Z_{e}(\vec{r}, \omega)$ é dependente da frequência e posição e, uma vez que pressão e velocidade podem diferir em fase, $Z_{e}(\vec{r}, \omega)$ é uma grandeza complexa.

O caso mais simples seria a propagação de uma onda plana em um meio não-viscoso. Consequentemente, a pressão e a velocidade estariam em fase, e a relação entre a velocidade da partícula e a pressão poderia ser definida por

$$
\frac{p}{v}=\rho_{0} c_{0}
$$

sendo $\rho_{0}$ a densidade no equilíbrio.

Substituindo 2.8 em 2.7 define-se a impedância acústica característica por

$$
Z=Z_{0}=\rho_{0} c_{0}
$$




\subsection{Coeficientes de reflexão e de transmissão}

Considerando dois meios 1 e 2, o coeficiente de reflexão, de intensidade $R_{i}$, é dado pela relação entre a média temporal das magnitudes de pressão das ondas refletidas e incidentes.

$$
R_{p}=\frac{Z_{02} \cos \theta_{i}-Z_{01} \cos \theta_{t}}{Z_{02} \cos \theta_{i}+Z_{01} \cos \theta_{t}}
$$

sendo $\theta_{t}$ o ângulo de transmissão da onda e $\theta_{i}$ o ângulo de incidência da onda.

O coeficiente de transmissão é dado pela relação entre a média temporal das magnitudes de pressão das ondas transmitidas e incidentes. Contudo, os coeficientes de reflexão e de transmissão são complementares e, considerando que há conservação de energia, portanto $T_{p}=R_{p}+1$, o coeficiente de transmissão pode ser definido simplesmente por

$$
T_{p}=\frac{2 Z_{02} \cos \theta_{i}}{Z_{02} \cos \theta_{i}+Z_{01} \cos \theta_{t}}
$$

Uma contribuição para o contraste na imagem de US é dada pela diferença entre as impedâncias características dos meios que, por sua vez, alteram os coeficientes de reflexão das interações entre os meios. A reflexão da onda está diretamente ligada ao contraste da imagem no modo-B, já que nessa modalidade a intensidade da imagem é dada pela intensidade da onda refletida em direção ao transdutor.

\subsection{Força de radiação acústica dinâmica}

Quando uma onda de US incide num meio que absorve, espalha ou reflete a radiação, uma força será exercida. Essa força é composta por uma componente oscilatória, decorrente da pressão acústica variante no tempo, e outra componente estática, que desloca o meio na direção do gradiente de pressão. A VA é uma modalidade de imagem que 
registra a resposta acústica de objetos excitados por uma força de radiação dinâmica e altamente localizada, gerada pela combinação não-linear de ondas ultrassônicas.

Esta força é produzida por mudanças na densidade de energia de um campo acústico incidente. A magnitude da força é proporcional à densidade de energia média da onda incidente $\langle E\rangle$ e à $S$, área projetada do objeto [19].

$$
F=d_{r} S\langle E\rangle
$$

sendo $d_{r}$ o coeficiente de arrasto. Para uma onda plana, a densidade de energia é dada por

$$
E=\frac{p^{2}(t)}{\rho c^{2}}
$$

sendo $p(t)$ a pressão total no tempo $t$ e $\rho$ a densidade do meio de propagação.

A força de radiação de baixa frequência pode ser produzida pela modulação de um único feixe ou pela combinação não-linear de dois feixes de frequências ligeiramente diferentes. Chen et al. [38] estudaram três formas diferentes para a formação da onda de baixa frequência incluindo o uso de amplitude modulada (AM), transdutores confocal e X-focal. Neste trabalho utilizou-se o transdutor confocal (Figura 2.1) para geração da onda de baixa frequência. A imagem de VA utilizando esse tipo de transdutor apresenta alta resolução, limitada pela região de combinação não-linear entre as duas ondas de US aplicadas. As Figuras 2.2(a) e 2.2(b) mostram o campo de pressão acústico nos planos sagital e axial/azimutal, simulado em Field II [39], de um transdutor confocal com mesmas dimensões do mostrado na Figura 2.1. A zona focal e a largura da região de combinação não-linear das ondas obtidas da simulação foram de aproximadamente $1 \mathrm{~cm}$ e 0,7 $\mathrm{mm}$, respectivamente.

O transdutor confocal consiste de uma cerâmica em forma de disco 


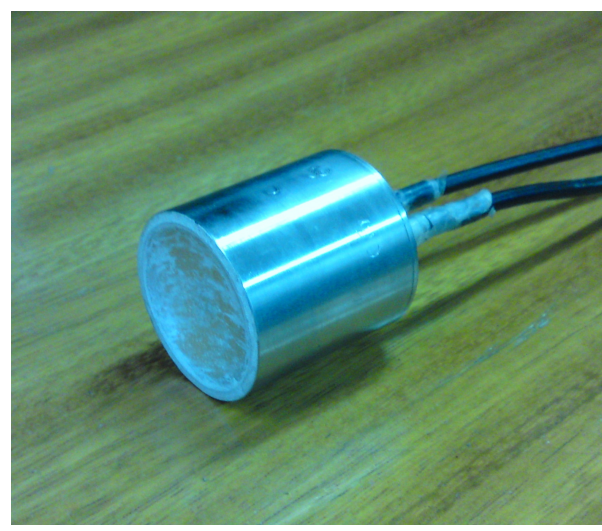

Figura 2.1: Transdutor confocal de duas cerâmicas utilizado na aquisição em modo de VA.

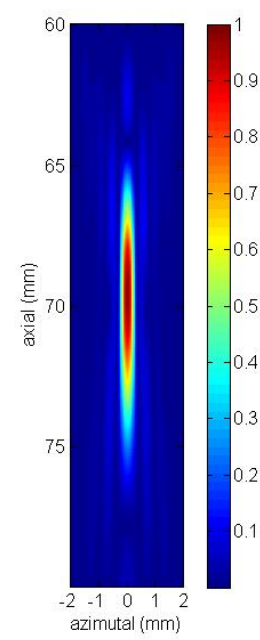

(a)

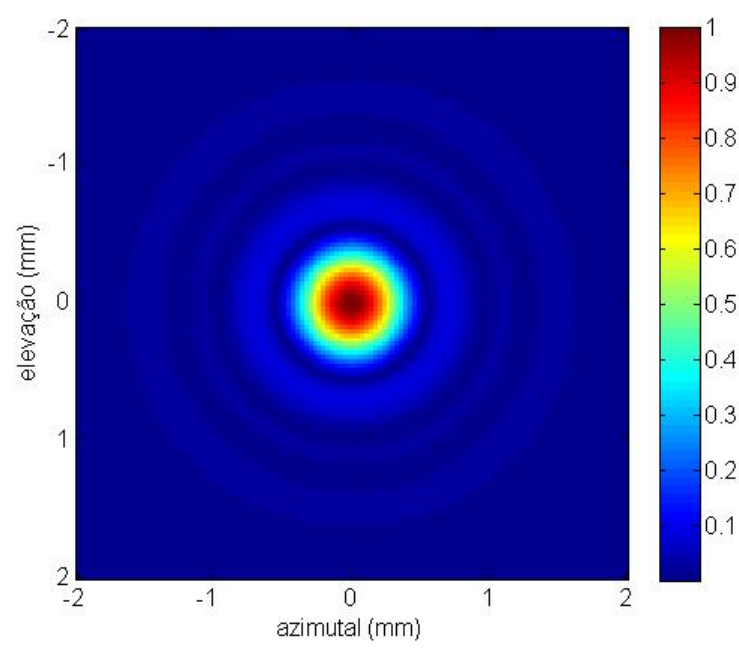

(b)

Figura 2.2: Mapa acústico do transdutor confocal simulado em Field II [38]. (a) Sagital na região focal $(7 \mathrm{~cm})$ e (b) plano azimutal.

na parte central (com raio $a_{1}$ ) e outra cerâmica em forma de anel na parte externa (com raio interno $a_{21}$ e raio externo $a_{22}$ ) que geram dois feixes de US coaxiais no mesmo ponto focal.

$\mathrm{Na} V A$, os dois feixes de US com frequências $\omega_{1}=\omega_{0}+\Delta \omega / 2$ e $\omega_{2}=\omega_{0}-\Delta \omega / 2$ apresentam frequências próximas e da ordem de $\mathrm{MHz}$, sendo $\Delta \omega$ da ordem de $\mathrm{kHz}$. O fenômeno de combinação não-linear de frequência observado na VA é descrito pelos cálculos das pressões $p_{1}\left(\vec{r}: \omega_{1}\right)$ e $p_{2}\left(\vec{r}: \omega_{2}\right)$, no mesmo plano, à distância $\vec{r}$ para as duas 
fontes de onda de frequências $\omega_{1}$ e $\omega_{2}$. A resposta de baixa frequência $(\Delta \omega)$ é captada por um hidrofone acoplado ao sistema, como mostra a Figura 2.3.

O campo de pressão resultante no plano $z=0$ pode ser escrito como [38]:

$$
p(\vec{r}, t)=p_{1}(\vec{r}) \cos \left(\omega_{1} t+\phi_{1}(\vec{r})\right)+p_{2}(\vec{r}) \cos \left(\omega_{2} t+\phi_{2}(\vec{r})\right)
$$

sendo $\phi_{1}$ e $\phi_{2}$ as funções de fase das ondas de frequências $\omega_{1}$ e $\omega_{2}$, respectivamente. As amplitudes são dadas por

$$
p_{1}(\vec{r})=\rho c u_{0} \frac{\pi a_{1}^{2}}{\lambda_{1} R} j \operatorname{inc}\left(\frac{r a_{1}}{\lambda_{1} R^{\prime}}\right)
$$

e

$$
p_{2}(\vec{r})=\rho c u_{0} \frac{\pi}{\lambda_{2} R}\left[a_{22}^{2} j i n c\left(\frac{r a_{22}}{\lambda_{2} R}\right)-a_{21}^{2} j i n c\left(\frac{r a_{21}}{\lambda_{2} R}\right)\right]
$$

sendo $i=1,2, \lambda_{i}=2 \pi c / \omega_{i}$ o comprimento de onda, $u_{0}$ a velocidade da partícula na superfície do transdutor, $\operatorname{jinc}(x)=J_{1}(2 \pi x) / \pi x$ e $J_{1}($.$) é a$ função de Bessel cilíndrica de primeira ordem.

A média temporal de $p^{2}(t)$ é

$$
\left\langle p^{2}(t)\right\rangle_{T}=\frac{\left(p_{1}^{2}+p_{2}^{2}\right)}{2}+p_{1} p_{2} \cos \left(\Delta \omega t+\phi_{1}-\phi_{2}\right)
$$

Logo, a força resultante $F$ no foco é dada por

$$
F=\frac{d_{r} S}{\rho c^{2}}\left\{\frac{p_{1}^{2}(r)}{2}+\frac{p_{2}^{2}(r)}{2}+p_{1}(r) p_{2}(r) \cos \left[\left(\omega_{2}-\omega_{1}\right) t+\left(\phi_{2}(r)-\phi_{1}(r)\right)\right]\right\}
$$

A componente dinâmica da força na Equação (2.18) é dada por 


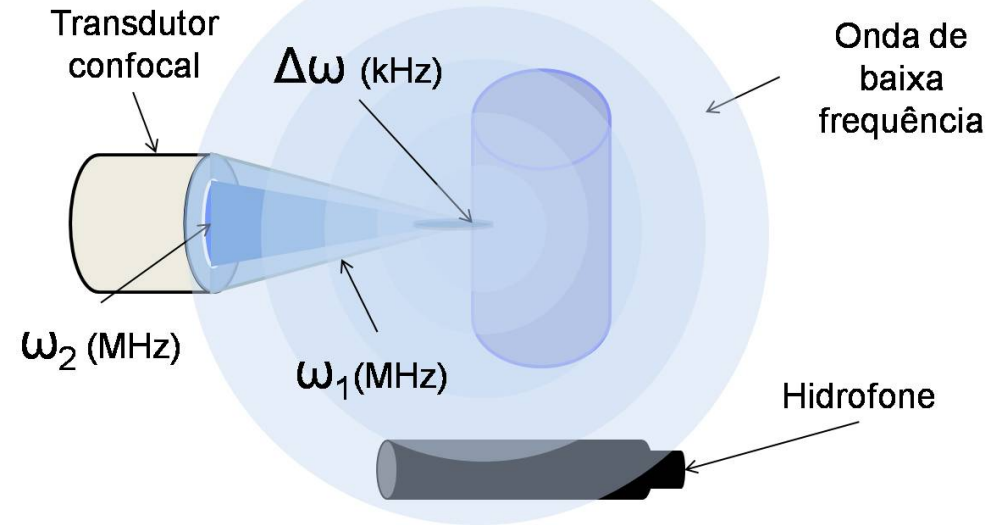

Figura 2.3: Esquema simplificado mostrando sistema de excitação e detecção da VA.

$$
F_{d}=\frac{d_{r} S}{\rho c^{2}}\left\{p_{1}(r) p_{2}(r) \cos \left[\Delta \omega t+\left(\phi_{2}(r)-\phi_{1}(r)\right)\right]\right\}
$$

sendo $\Delta \omega$ a diferença entre as frequências $\omega_{1}$ e $\omega_{2}$.

A imagem de VA depende da função de espalhamento de ponto PSF (PSF, do inglês Point Spread Function) do sistema de imagem, que é a combinação da distribuição espacial do campo de pressão de radiação aplicado e da emissão acústica do objeto em resposta ao estímulo. Com isso, a otimização da formação do foco é de extrema importância nessa modalidade de imagem. Transdutores matriciais comerciais, como o linear e o de fase, vêm sendo estudados para a geração de imagens de VA [40], facilitada pela implementação da técnica em máquinas comerciais [41].

A nomenclatura para transdutores apresentada na Tabela 2.1 categoriza transdutores, de acordo com seus graus de liberdade no controle dos diversos parâmetros. O transdutor 1D apresenta de 32 a 300 elementos (Figura 2.4(a)). Ele é capaz de realizar varreduras no plano azimutal com excelentes resoluções lateral e axial. Contudo, lentes cilíndricas limitam o comprimento focal à uma posição fixa no plano de elevação. O transdutor 1,25D apresenta subdivisões nas conexões no plano de elevação em linhas de elementos, cujas 
Tabela 2.1: Nomenclatura para transdutores de ultrassom matriciais.

\begin{tabular}{ll}
\hline \hline Tipo & Propriedades de elevação \\
\hline 1D & Foco e abertura fixos \\
1,25D & Foco fixo, mas com abertura variável \\
1,5D & Apodização, focalização e abertura variáveis, porém todas simétricas \\
& em relação à linha de centro da matriz \\
1,75D & O mesmo que 1,5D, mas sem a restrição de simetria \\
2D & Controle total da varredura eletrônica, focalização, apodização e abertura \\
\hline
\end{tabular}

Fonte: Wildes et al. IEEE Trans. Ultrason. Ferroelectr. Freq. Control, 1997 [42].

linhas externas estão conectadas em paralelo (Figura 2.4(b)). Com isso, a focalização no plano de elevação continua estática, mas com abertura variável. O transdutor $1,5 \mathrm{D}$ permite a focalização dinâmica e a apodização ${ }^{1}$ em elevação através do uso de vários canais que controlam as linhas de elementos aos pares, simetricamente em relação ao centro (Figura $2.4(\mathrm{c})$ ). Isso permite uma melhoria substancial na resolução, especialmente nos campos médio e distante. O transdutor 1,75D acrescenta a possibilidade de se realizar uma varredura eletrônica do feixe limitada à ângulos menores que $30^{\circ}$ na direção de elevação, através da multiplexação de um grande número de canais (Figura 2.4(d)). Por fim, o transdutor 2D apresenta um grande número de elementos conectados eletronicamente, permitindo o controle total da varredura eletrônica, focalização, apodização e abertura em todas as direções [36] [42] (Figura 2.4(e)).

No Capítulo 5 é sugerido o uso de transdutores matriciais reconfiguráveis 2D, devido à possibilidade de se gerar campos de US similares aos gerados pelo transdutor côncavo confocal, sem os problemas de acoplamento inerentes desse último transdutor.

Para objetos de alta densidade (por exemplo, osso e metal), a onda incidente de alta frequência $(\mathrm{MHz})$ é altamente atenuada (Equação

\footnotetext{
${ }^{1}$ Ponderação da amplitude do sinal elétrico aplicado aos elementos, de maneira a reduzir os lóbulos laterais em relação ao lóbulo central.
} 


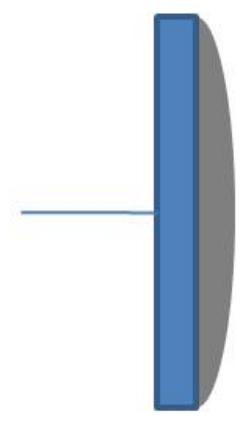

(a)

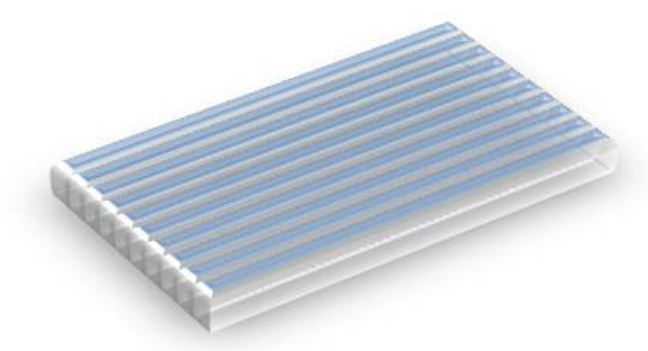

(d)

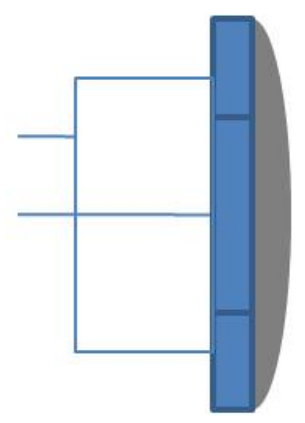

(b)

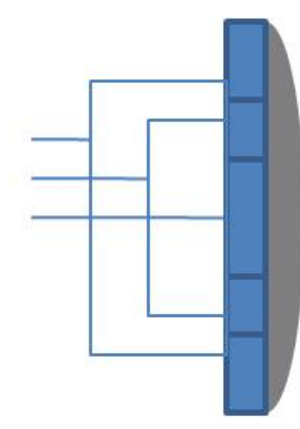

(c)

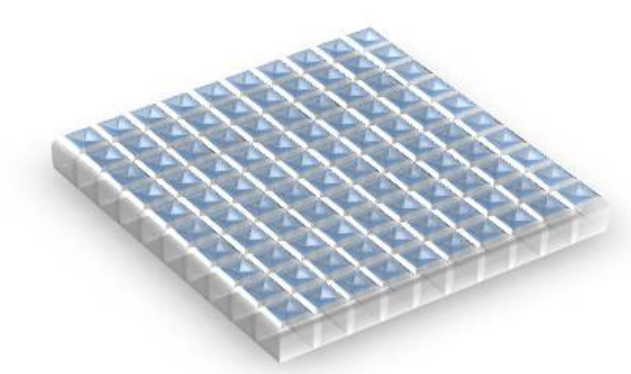

(e)

Figura 2.4: Esquema das conexões elétricas para os diferentes transdutores matriciais. (a) 1D; (b) 1,25D; (c) 1,5D; (d) 1,75D e (e) 2D.

2.5). Assim, a imagem de VA obtida dessas regiões refere-se à resposta acústica da região superficial dos objetos, uma vez que a onda de US pouco penetra os mesmos (poucos milímetros). Essa característica é bastante interessante para a análise superficial de objetos densos, já que a resposta da VA corresponde à sobreposição do volume coberto pelo foco do transdutor (Figura 2.2). Dessa forma, a seleção da região de interesse na VA é realizada primeiramente pelo posicionamento do foco (distância focal) e também pelo volume irradiado pela onda de US, limitado pela atenuação.

A Figura 2.5 mostra imagens de VA de um osso de frango utilizando um transdutor confocal de foco fixo de frequência central de $3,40 \mathrm{MHz}$ à distância de aproximadamente $7 \mathrm{~cm}$ (Figura 2.1), com diferentes posicionamentos do foco sobre o osso. A frequência de batimento utilizada foi de $50 \mathrm{kHz}$. Nela verifica-se a abrangência do foco e o efeito 

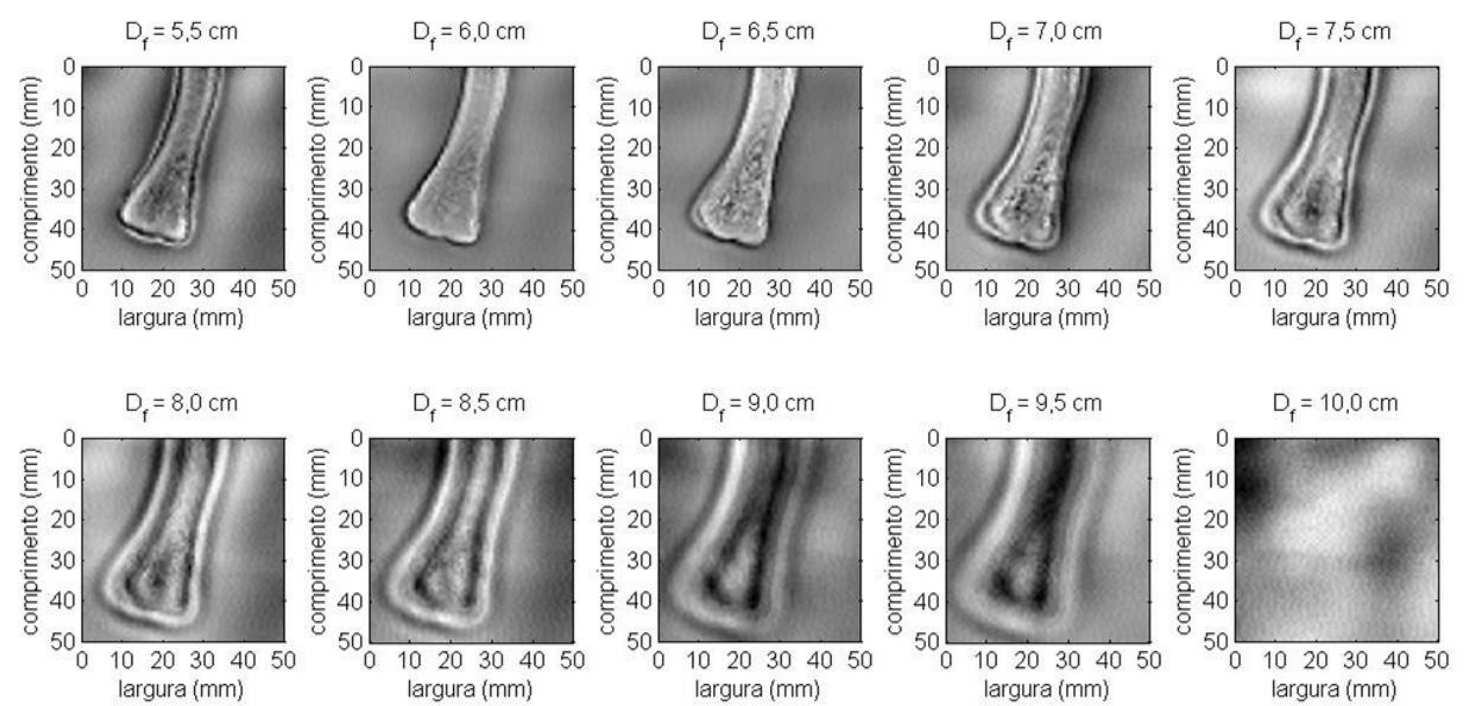

Figura 2.5: Imagens de osso de frango por VA utilizando transdutor confocal de foco fixo à aproximadamente $7 \mathrm{~cm}$, para diferentes distâncias entre transdutor e osso.

de borramento ocorrido quando o foco não foi devidamente posicionado sobre o osso.

A seletividade da região de interesse devido à zona focal é uma grande vantagem da VA. Desta forma, somente a superfície de interesse pode ser vista na imagem e o efeito de sobreposicionamento observado em outras técnicas, como a radiografia por raios- $X$, não ocorre nessa modalidade. 


\section{Capítulo}

\section{Materiais e métodos}

A ATQ, como definida anteriormente, é o processo cirúrgico de substituição de parte do fêmur e do acetábulo por implantes. O objetivo do trabalho foi a avaliação pós-cirúrgica por VA da cobertura da componente acetabular implantada na pelve de pacientes. Para tanto, foi utilizado um modelo ósseo de pelve, com propriedades mecânicas similares as de uma pelve real, e uma componente acetabular metálica. Um objeto simulador à base de gelatina animal foi desenvolvido para simular o tecido mole adjacente à região avaliada.

Imagens bidimensionais de VA da região do implante não coberta pela pelve foram adquiridas em um tanque com água, simulando as condições reais encontradas em casos de ATQ.

Para uma avaliação mais precisa da região do implante, modelos tridimensionais baseados na topologia do implante e em aquisições em modo-B foram utilizados para a representação tridimensional da imagem por VA. Processos de segmentação foram aplicados na imagem, para a identificação da região de interesse. Em seguida, foi realizada a avaliação tridimensional da área superficial do implante.

Como padrão-ouro, um sistema ótico tridimensional de digitalização auxiliado por software de DAC (Desenho Assistido por Computador ou $C A D$, do inglês Computer Aided Design) foi utilizado para a avaliação superficial do implante. 


\subsection{Modelo para representação de artroplastia total de quadril}

\subsubsection{Pelve e implante metálico}

Para a simulação de ATQ foram utilizados: um modelo ósseo (Sawbones modelo 1301-1, WA, EUA) feito de material esponjoso (Foam Cortical Shell), com dimensões típicas de uma pelve masculina adulta e módulo elástico de $210 \mathrm{MPa}$ (Figura 3.1); e um implante acetabular metálico, material M30NW, tipicamente utilizado em procedimentos reais, de diâmetro 57,10 \pm 0,05 mm (Amplitude, França) (Figura 3.2).

O implante foi fixado no acetábulo do modelo pélvico utilizando-se cola de alta aderência (Super Glue ${ }^{\circledR}$ ), de maneira a expor parte do implante, simulando uma cobertura parcial.

\subsubsection{Tecido mole}

A região da cintura pélvica (cíngulo) é composta por camadas de músculos esqueléticos (glúteo máximo e médio) e gordura. A espessura total da região varia muito de indivíduo para indivíduo, porém é superior a $5 \mathrm{~cm}$ para um adulto. Baseado no decaimento da intensidade da onda de US propagada por meios homogêneos (Equação

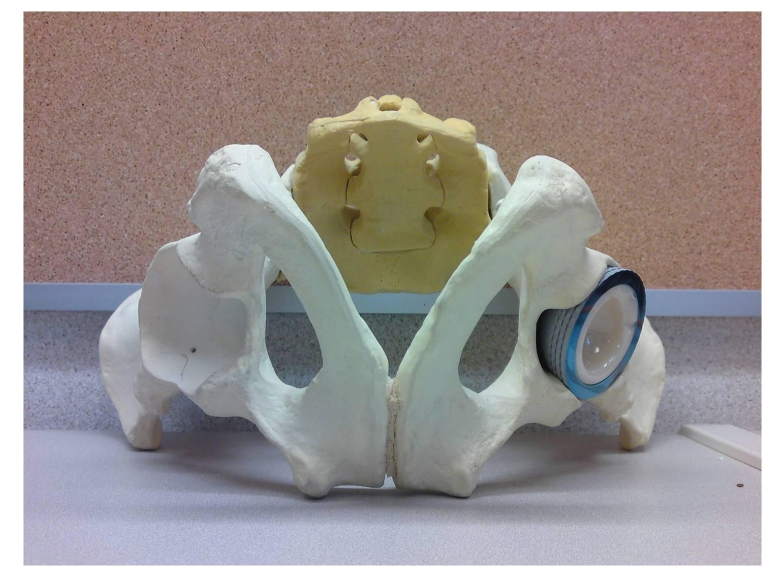

Figura 3.1: Modelo ósseo de pelve masculina adulta feito de material esponjoso. 


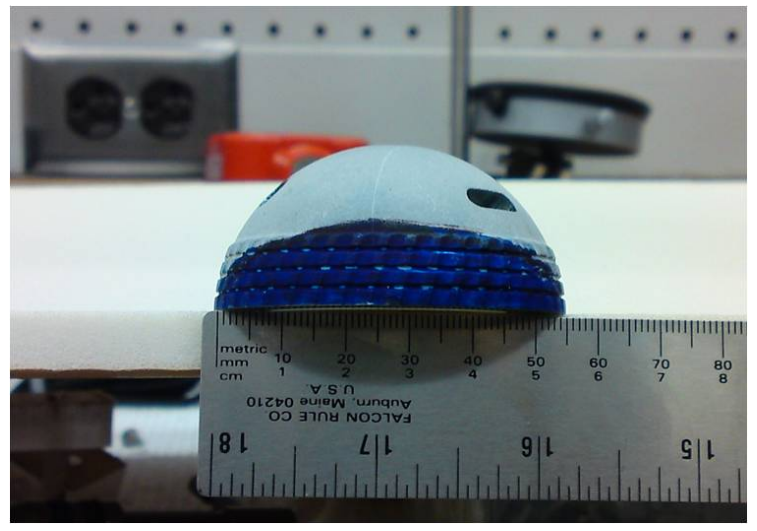

Figura 3.2: Componente acetabular metálica utilizada em artroplastia total de quadril.

2.5), o coeficiente de atenuação da onda resultante nas camadas de músculo e gordura pode ser calculado por

$$
\alpha=\frac{\alpha_{g} \cdot d_{g}+\alpha_{m} \cdot d_{m}}{d_{g}+d_{m}}
$$

sendo $\alpha_{g}, d_{g}, \alpha_{m}$ e $d_{m}$, respectivamente, o coeficiente de atenuação da gordura, espessura da camada de gordura, coeficiente de atenuação do músculo e espessura da camada de músculo.

Valores de referência para velocidade do som, densidade e atenuação para alguns tecidos moles humanos podem ser encontrados na Tabela 3.1.

Da Tabela 3.1, os valores empíricos para os coeficientes de atenuação para gordura e músculos esqueléticos são: $\alpha_{g}=0,48$ $\mathrm{dB} . \mathrm{cm}^{-1}$ e $\alpha_{m}=0,74 \mathrm{~dB} . \mathrm{cm}^{-1}$, respectivamente. Assumindo um paciente com glúteos de espessura total de $5 \mathrm{~cm}$, os quais $2 \mathrm{~cm}$ são músculo e $3 \mathrm{~cm}$ são gordura, o coeficiente de atenuação resultante calculado pela Equação (3.1) é de $\alpha=0,58 \mathrm{~dB} \cdot \mathrm{cm}^{-1}$.

Baseado no valor resultante para atenuação na região dos glúteos, um objeto simulador de tecido mole (OSTM) à base de gelatina animal e leite evaporado foi preparado para simular o tecido mole em torno da região de interesse (Figura 3.3). A atenuação do objeto simulador pôde ser controlada pela diluição de leite evaporado na mistura 
Tabela 3.1: Valores empíricos para velocidade do som, densidade e atenuação para diferentes tecidos para uma onda de $1 \mathrm{MHz}$.

\begin{tabular}{lccc}
\hline \hline Tecido & $\begin{array}{c}c_{0} \\
(\mathrm{~m} / \mathrm{s})\end{array}$ & $\begin{array}{c}\rho_{0} \\
\left(\mathrm{~kg} / \mathrm{m}^{3}\right)\end{array}$ & $\begin{array}{c}\alpha \\
(\mathrm{dB} / \mathrm{cm})\end{array}$ \\
\hline Gordura & 1478 & 950 & 0,48 \\
Músculo esquelético & 1580 & 1050 & 0,74 \\
Músculo cardíaco & 1576 & 1060 & 0,52 \\
Pele & 1615 & 1090 & 0,35 \\
Sanguíneo & 1584 & 1060 & 0,20 \\
\hline
\end{tabular}

Adaptado de: Mast et al. Acoustics Research

Letters Online, 2000 [43].

Tabela 3.2: Ingredientes do objeto simulador de tecido mole simulando músculo esquelético e gordura.

\begin{tabular}{ll}
\hline \hline \multicolumn{2}{c}{ Ingredientes do objeto simulador } \\
\hline $0,9 \mathrm{~L}$ & água \\
$0,9 \mathrm{~L}$ & leite evaporado \\
$18 \mathrm{~g}$ & sorbato de potássio (10 g/L) \\
$180 \mathrm{~g}$ & gelatina de porco (10\% do volume total) \\
$180 \mathrm{~mL}$ & glicerina (10\% do volume total) \\
4 gotas & antiespumante e emulsificador \\
\hline
\end{tabular}

[44]. A atenuação atingida foi de aproximadamente $0,5 \mathrm{~dB} \cdot \mathrm{cm}^{-1}$ e a velocidade de propagação de $1500 \mathrm{~m} \cdot \mathrm{s}^{-1}$. O volume total do objeto foi de aproximadamente $2 \mathrm{~L}$, com espessura máxima de $5 \mathrm{~cm}$ na região do implante.

O leite evaporado contribui para a atenuação da mistura de forma controlada, dada a proporção de leite evaporado e água [44]. O sorbato de potássio facilita a dissolução da mistura e auxilia na conservação do OSTM, pelo controle do crescimento de bactérias e fungos. A glicerina é responsável pelo controle da velocidade do som e o antiespumante auxilia no processo de desgaseificação da mistura. 


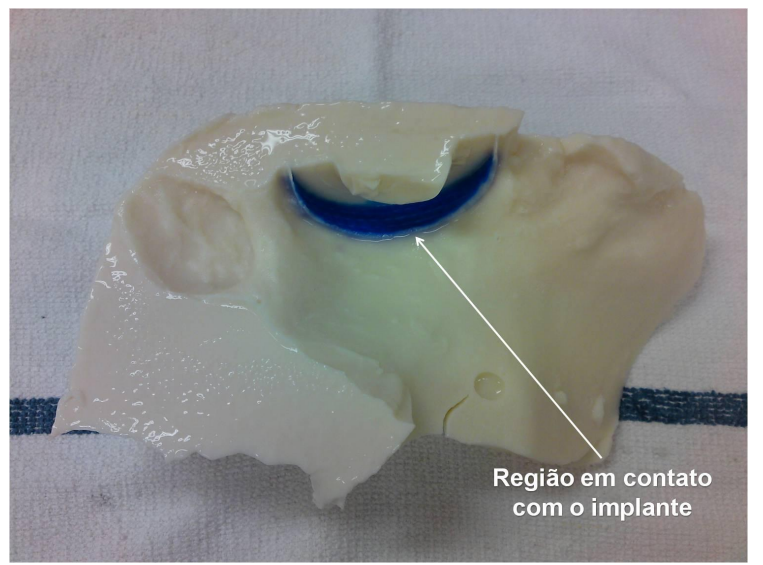

Figura 3.3: Objeto simulador à base de gelatina de porco e leite evaporado, moldado no formato do modelo pélvico.

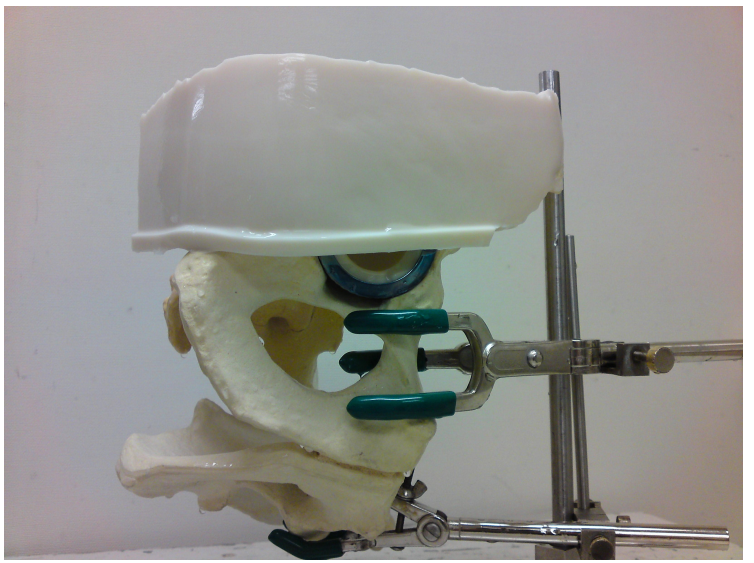

(a)

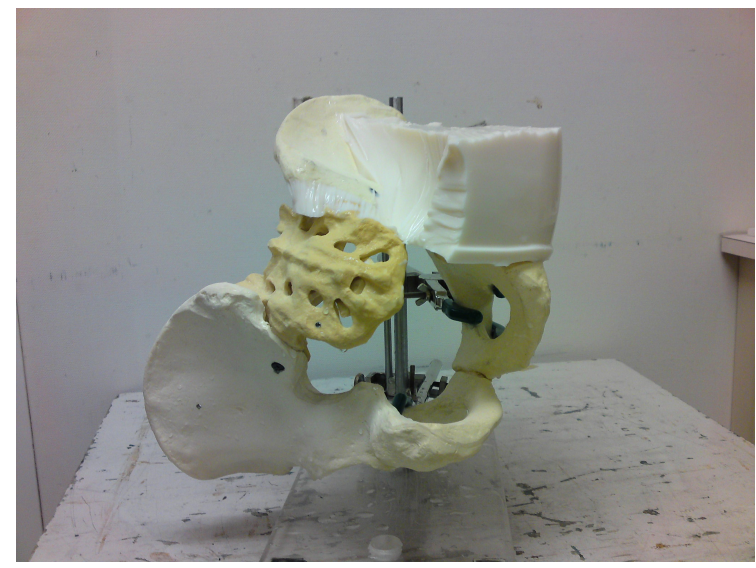

(b)

Figura 3.4: Modelo pélvico simulando artroplastia total de quadril composto de: pelve feita de Foam Cortical Shell, tecido mole à base de gelatina e leite evaporado, e componente acetabular.

A água, o leite evaporado, o sorbato de potássio e a gelatina foram cuidadosamente misturados num Becker de $2 \mathrm{~L}$ com o auxílio de um agitador. Ligou-se o aquecedor e colocou-se a glicerina sob aquecimento em um outro Becker, ao lado do Becker maior, para reduzir a viscosidade da glicerina. Após a mistura atingir a temperatura aproximada de $50{ }^{\circ} \mathrm{C}$, a glicerina foi adicionada à mistura, assim como o antiespumante. Esperou-se aproximadamente 30 minutos até que a mistura se tornasse homogênea. Em seguida, o Becker foi colocado sob vácuo para que as bolhas presentes na mistura fossem removidas. 
Para a construção de um OSTM mais realista, o modelo pélvico foi mergulhado dentro da mistura, de forma que fosse moldado à região de interesse (Figura 3.4). Após algumas horas em temperatura ambiente $\left(\approx 20^{\circ} \mathrm{C}\right)$, o objeto foi colocado sob refrigeração $\left(\approx 3^{\circ} \mathrm{C}\right)$.

\subsection{Aquisiç̧ões}

A avaliação da área foi realizada sobre a imagem de VA. Para uma avaliação mais precisa da área, foram aplicadas correções na topologia da imagem, de forma a representá-la no espaço tridimensional. Duas metodologias foram utilizadas para a correção da topologia, sendo uma baseada nas dimensões do implante e outra baseada em aquisições tridimensionais por modo-B (ou, do inglês, $B$-scans). Para tanto, foram adquiridas imagens bidimensionais em modo de VA e imagens em modo-B de seções do volume da região de interesse. Ambas as técnicas foram conduzidas dentro de um tanque de água desgaseificada, por proporcionar um bom acoplamento acústico e permitir liberdade de movimento dos transdutores (Figura 3.5).

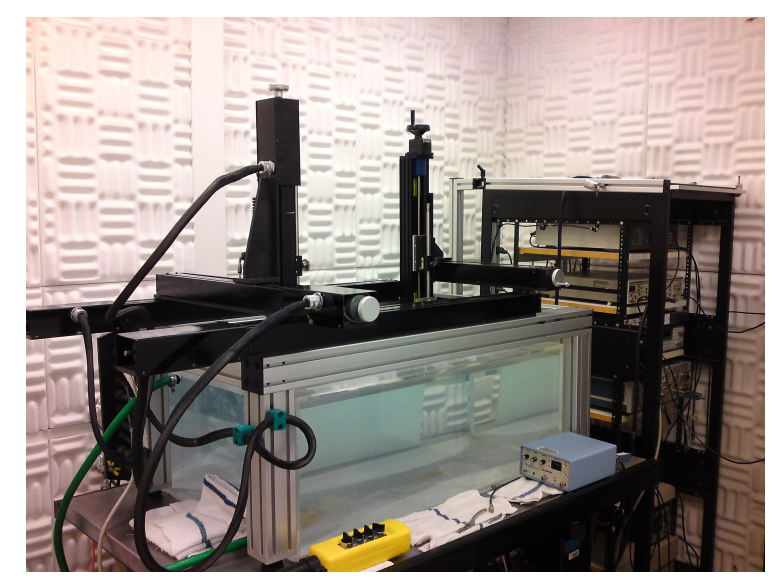

Figura 3.5: Tanque acústico preenchido com água desgaseificada e sistema de motores para realização de varreduras em modo de VA e modo-B. 


\subsubsection{Modo de vibroacustografia}

A aquisição em modo de VA foi realizada utilizando um transdutor confocal de diâmetro externo de $45 \mathrm{~mm}$ e distância focal de $7 \mathrm{~cm}$ (Figura 2.1). A varredura do transdutor pela região de interesse foi auxiliada por um sistema mecânico de varredura, composto por 3 eixos controlados por motores de corrente contínua (Figura 3.5). A imagem foi adquirida com resolução de $0,25 \mathrm{~mm}$.

O transdutor confocal foi excitado por sinais pulsados com frequências $f_{1}=3,05 \mathrm{MHz}$ e $f_{2}=3,10 \mathrm{MHz}$ fornecendo, por interferência [4], uma diferença de frequência de $\Delta f=50 \mathrm{kHz}$ na região focal. Utilizou-se dois geradores de função Tektronix modelo AFG320 para geração dos pulsos que, por sua vez, passaram por um amplificador de potência antes de excitar as cerâmicas. A resposta à excitação acústica foi adquirida por um hidrofone International Transducer Corp. modelo ITC-6080C e um filtro passa-banda Stanford Research System, INC. modelo SR650 que limitou a banda passante em $50 \pm 1 \mathrm{kHz}$. Uma placa de aquisição AlazarTech modelo ATS460 digitalizou a resposta, que foi sincronizada com as informações de posição dos motores do sistema mecânico, gerando o mapa acústico da área excitada. As Figuras 3.6 e 3.7 mostram detalhes do aparato experimental para execução da técnica de VA, incluindo os aparelhos eletrônicos e o modelo pélvico fixado dentro do tanque.

A zona focal do transdutor confocal é de aproximadamente $1 \mathrm{~cm}$ (Figura 2.2). Toda a região focal contribui para o sinal acústico na formação da imagem de VA. A região de interesse exigiu uma cobertura do foco com profundidade de pouco mais de $2 \mathrm{~cm}$. Dessa forma, foram realizadas aquisições por VA em três distâncias diferentes: 5,3 cm, 5,8 $\mathrm{cm}$ e $6,3 \mathrm{~cm}$. Em seguida, as imagens foram combinadas, permitindo uma cobertura mais abrangente da região descoberta do implante. 


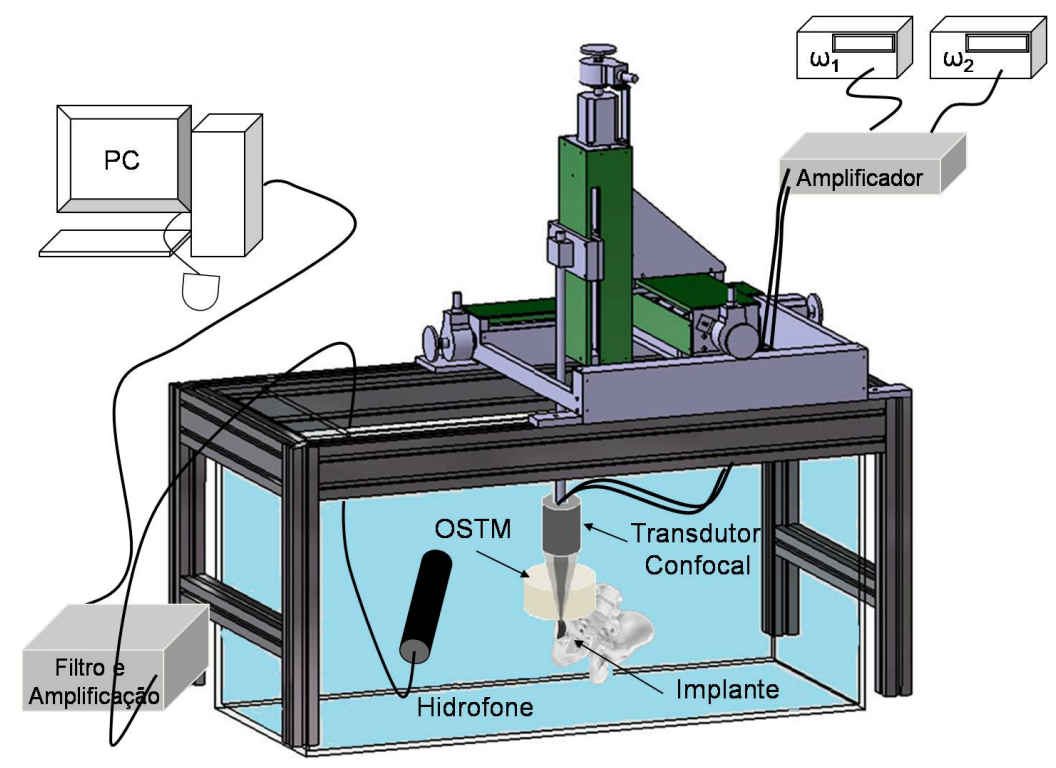

Figura 3.6: Descrição do sistema de VA e montagem experimental para estudo de artroplastia total de quadril. O sistema mecânico de varredura controlado pelo computador permite o ajuste da posição do foco.

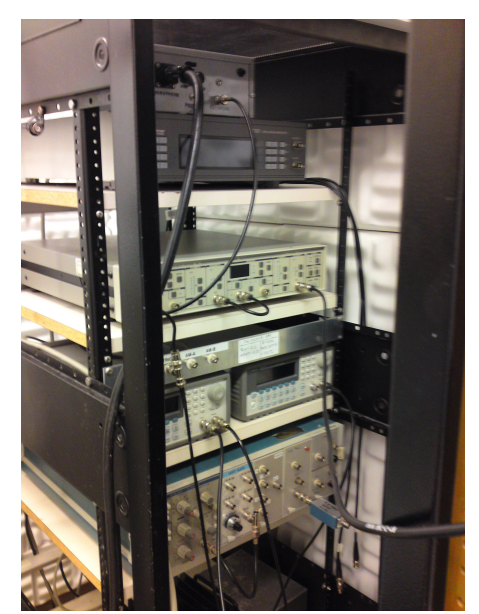

(a)

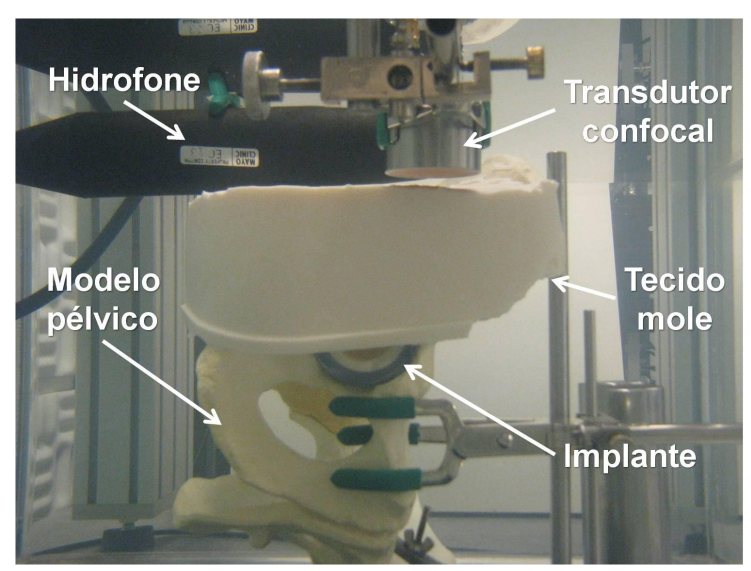

(b)

Figura 3.7: (a) Equipamentos eletrônicos utilizados na geração de imagens por VA, de cima para baixo: fonte de alimentação e pré-amplificador para hidrofone, amplificador lock-in (não utilizado), filtro passa-banda, geradores de função e amplificador de potência. (b) Aparato experimental simulando ATQ dentro do tanque de água. 


\subsubsection{Modo-B}

As aquisições em modo-B também foram usadas para determinar a topologia tridimensional da região de interesse. Nesta seção, é apresentada uma alternativa para a correção da topologia da imagem de VA através das informações de distâncias fornecidas por imagens em modo-B.

Para as aquisições de imagens em modo-B do modelo pélvico foi utilizado um aparelho de US comercial modelo Vivid 7 (General Electric Company, Milwaukee, EUA) (Figura 3.8(a)) e um transdutor linear GE 7L de 192 elementos e frequência de operação entre 2,5 e 7,0 MHz. Foram adquiridas 280 imagens em modo-B, com intervalos de 0,25 $\mathrm{mm}$ de distância, definido como modo de escaneamento linear 3D [34]. Nesse escaneamento, o transdutor tem sua varredura controlada eletronicamente no plano $x z$ (plano azimutal) e mecanicamente na direção $y$. As imagens em modo-B tiveram seus parâmetros de controle de contraste e frequência ajustados para adquirir, principalmente, as superfícies do osso e do implante. Os parâmetros de controle da máquina foram ajustados para que a onda de US penetrasse pouco no osso e implante e a reverberação da onda entre o transdutor e as superfícies analisadas fosse reduzida. O controle desses parâmetros também contribuiu para reduzir o speckle nas imagens.

\subsection{Processamento de imagens}

O processamento de imagens envolveu duas etapas:

1. Segmentação da imagem gerada por VA, com o objetivo de se identificar a superfície descoberta do implante;

2. Representação da imagem por VA no espaço tridimensional, para avaliação mais precisa da área descoberta do implante.

Todo o processamento e avaliação da área das imagens foram realizados no software Matlab ${ }^{\circledR}$ R2008a versão 7.6.0.324. 


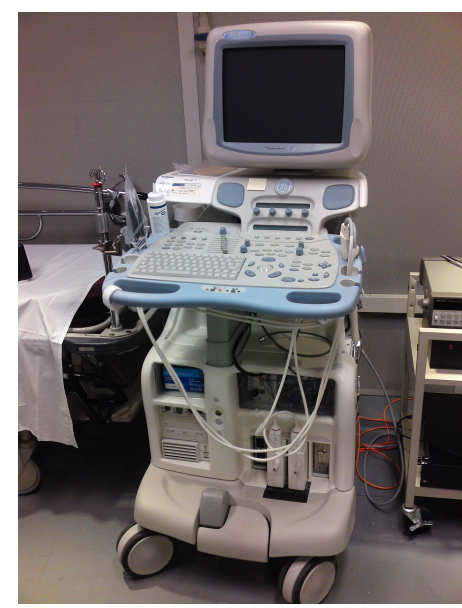

(a)

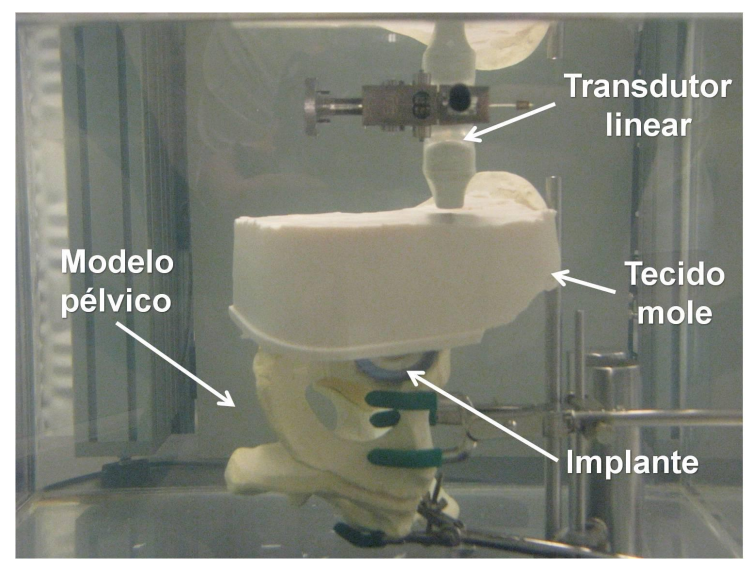

(b)

Figura 3.8: (a) Aparelho convencional de ultrassom GE modelo Vivid 7 utilizado para aquisições em modo-B do modelo pélvico. (b) Aparato experimental para aquisições em modo-B.

\subsubsection{Segmentação}

A área descoberta do implante foi identificada pelo processo de segmentação por contorno, aplicado sobre a imagem resultante da combinação linear das imagens por VA adquiridas em três profundidades diferentes.

O processo de segmentação por contorno utiliza-se do método de detecção de borda baseado no gradiente. As bordas são descritas como a posição da imagem onde ocorrem mudanças na intensidade local do nível de cor ao longo de uma orientação particular [45]. As derivadas parciais nas direções $x$ e $y$ identificam as regiões de variação de intensidade nas duas direções (Equação 3.2).

$$
|\nabla \operatorname{Im}(x, y)|=\sqrt{\left(\frac{\partial \operatorname{Im}(x, y)}{\partial x}\right)^{2}+\left(\frac{\partial \operatorname{Im}(x, y)}{\partial y}\right)^{2}}
$$

sendo $\operatorname{Im}(x, y)$ a função que descreve a imagem nas direções $x$ e $y$.

Numericamente, a magnitude do gradiente foi calculada através da utilização do operador de Sobel nas direções horizontal e vertical da imagem, o que definiu a máscara do gradiente da imagem. O operador de Sobel utiliza filtros lineares em formas de matrizes $3 \times 3$ que calculam 


\begin{tabular}{|l|c|c|c|}
\hline \multirow{3}{*}{$\frac{\partial}{\operatorname{lm}}(x, y)$} & 1 & 2 & 1 \\
\cline { 1 - 3 }$\partial \mathbf{x}$ & 0 & 0 & 0 \\
\cline { 2 - 5 } & -1 & -2 & -1 \\
\hline
\end{tabular}

as componentes locais do gradiente [45]. A máscara do gradiente foi binarizada e espaços com pixeis de valor zero não permitiram um completo delineamento da região de interesse. Com isso, aplicou-se operações básicas de morfologia [46], tais como: operação de adição de pixeis na borda do objeto (imdilate) para melhoria da definição do contorno da região de interesse; operação de preenchimento (imfill) para completar espaços vazios dentro da região de interesse; operação de remoção de pixeis na borda da região de interesse (imerode); e remoção de objetos conectados à borda da imagem (imclearborder).

\subsubsection{Correção da topologia}

A área superficial do implante deve ser avaliada tridimensionalmente e, portanto, foram necessárias correções de sua topologia. As correções da topologia da imagem de VA foram realizadas por duas metodologias: analítica e por aquisições em modo-B.

Analítica A metodologia analítica para a correção da topologia da imagem de VA foi baseada nas dimensões do implante. Uma vez que os implantes inseridos em pacientes nos procedimentos de ATQ têm suas dimensões registradas nos prontuários, é possível, através da equação da esfera (Equação 3.3), representar a componente acetabular (implante) matematicamente.

$$
x^{2}+y^{2}+z^{2}=r^{2}
$$

sendo $r$ o raio da componente acetabular e $x, y, z$ as coordenadas espaciais.

O raio $r$ da componente acetabular foi medido com auxílio de um paquímetro digital. 
Centralizou-se a imagem de VA através da identificação do ponto médio na borda superior da região segmentada (superfície descoberta do implante). O ponto médio foi definido como o ponto localizado na metade da borda superior do implante, obtida pela contagem de pixeis da largura da região segmentada. Identificou-se também, o ponto médio da representação 3D da semiesfera no meio da imagem. Em seguida, aplicou-se a imagem de VA como textura sobre a representação tridimensional da semiesfera, alinhando-se os pontos médios das duas representações. Para tanto, multiplicou-se a imagem segmentada de VA pela representação tridimensional analítica. Como a imagem segmentada era binária, na qual a região segmentada representava valor 1 (um) e fora desta, valor 0 (zero), o resultado da multiplicação forneceu a representação tridimensional somente da região segmentada, ou seja, da região descoberta do implante.

Assim, o cálculo da área superficial na representação tridimensional foi realizado numericamente, somente na região marcada pela região segmentada.

Por aquisições em modo-B A segunda metodologia para a correção da topologia da imagem de VA baseada em aquisições em modo-B é proposta para casos em que as dimensões do objeto em estudo são desconhecidas. Esta seção demonstra a viabilidade deste procedimento através da correção da topologia do implante e da região óssea adjacente a este. Nesse caso, as imagens em modo-B fornecem a topologia do objeto em estudo e a imagem por VA fornece a textura ao modelo tridimensional com alta resolução e contraste.

Para a representação tridimensional da superfície baseada em modo-B foi realizado o seguinte processamento das 280 imagens adquiridas:

1. Extraiu-se das imagens em modo-B apenas a faixa delimitada pelas alturas máxima e mínima do implante. Com isso, acima da faixa, eliminou-se a região do OSTM e, abaixo da faixa, a região 
após o osso e implante, onde existia demasiada reverberação, devido ao alto coeficiente de reflexão dos objetos em estudo.

2. Equalizou-se as resoluções espaciais das imagens em modo-B e da imagem de $V A$. A resolução das imagens em modo-B originalmente era de $0,19 \mathrm{~mm} /$ pixel e da imagem de VA $0,25 \mathrm{~mm} /$ pixel. Logo, para a equalização das resoluções o seguinte fator $f_{R}$ foi calculado

$$
f_{R}=\frac{R_{m B}}{R_{G}}=\frac{0,19}{0,25}=0,77
$$

sendo $R_{m B}$ a resolução em modo-B e $R_{G}$ a resolução geral. Esta última representa a resolução da imagem de VA e resolução de distanciamento entre as imagens de modo-B.

Com isso, redimensionou-se as imagens em modo-B pelo fator $f_{R}$. Feita a correção, todas as imagens apresentaram resolução espacial de $0,25 \mathrm{~mm} /$ pixel.

3. Extraiu-se a coordenada do pixel de valor máximo de cada coluna, separadamente. Substitui-se este valor por 255 e os demais por 0 .

4. Aplicou-se o filtro de média nas imagens para que pixeis isolados fossem removidos.

5. Aplicou-se uma correção por interpolação entre os segmentos de máximos para compensação dos pontos eliminados pelo filtro.

6. Construiu-se uma nova imagem bidimensional com as linhas de máximo extraídas das imagens em modo-B. Para tanto, realizou-se uma mudança de coordenadas, na qual a coordenada de profundidade das imagens de modo-B representasse o valor do pixel na imagem bidimensional.

7. As dimensões das imagens foram equalizadas para que houvesse o casamento entre a imagem de VA (como textura) e a representação tridimensional em modo-B. 
8. Por fim, para a avaliação da área também por esse método, multiplicou-se a imagem segmentada de VA pela representação 3D de modo-B. A multiplicação da imagem segmentada binária pela representação 3D resultou na representação 3D apenas da região descoberta do implante.

9. Realizou-se então a avaliação da área superficial utilizando a metodologia detalhada na próxima seção.

\subsection{Avaliação da área superficial}

O cálculo da área superficial do implante foi realizado sobre as representações tridimensionais, analítica e baseada em modo-B, da imagem por VA. Além disso, um método de digitalização ótica foi utilizado como padrão-ouro da medida de área.

Por vibroacustografia Após as correções da topologia da imagem de VA, a área segmentada da superfície do implante foi calculada. Para tanto, a superfície da região de interesse foi subdividida em triângulos delimitados pelas coordenadas de três pontos vizinhos. A área superficial total foi obtida pela soma das áreas dos subelementos triangulares.

A área de cada subelemento pôde ser calculada pela metade do módulo do produto vetorial entre dois vetores com origem numa dada coordenada $x_{i}, y_{i}, z_{i}$ e delimitados por pontos adjacentes à origem [47]. O produto vetorial entre os vetores $v \vec{e} t_{1}$ e $v \vec{e} t_{2}$ (Figura 3.9) é definido por

$$
\frac{\left|v \vec{e} t_{1} \times v \vec{e} t_{2}\right|}{2}=\frac{\left|v \vec{e} t_{1}\right| \cdot\left|v \vec{e} t_{2}\right| \cdot \operatorname{sen} \theta}{2} \hat{n}
$$

sendo $\theta$ o ângulo entre os vetores e $\hat{n}$ o vetor unitário com direção normal ao plano de $v \vec{e} t_{1}$ e ve $t_{2}$. Geometricamente $\left|v \vec{e} t_{1} \times v \vec{e} t_{2}\right|$ representa a área do paralelogramo formado entre os vetores. Logo, 


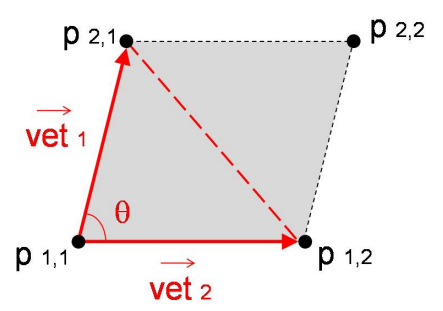

Figura 3.9: Vetores formados pelas coordenadas da superfície 3D do implante. Geometricamente, o produto vetorial entre dois vetores representa a área do paralelogramo.

$\frac{\left|v \vec{e} t_{1} \times v \vec{e} t_{2}\right|}{2}$ é a área do triângulo formado pelos vetores e a diagonal do paralelogramo.

Considerando que os pontos que definem a superfície são equidistantes, o ângulo $\theta$ é igual a $\pi / 2$ radianos e, portanto, o módulo do produto vetorial é dado por $\frac{\mid \text { vet }_{1}|\cdot| \text { vet }_{2} \mid}{2}$.

As coordenadas no espaço tridimensional $x, y$ e $z$ definem os vértices dos triângulos dados por $v_{i}=\left(x_{i}, y_{i}, z_{i}\right)$. A área de cada triângulo pode ser calculada por:

$$
A_{i}=\frac{1}{2} *\left|\left(v_{1}-v_{0}\right) \times\left(v_{2}-v_{0}\right)\right|
$$

sendo $v_{0}$ a coordenada da origem e $v_{1}$ e $v_{2}$ as coordenadas dos pontos adjacentes.

Logo, a área total da superfície é dada por

$$
A_{\text {total }}=\sum_{i} A_{i}
$$

Por digitalização ótica Para a avaliação dos resultados obtidos pela VA, a área descoberta do implante também foi medida com o auxílio do sistema ótico de digitalização Optotrak Certus ${ }^{\top M}$ capture system (NDI, Ontario, Canadá) e o software CAD Solidworks ${ }^{\top M}$ (Dassault Systemes, França). A ponta de prova do digitalizador foi posicionada nos locais de interesse e, através de um comando no computador acoplado ao sistema ótico, as coordenadas da ponta de prova foram registradas. 


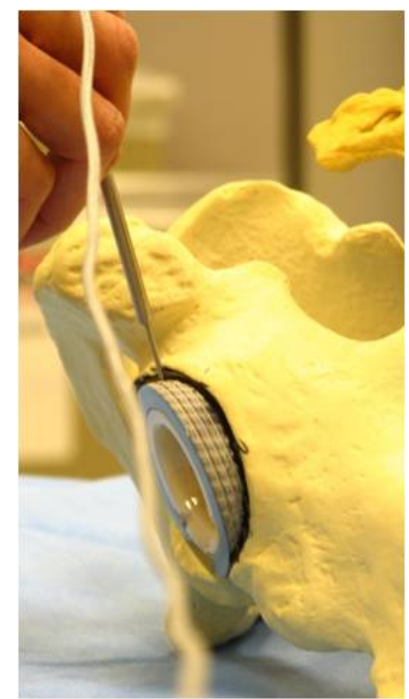

(a)

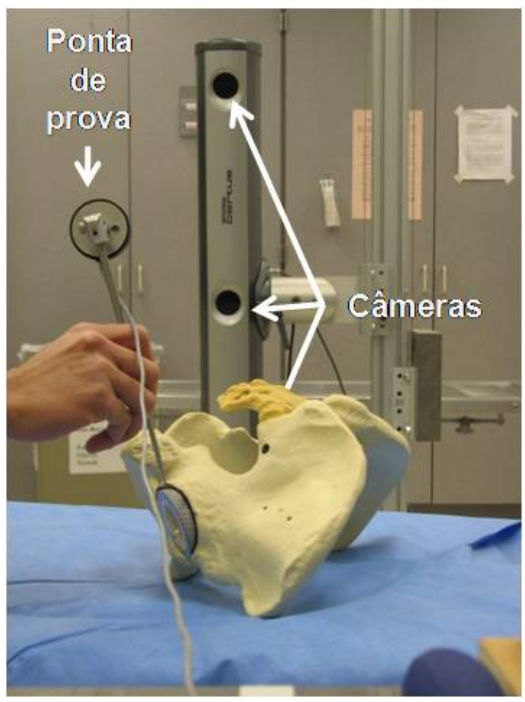

(b)

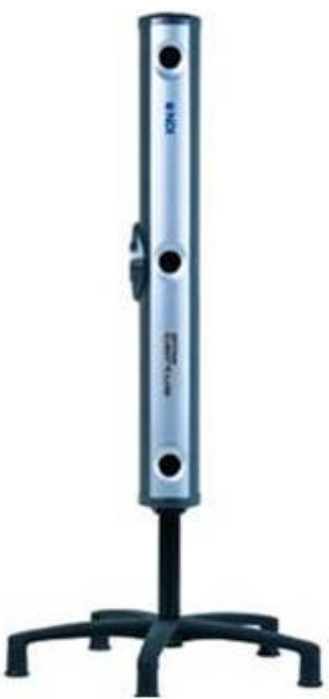

(c)

Figura 3.10: Sistema de digitalização. (a) Ponta de prova em contato com a borda para digitalização de pontos escolhidos pelo usuário, (b) arranjo experimental para digitalização e (c) sistema de digitalização ótica NDI modelo Optotrak Certus ${ }^{\mathrm{TM}}$.

O posicionamento da ponta de prova foi realizado manualmente, o que incluiu erros às medidas devido ao experimentador. Contudo, o sistema de captura apresenta alta precisão de $0,15 \mathrm{~mm}$, a uma distância de 2,25 m (Figura 3.10).

O modelo pélvico foi posicionado sobre uma mesa rígida parada em relação ao sistema ótico. A ponta de prova do digitalizador foi posicionada sobre a borda do implante em seis pontos diferentes, com o intuito de se registrar o diâmetro deste. Além disso, outros vinte pontos foram registrados sobre a borda do implante com o osso. Assim, foi determinada a linha de borda que delimita a área superficial descoberta do implante.

Feita a digitalização, utilizou-se o software de CAD Solidworks ${ }^{\top \mathrm{TM}}$ para a construção da superfície que representa a área descoberta do implante. Para tanto, a partir dos seis pontos adquiridos sobre a borda do implante gerou-se uma semiesfera que representa o implante. Em seguida, uma linha tridimensional ajustada sobre os vinte 
pontos adquiridos sobre a borda do implante e osso delimitou a área descoberta do implante.

Após a delimitação da superfície descoberta do implante, através de ferramenta de avaliação de superfície do software Solidworks ${ }^{\top M}$, obteve-se a área superficial da região de interesse. 


\section{Capítulo}

\section{Resultados e discussão}

Três imagens de VA para diferentes profundidades foram combinadas, o que permitiu uma visualização ampla da área de interesse. A segmentação da imagem baseada em detecção de bordas destacou a superfície descoberta do implante.

Como alternativa para reconstrução tridimensional da superfície, reconstruiu-se o volume da região de interesse a partir de aquisições em modo-B e extraiu-se a superfície do implante e da região óssea adjacente.

A correção analítica e a correção baseada em modo-B para a representação tridimensional da imagem de VA permitiram a reconstrução da superfície do implante em três dimensões. Por fim, as medidas de área obtidas pelos métodos propostos foram comparadas com a medida obtida pelo método ótico.

\subsection{Imagens de vibroacustografia}

As imagens resultantes das aquisições por VA mostram a focalização das diferentes regiões do implante, de acordo com o posicionamento do foco (Figura 4.1). Definindo-se o topo do implante como sendo o ponto do implante mais próximo do transdutor, tem-se $d$ como a distância entre o topo do implante e o transdutor confocal. A distância $d$ foi medida experimentalmente com o auxílio de um dispositivo Pulser-receiver (Panametrics modelo 5601A), uma vez que o OSTM não 

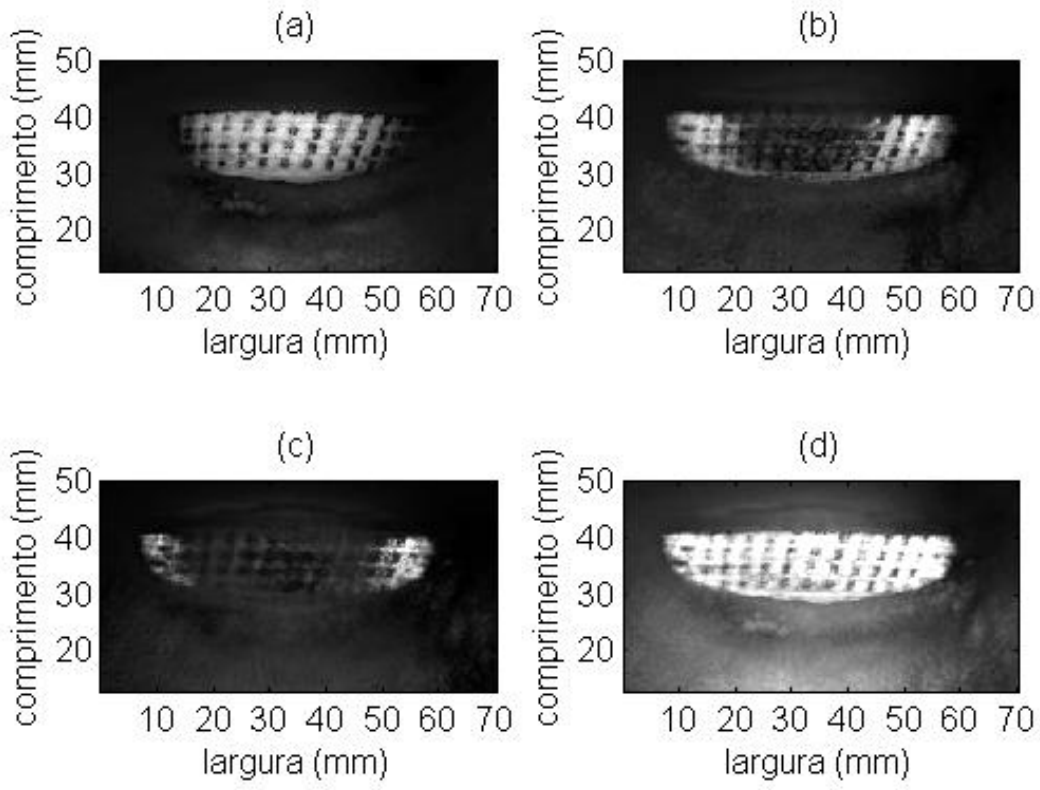

Figura 4.1: Imagens de VA em diferentes posicionamentos do foco, com distâncias $d$ entre o transdutor e o topo do implante iguais a: (a) $6,3 \mathrm{~cm}$, (b) $5,8 \mathrm{~cm}$ e (c) $5,3 \mathrm{~cm}$. A Figura (d) mostra a combinação linear das imagens com igual ponderação.

permitia o uso de qualquer outro dispositivo de medida direto, tais como paquímetro, régua ou trena. Com esse dispositivo um pulso de US é enviado por um transdutor em direção ao objeto que reflete a onda de volta para o transdutor. A distância foi obtida baseada no tempo de vôo da onda de US, dada por $\Delta S=c . \Delta t$, sendo $\Delta S=2 . d$ a distância e $\Delta t$ o tempo de vôo da onda. Assim, para $d$ igual a $6,3 \mathrm{~cm}$, o foco do transdutor varreu, principalmente, a região intermediária do implante, mais próxima do transdutor (Figura 4.1(a)). Para distâncias $d$ menores, ou seja, com o transdutor mais próximo do implante, a focalização do feixe de US atinge as regiões mais externas do implante. Isto pode ser observado nas Figuras 4.1(b) e 4.1(c) adquiridas para distâncias $d$ iguais a 5,8 e 5,3 cm, respectivamente. Aquisições com o transdutor mais próximo do implante não apresentaram significativas contribuições na aquisição da borda do implante e, ainda, o problema clínico de ATQ limita a distância entre o transdutor e o implante em 
aproximadamente $5 \mathrm{~cm}$, devido a camada de gordura e músculo nessa região anatômica. Portanto, as aquisições foram limitadas a três distâncias.

As imagens em diferentes profundidades do foco foram combinadas linearmente com igual ponderação. A imagem resultante (Figura 4.1(d)) fornece uma boa cobertura da região de interesse, apresentando alto contraste e alta resolução na região descoberta do implante.

\subsection{Segmentação}

O procedimento de segmentação baseado no gradiente de cor da imagem (VA combinada) é ilustrado na Figura 4.2, mostrando as diferentes fases do processo. Inicialmente, aplicou-se o operador de Sobel nas direções $x$ e $y$ da imagem, que resultou no gradiente de magnitude mostrado na Figura 4.2(b). Os contornos nesta figura são os locais de máximas derivadas indicando as regiões de mudanças bruscas de intensidade de cor.

Em seguida, o gradiente de magnitude foi binarizado e realizou-se operações de dilatação, preenchimento e remoção de pixeis desconexos à região de interesse, resultando na Figura 4.2(c). Por fim, a região segmentada foi destacada na figura de VA original (Figura 4.2(d)).

A largura da região descoberta do implante na imagem bidimensional foi de $52,5 \mathrm{~cm}$, o que representa $91,9 \%$ do diâmetro do implante.

O procedimento de segmentação foi facilitado, dado o alto contraste apresentado na imagem de VA. Além disso, a boa resolução da imagem de VA revela detalhes da estrutura do implante, tal como a superfície rugosa em forma de pequenos quadrados, responsável por melhorar a fixação do implante na pelve. 

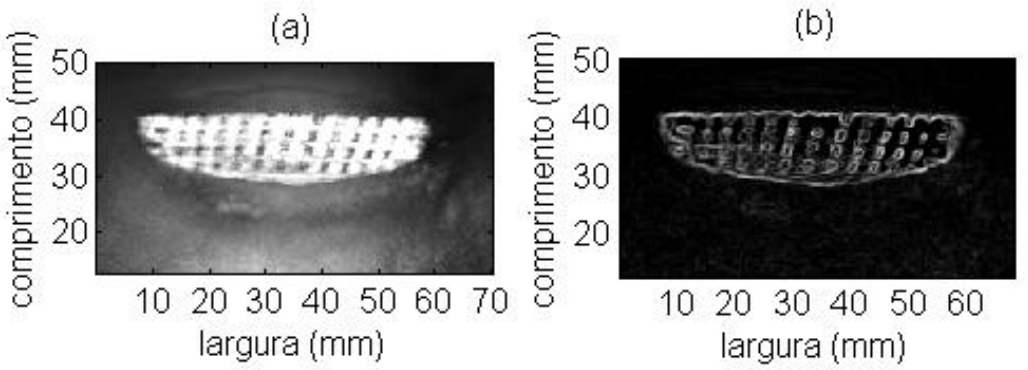

(c)

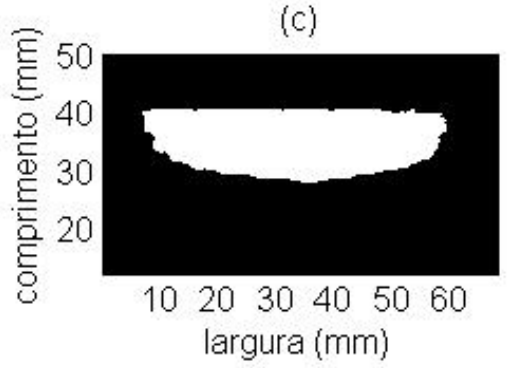

(d)

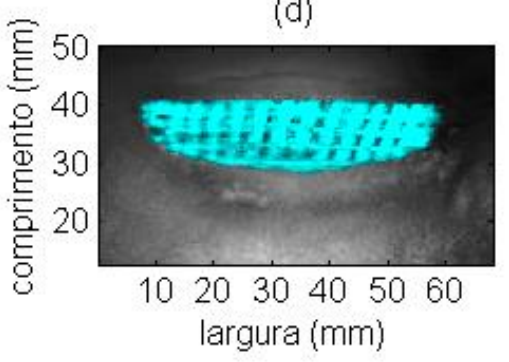

Figura 4.2: Segmentação por contorno da imagem de VA para identificação da área descoberta do implante. (a) Imagem combinada de VA, (b) gradiente de magnitude, (c) região segmentada e (d) região segmentada destacada na imagem original.

\subsection{Correção de topologia}

\subsubsection{Método analítico}

A Figura 4.3(a) mostra a superfície gerada analiticamente utilizandose a equação da esfera, com raio do implante $r$ igual a 57,1 $\pm 0,05 \mathrm{~mm}$ (medido com paquímetro). Para facilitar a visualização tridimensional do implante, a representação analítica foi limitada em um quarto de esfera.

A imagem segmentada de VA (Figura 4.2(d)) foi aplicada como textura sobre a superfície tridimensional analítica (Figura 4.3(a)), resultando na representação gráfica da Figura 4.3(b). Essa representação serviu apenas para a visualização do problema.

Para a avaliação da área superficial da região de interesse, realizou-se a multiplicação da imagem da superfície tridimensional analítica (Figura 4.3(a)) pela imagem binária da região segmentada 


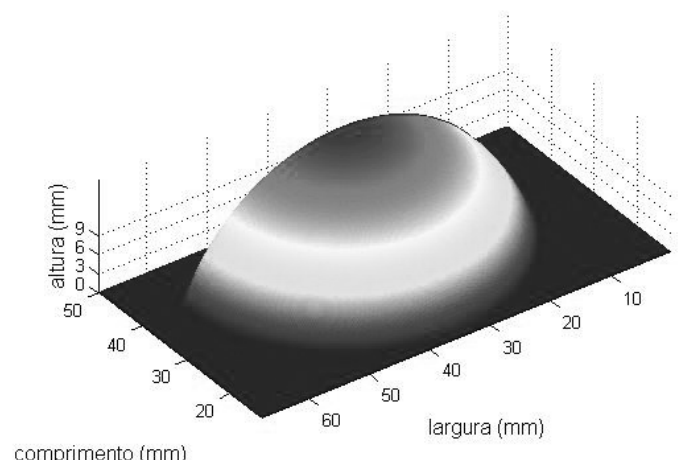

(a)

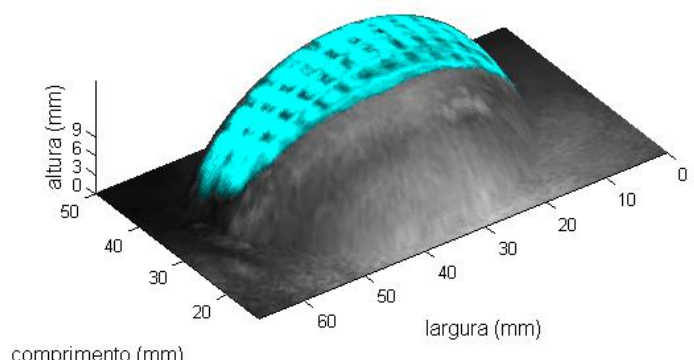

(b)

Figura 4.3: Representação $3 D$ da imagem de VA pelo método analítico de correção da topologia. (a) Topologia 3D definida pela equação da esfera com diâmetro de 57,1 $\pm 0,05 \mathrm{~mm}$, igual ao do implante e (b) representação 3D da imagem de VA.

(Figura 4.2(c)). Uma vez que, a imagem binária segmentada apresentava valor 1 (um) na região segmentada e 0 (zero) no restante, após a multiplicação das imagens, a representação tridimensional da superfície limitou-se à região segmentada (Figura 4.4). A Figura 4.4(a) mostra a vista em perspectiva da representação tridimensional da superfície descoberta do implante e a Figura 4.4(b) mostra a vista de topo da mesma região. O cálculo da área foi realizado na superfície da Figura 4.4 .

As aquisições das imagens de VA foram realizadas com o implante criteriosamente alinhado à borda da imagem. Isso foi possível por se tratar de um experimento in vitro, dentro do tanque de água, com total liberdade para posicionamento do modelo pélvico. Com isso, o alinhamento da representação tridimensional analítica e a imagem de VA foi facilitado, tomando-se como referência a linha horizontal do topo da representação tridimensional e a linha horizontal do topo do implante. Na aplicação clínica, o total alinhamento do implante nem sempre será possível. Contudo, devido à simetria esférica do implante, a metodologia analítica para a representação 


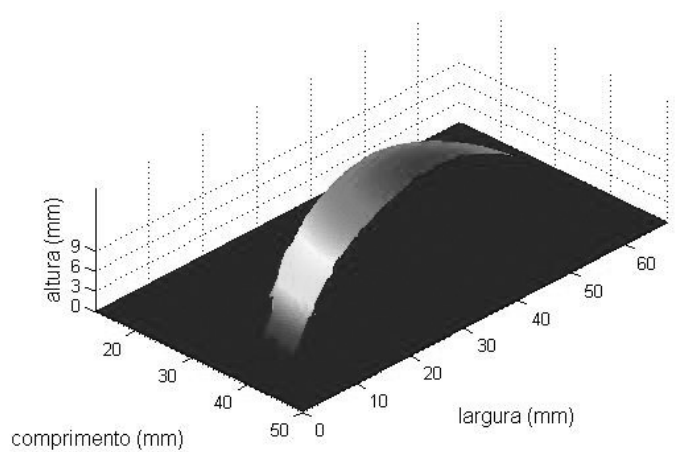

(a)

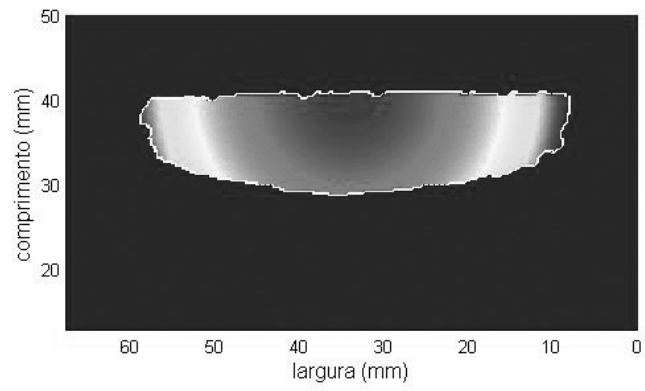

(b)

Figura 4.4: Representação $3 D$ da área descoberta do implante a partir de método analítico de reconstrução da topologia do implante e imagem adquirida por VA. (a) Representação 3D da área descoberta e (b) vista de topo da área descoberta.

tridimensional da superfície permite a representação da imagem de VA na forma de meia esfera (Figura 4.5(a)). Essa representação dispensa o alinhamento no plano $x y$ (plano indicado por largura versus comprimento), no qual o alinhamento pode ser referenciado pelo ponto central da borda superior da região segmentada e o centro da representação de meia esfera. Essa representação é suficiente para a correta avaliação da área superficial da região de interesse. Para exemplificar um possível desalinhamento, a imagem de VA foi rotacionada numericamente e multiplicada pela representação tridimensional analítica (Figura 4.5(b)).

Deve-se atentar que o alinhamento do eixo na direção de propagação da onda de US e a face da base do implante durante a aquisição da imagem de VA são indispensáveis. Estes devem estar paralelamente posicionados para uma correta representação tridimensional do implante. 


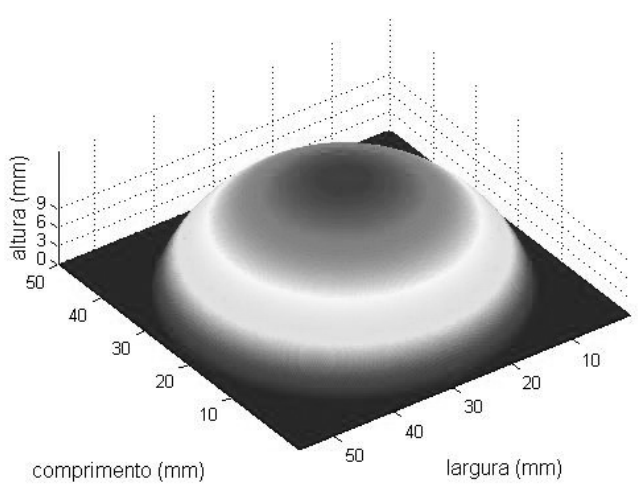

(a)

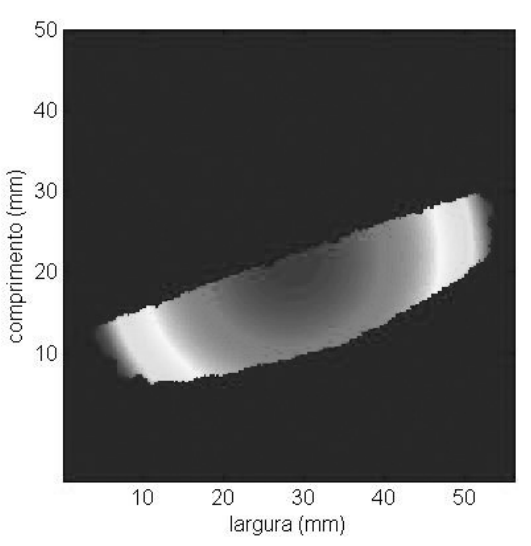

(b)

Figura 4.5: (a) Representação analítica de semiesfera para a topologia do implante e (b) exemplo de possível desalinhamento da região exposta do implante na aquisição da imagem de VA (vista de cima).

\subsubsection{Método baseado nas aquisições em modo-B}

Foram adquiridas 280 imagens em modo-B, distanciadas de 0,25 $\mathrm{mm}$. Os parâmetros de contraste, brilho, distância focal, escala de cores e potência da onda gerada (disponíveis na máquina de US GE Vivid 7) foram ajustados para otimizar a visualização da superfície do osso e do implante, evitando a visualização do OSTM e speckles. A Figura 4.6, referente à aquisição realizada no centro do implante, mostra que, mesmo com os ajustes na aquisição, os speckles não puderam ser totalmente eliminados. A Figura 4.6(b) mostra a imagem da Figura 4.6(a) processada no software ImageJ, utilizando-se a ferramenta de visualização (plugin) ImageJ3D. Essa visualização indica o alto coeficiente de reflexão da superfície do implante e do osso mostrados em amarelo. A otimização da visualização da superfície também é possível em pós-processamento através da aplicação de um limiar da escala de cores (em inglês, threshold) como será mostrado no processo de obtenção da superfície nesta seção.

$\mathrm{Na}$ Figura 4.6, o transdutor de US foi posicionado na parte superior da imagem apontando para baixo. Na Figura 4.6(a), a profundidade 


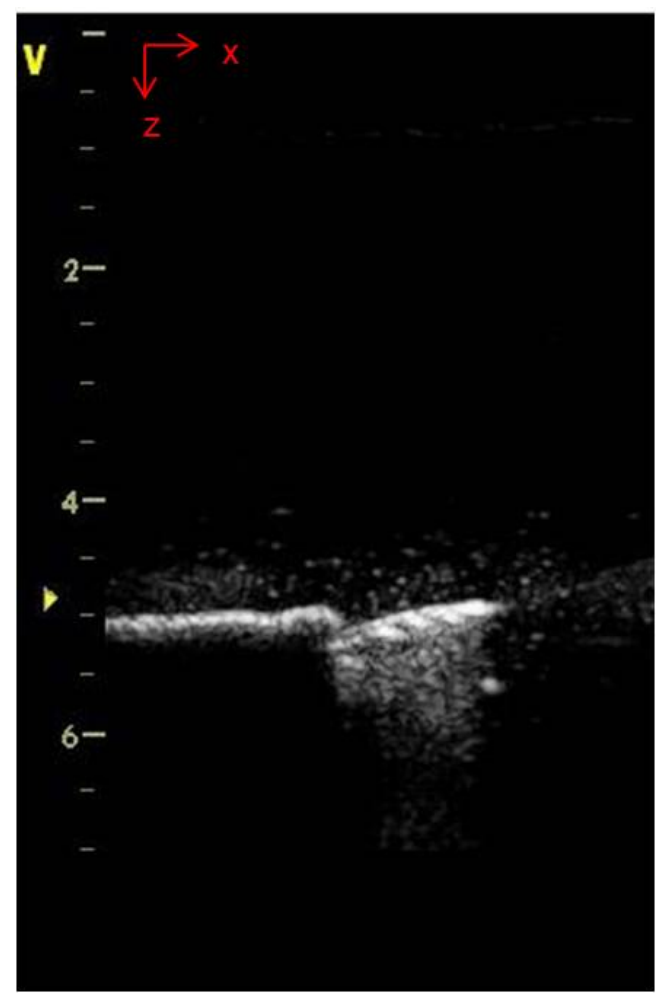

(a)

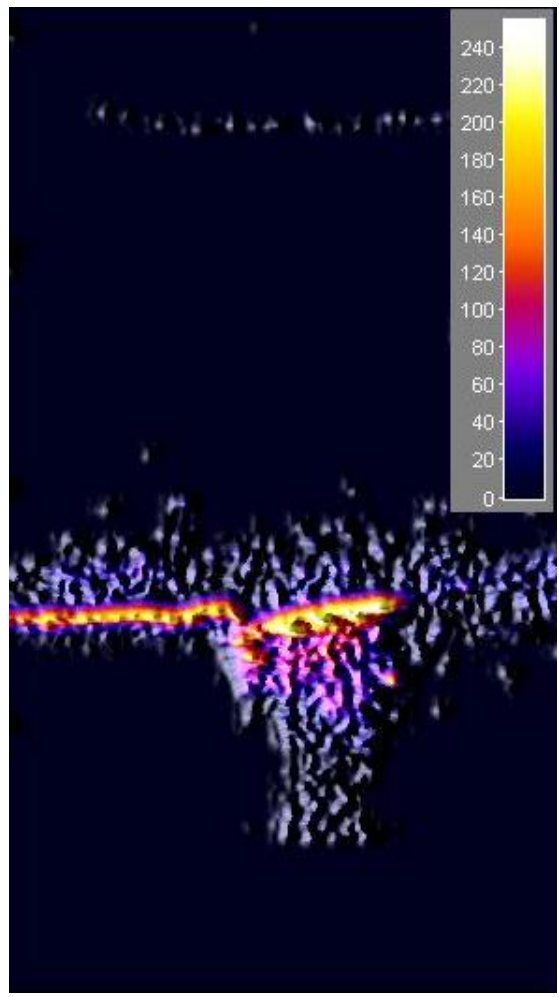

(b)

Figura 4.6: Aquisição de imagem em modo-B fornecida pela máquina GE Vivid 7 mostrando a superfície do implante e a região óssea do modelo. (a) Imagem original, com escala de profundidade à esquerda da imagem (em amarelo) apresentada em centímetros e (b) visualização da mesma imagem processada no software ImageJ, mostrando as superfícies do implante e do osso em amarelo com alta reflexão da onda ultrassônica.

indicada no eixo $z$ é mostrada em centímetros. O foco do transdutor foi posicionado a uma distância de aproximadamente $5 \mathrm{~cm}$. Na profundidade de aproximadamente $1 \mathrm{~cm}$, observa-se a superfície do OSTM gerada pela reflexão da onda de US, devido à impedância entre a água e o objeto. As regiões óssea e do implante encontram-se na profundidade de $5 \mathrm{~cm}$. Devido à alta diferença de impedância entre o implante e os tecidos adjacentes, observa-se uma alta reverberação da onda de US em torno dessas regiões nas imagens de modo-B.

Para determinar a resolução espacial da imagem de US, fez-se a contagem de pixeis numa distância conhecida. Tomando-se uma 
distância de $0,5 \mathrm{~cm}$ indicada por dois traços consecutivos da escala, contabilizou-se 26 pixeis. Com isso, têm-se $5 \mathrm{~mm}$ por 26 pixeis ou 0,19 $\mathrm{mm} /$ pixel de resolução espacial no plano $x z$. As imagens de VA, assim como o distanciamento das imagens em modo-B, foram adquiridas com resolução de $0,25 \mathrm{~mm} /$ pixel. Adotou-se como resolução padrão a resolução espacial de $0,25 \mathrm{~mm} /$ pixel e, com isso, redimensionou-se as imagens em modo-B pelo fator obtido na Equação 3.4.

O processamento das 280 imagens adquiridas em modo-B seguiu a sequência mostrada na Figura 4.7. Uma vez corrigida a resolução espacial das imagens, extraiu-se a região de interesse ( $201 \times 82$ pixeis), incluindo a região do implante e parte da região óssea adjacente (Figura 4.7(a)). Aplicou-se um threshold de $80 \%$ que permitiu que somente pixeis com valor superior a $80 \%$ do valor máximo permanecessem na imagem. Em seguida, o filtro de média foi aplicado na imagem para remoção de pixeis isolados da superfície (Figura 4.7(b)). Extraiu-se os pixeis de maior valor de cada coluna e binarizou-se a imagem (Figura 4.7(c)). Eliminou-se os intervalos vazios entre os pixeis da superfície através da interpolação linear dos pontos (Figura 4.7(d)). Por último, formou-se uma nova imagem (Figura 4.7(e)), na qual as colunas representam os contornos extraídos das imagens em modo-B. A distribuição espacial dessa nova imagem representa o comprimento versus a largura do implante e o contraste representa a profundidade do implante no eixo $z$.

Após o procedimento de reconstrução tridimensional, a imagem segmentada de VA (Figura 4.2(d)) foi aplicada como textura sobre a superfície 3D obtida pelo modo-B (Figura 4.8(a)), resultando na representação gráfica da Figura 4.8(b).

Seguindo o mesmo procedimento utilizado no método analítico para a avaliação da área superficial da região de interesse, realizou-se a multiplicação da imagem da superfície tridimensional (Figura 4.8(a)) pela imagem binária da região segmentada (Figura 4.2(c)). Uma vez que a imagem binária segmentada apresentava valor 1 (um) 
(a)

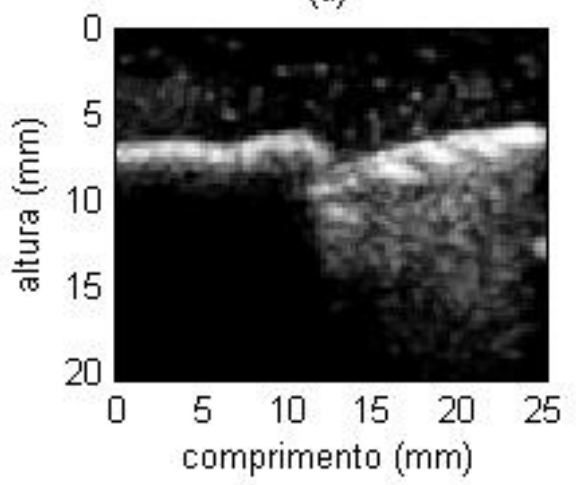

(c)

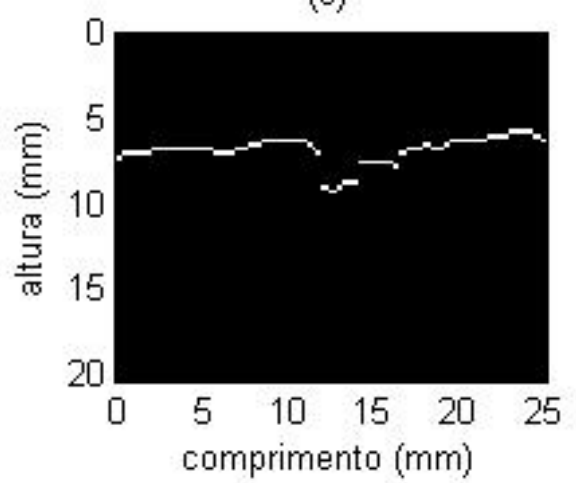

(b)

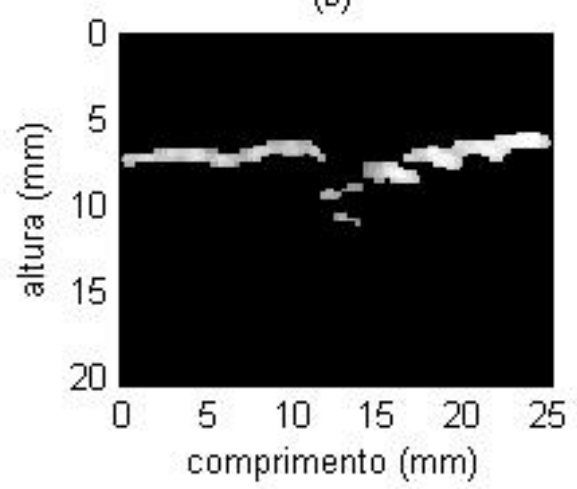

(d)

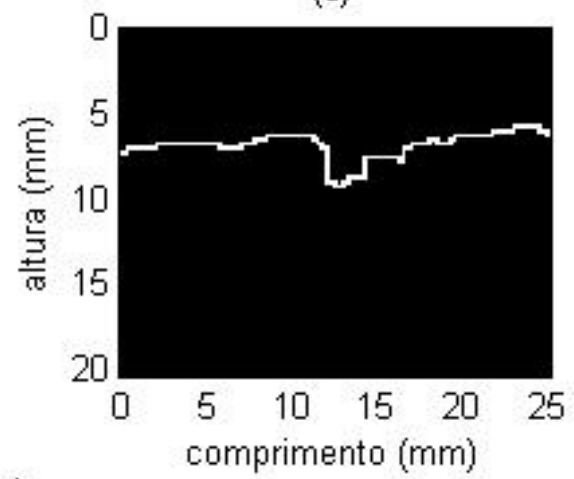

(e)

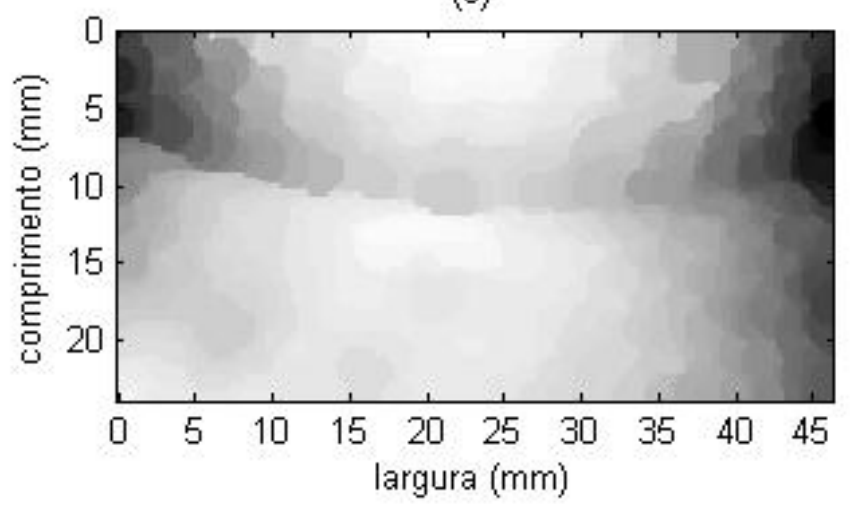

Figura 4.7: Sequência de processamento aplicada nas 280 imagens adquiridas em modo-B para extração de superfície tridimensional. (a) Correção da resolução espacial e extração da região de interesse, (b) aplicação de $80 \%$ de threshold e filtro de média, (c) extração dos pixeis de maior valor e binarização da imagem, (d) ligação entre os pontos por interpolação linear e (e) construção da superfície tridimensional da região de interesse a partir das linhas extraídas do processo exemplificado em (d). 


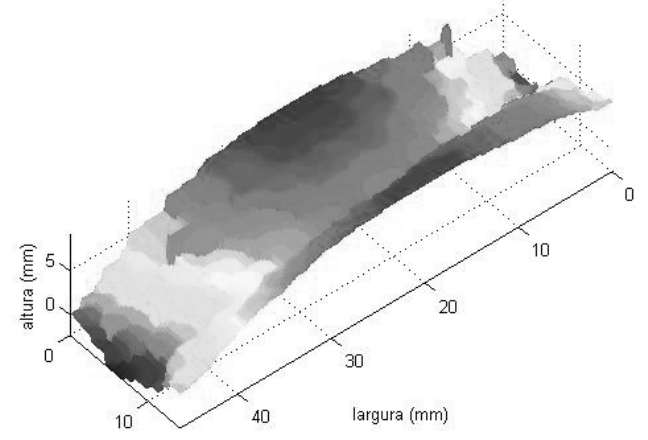

coomprimento (mm)

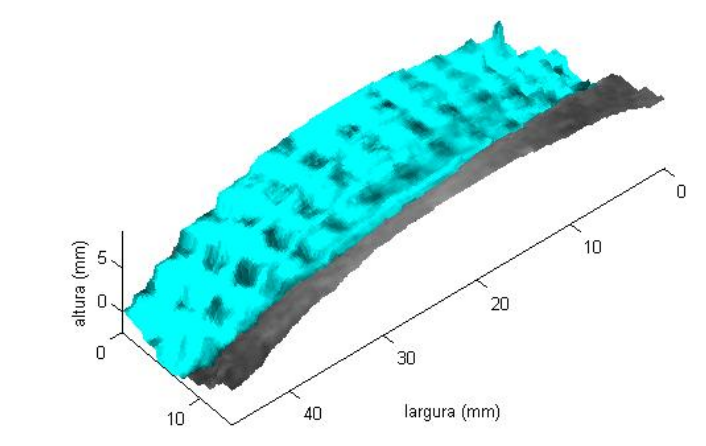

coomprimento (mm)

(a)

(b)

Figura 4.8: Representação $3 D$ da imagem de VA com correção da topologia a partir de imagens adquiridas em modo-B. (a) Topologia 3D a partir da aquisição de 280 imagens em modo-B da região de interesse e (b) representação 3D da imagem de VA.

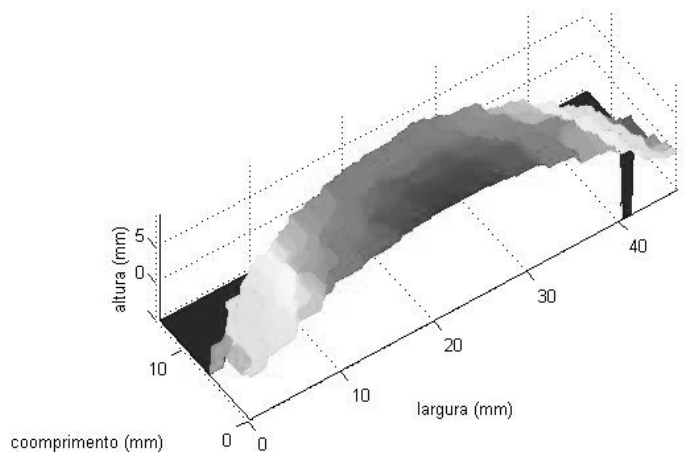

(a)

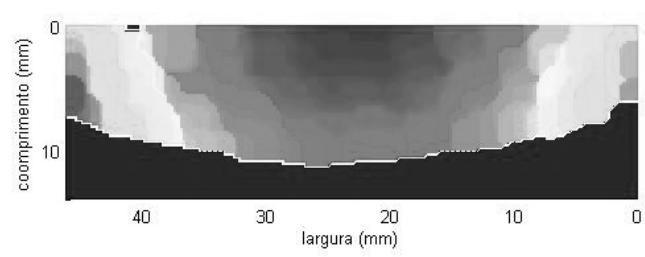

(b)

Figura 4.9: Representação $3 D$ da área descoberta do implante a partir de imagens adquiridas em modo-B e por VA. (a) Representação 3D da área descoberta e (b) vista de topo da área descoberta.

na região segmentada e 0 (zero) no restante, após a multiplicação das imagens a representação tridimensional da superfície limitou-se à região segmentada (Figura 4.9).

A metodologia para representação tridimensional a partir de imagens adquiridas em modo-B pode ser útil nos casos em que se desconhece o formato do objeto em estudo. Nesta aplicação, a 
aquisição em modo-B também pode ser útil revelando fissuras ou fraturas no acetábulo causadas pelo atrito entre o acetábulo e o implante.

\subsection{Avaliação da área superficial}

Dado o diâmetro do implante de $5,71 \mathrm{~cm}$, sua área superficial total foi de $51,2 \mathrm{~cm}^{2}$. Avaliou-se, então, a porcentagem da área do implante que estava descoberta pelo acetábulo. Para tanto, resultados utilizando o método ótico descrevem uma medida padrão-ouro para comparação com os métodos propostos.

Apresenta-se resultados da medida da área descoberta do implante utilizando os métodos analítico, baseado em aquisições de modo-B e baseado na digitalização ótica.

\subsubsection{Método ótico}

Com o auxílio do sistema de captura Optotrak Certus ${ }^{\top \mathrm{M}}$ foram adquiridos 6 pontos sobre a aresta do implante para a definição de seu diâmetro e 20 pontos sobre a borda da região descoberta do implante. As coordenadas dos pontos foram carregadas no software de $C A D$ Solidworks ${ }^{T M}$ (Figura 4.10(a)). Os pontos adquiridos sobre a aresta do implante definiram o semicírculo utilizado para a construção do modelo tridimensional da semiesfera (Figura 4.10(b)). Os outros 20 pontos adquiridos na borda da região descoberta do implante foram utilizados para a construção da linha tridimensional que definiu a aresta em laranja da Figura 4.10(c). Então, operações de corte de superfície foram aplicadas para a representação superficial da região descoberta do implante (Figura 4.10(d)).

Finalmente, a área superficial da região descoberta do implante (Figura $4.10(d)$ ) foi calculada por ferramenta específica dentro do software de $C A D$ resultando em $6,64 \mathrm{~cm}^{2}$. 


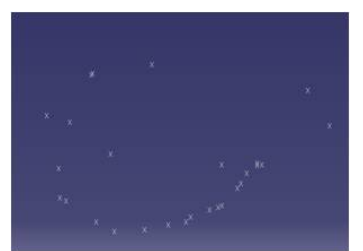

(a)

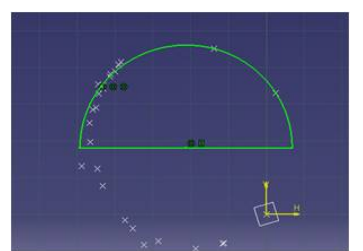

(b)

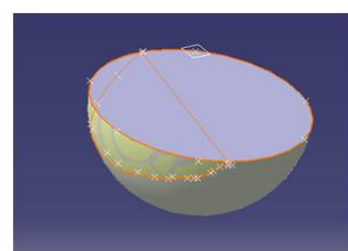

(c)

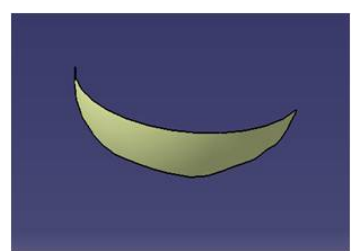

(d)

Figura 4.10: Processo de geração de superfície em software de CAD (Solidworks ${ }^{\top \mathrm{M}}$ ) baseado nos pontos digitalizados pelo sistema ótico (Optotrak Certus ${ }^{\top \mathrm{T}}$ ). (a) Pontos digitalizados em espaço tridimensional, (b) semicírculo gerado a partir dos pontos capturados sobre a borda do implante, (c) semiesfera representando o implante e linha de borda determinada pelos pontos adquiridos na borda osso/implante e (d) superfície descoberta do implante determinada a partir dos pontos digitalizados na borda entre osso e implante.

\subsubsection{Por vibroacustografia}

Utilizando o método analítico para a reconstrução 3D da superfície do implante, a área descoberta do implante foi de $6,10 \mathrm{~cm}^{2}$, o que representou $11,9 \%$ do implante. Pelo método baseado em imagens em modo-B, a área descoberta do implante foi de $6,30 \mathrm{~cm}^{2}$, o que representou $12,3 \%$ do implante.

A Tabela 4.1 resume os resultados obtidos entre os métodos estudados. A cobertura do implante pela pelve foi igual ou superior a $87 \%$ da área total, avaliada pelos três métodos de avaliação. 0 erro obtido pelo método analítico em comparação com o padrão-ouro adotado foi de 1,1 ponto percentual. No caso do método baseado em modo-B, o erro foi de 0,7 ponto percentual.

\subsection{Discussão}

Apesar de o sistema ótico não ser utilizado em procedimentos clínicos de ATQ, este método forneceu uma medida para comparação da área tridimensional da superfície descoberta do implante. Os métodos clínicos atuais (radiografia 2D) fornecem apenas uma estimativa da região descoberta através de medidas de ângulos da 
Tabela 4.1: Resultados das avaliações das áreas descoberta e coberta do implante pelos métodos ótico, analítico e baseado em imagens por modo-B.

\begin{tabular}{llccc}
\hline \hline \multirow{2}{*}{ Métodos } & \multicolumn{2}{c}{ Área descoberta } & \multicolumn{2}{c}{ Área coberta } \\
& $\mathrm{cm}^{2}$ & $\%$ & $\mathrm{~cm}^{2}$ & $\%$ \\
\hline ótico & 6,64 & 13,0 & 44,6 & 87,0 \\
analítico & 6,10 & 11,9 & 45,1 & 88,1 \\
modo-B & 6,30 & 12,3 & 44,9 & 87,7 \\
\hline
\end{tabular}

borda descoberta. O método ótico apresenta alguns problemas, dada a limitação da digitalização a alguns pontos acessíveis ao contato direto da ponta de prova. Além disso, apesar da alta precisão do instrumento $(0,15 \mathrm{~mm})$, o controle manual da ponta de prova introduziu erros adicionais devido ao experimentador. A área descoberta avaliada pelos métodos utilizando VA foi bem próxima da área obtida pelo método ótico. A diferença percentual causada tanto por erros no método ótico quanto no método VA foi de no máximo $1,1 \%$, o que viabiliza as metodologias utilizando VA para a avaliação de ATQ.

A imagem de VA representa o mapa de resposta acústica devido à absorção e espalhamento de meios ou amostras sob incidência de ondas de baixa frequência [4]. Diferenças em propriedades mecânicas de objetos, tais como densidade, impedância acústica e geometria, determinaram o contraste e resolução das imagens apresentadas. Baixas frequências e altas frequências interagem distintamente com o metal e com o osso. Na VA, diferenças nas propriedades mecânicas do osso e metal propiciaram alto contraste e resolução entre o osso e o implante. Além disso, a onda incidente é refletida e se propaga pelo meio sofrendo pouca atenuação até ser capturada pelo hidrofone, em comparação com ondas de alta frequência e, consequentemente, a resposta em baixa frequência na VA é muito menos afetada por variações no ângulo de incidência. Desta maneira, o posicionamento do hidrofone não é crítico e a geometria do objeto pode apresentar 


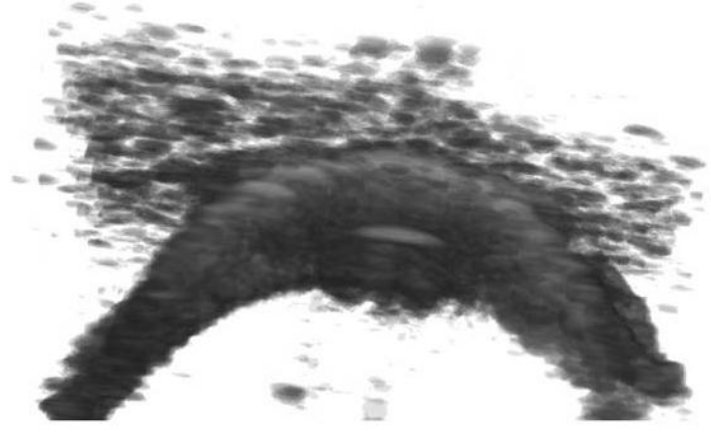

(a)

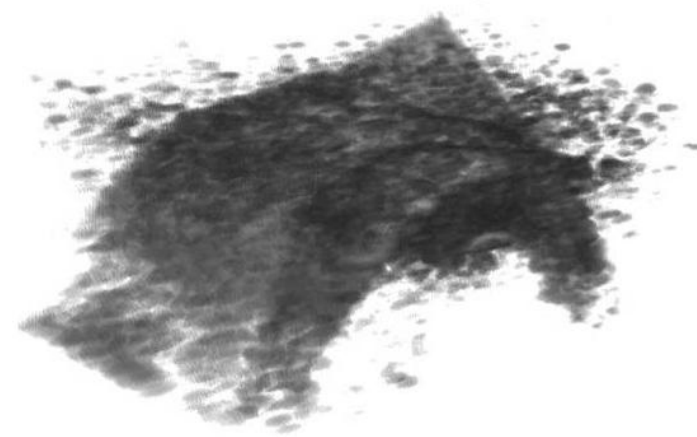

(b)

Figura 4.11: Representação 3D de 280 aquisições em modo-B, também conhecida do inglês como 3D B-scan, da região do implante e região óssea adjacente. (a) Vista frontal e (b) vista em perspectiva.

grandes variações de ângulos, desde que a onda incidente possa atingir a região de interesse diretamente. No modo- $B$, o contraste da imagem ocorre devido à reflexão da onda incidente em direção ao transdutor. Logo, se a onda incidente é refletida lateralmente para longe do transdutor, o sinal é perdido e nenhum contraste é observado na imagem. Além disso, devido à impedância característica do osso e do implante, os coeficientes de reflexão são próximos e dependentes da frequência entre essas regiões, piorando o contraste. A Figura 4.6(b) mostra a alta reflexão da onda de alta frequência no modo-B pelo osso e implante. O bom contraste e alta resolução fornecidos pela imagem de VA facilitaram o processo de segmentação por textura da área de interesse.

A Figura 4.11 mostra aquisições em modo de varredura 3D em modo-B. Essas imagens apresentaram speckles e alguns artefatos, devido ao espalhamento e reverberação das ondas de US entre o objeto e o transdutor. A varredura em modo-B apresenta erros inerentes à técnica devido ao posicionamento do sensor, à reconstrução 3D [48] [49] e ao sistema de aquisição (tais como reverberação, sombreamento e espalhamento devido ao ângulo de incidência). Na Figura 4.11(a) observa-se que o perfil esférico do 


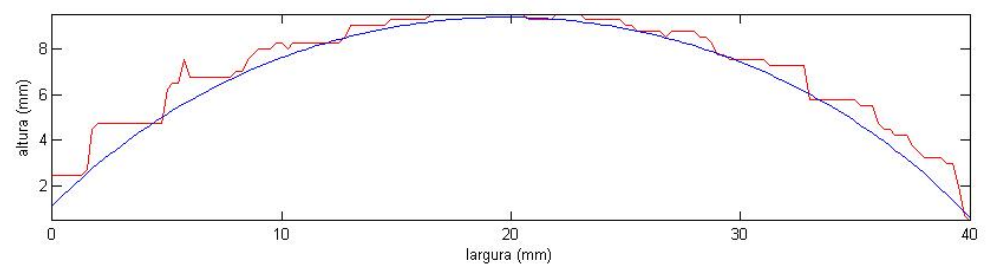

Figura 4.12: Perfis da região metálica obtidos pelo método analítico (em azul) e pelo método baseado em aquisições de modo-B (em vermelho). O método baseado em modo-B apresenta distorções, especialmente nas bordas laterais, causadas pelo espalhamento da onda ultrassônica pela superfície rugosa do implante.

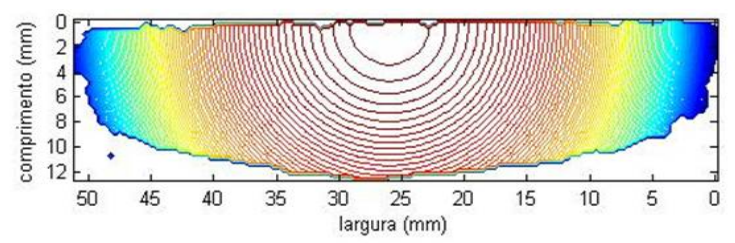

(a)

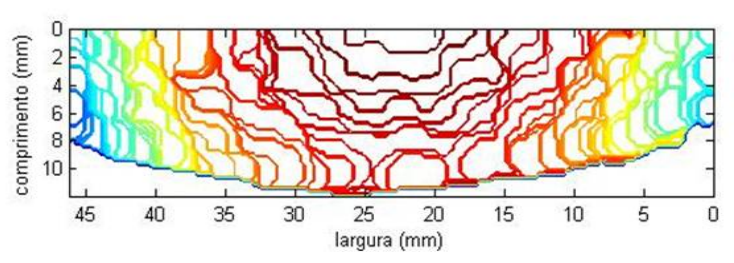

(b)

Figura 4.13: Curvas de nível da área descoberta. (a) Método analítico e (b) método baseado nas aquisições em modo-B.

implante foi distorcido, especialmente nas bordas da região inferior da imagem. Ainda na Figura 4.11(b) observa-se falhas na aquisição na região da borda devido à dependência angular da técnica. $\mathrm{O}$ efeito devido ao espalhamento da onda de US no modo-B pode ser observado na comparação entre os perfis da Figura 4.12 da região do implante obtidos pela metodologia utilizando a reconstrução analítica da geometria do implante e pela metodologia utilizando modo-B. Observa-se que o espalhamento aumenta proporcionalmente ao aumento do ângulo de incidência. A Figura 4.13 mostra as curvas de nível das topologias obtidas pelas duas metodologias, mostrando que a representação tridimensional obtida pelo modo-B apresenta deformidades.

Apesar dos problemas inerentes à correção da topologia baseada nas aquisições em modo- $B$, essa modalidade de imagem fornece 
informações de distância do objeto. Neste trabalho, mostrou-se o uso combinado das técnicas de VA e modo-B na representação 3D de superfícies, sendo principalmente útil na representação de superfícies, cujas dimensões são desconhecidas. Essas duas técnicas podem ser combinadas e potencialmente facilitar o procedimento cirúrgico de ATQ e a avaliação pós-operatória do implante e acetábulo, aumentando a longevidade das próteses. A combinação das técnicas pode fornecer detalhes em três dimensões com alta resolução (menor que $0,7 \mathrm{~mm}$ ) e alto contraste.

Uma vez que as dimensões do implante são conhecidas na aplicação clínica de ATQ, a correção analítica da topologia do implante pode ser aplicada com relativa facilidade sobre a imagem de VA. Devido à simetria esférica do implante, o alinhamento da imagem de VA à topologia 3D analítica é facilmente ajustado, mesmo em casos nos quais a imagem de VA não está totalmente alinhada, como mostrado no exemplo da Figura 4.5.

As principais limitações da VA foram a distância focal fornecida pelo transdutor utilizado $(7 \mathrm{~cm})$ e a potência da onda de US. Esses problemas poderiam ser superados pelo desenvolvimento de transdutores de ultrassom, discutido no capítulo 5. 


\section{Capítulo}

\section{Transdutor matricial reconfigurável para VA}

O desenvolvimento da tecnologia de transdutores, incluindo projeto mecânico, novos materiais e processamento de sinais, é essencial para promover melhorias nas imagens de US, tais como melhoria de resolução, contraste, relação sinal-ruído, taxa de aquisição etc. Transdutores matriciais permitem a geração de imagens de US sem a necessidade de varredura mecânica. Isso diminui o tempo de aquisição e evita artefatos de movimento, devido à baixa taxa de amostragem da varredura mecânica. Além disso, o transdutor matricial permite a ponderação da amplitude (apodização) do sinal aplicado nos elementos, permitindo o controle dos lóbulos laterais. A função de espalhamento de ponto PSF (PSF, do inglês point spread function) descreve a distribuição espacial da energia de excitação no plano de observação e facilita a análise do processo de varredura e efeitos da apodização. Transdutores matriciais bidimensionais apresentam maior flexibilidade no controle de fase, apodização e abertura. Essas características permitem melhorias na PSF, além de permitir a deflexão eletrônica do foco (em inglês steering) sobre o objeto-alvo em ambas as direções, azimutal e de elevação. Em transdutores matriciais lineares e de fase, o deslocamento mecânico do transdutor é necessário para a varredura no plano de elevação.

Os melhores resultados obtidos por VA para resolução e intensidade 
do foco são fornecidos por transdutores côncavos, devido à sua simetria axial da função de espalhamento de ponto, PSF. Contudo, para esse tipo de transdutor a varredura mecânica é necessária para a geração da imagem, trazendo problemas relacionados ao acoplamento entre o transdutor côncavo e o objeto. Esses problemas podem ser parcialmente resolvidos pelo uso de um tanque de água, no qual o objeto e o transdutor ficam imersos. Vários estudos de VA em laboratório utilizando o transdutor confocal e o tanque de água vêm sido realizados, como mencionado no Capítulo 1. O mesmo transdutor confocal tem sido também utilizado para medidas in vivo na avaliação de lesões em mama [50] [51] [52]. Estudos mais clinicamente orientados precisam ser realizados utilizando transdutores matriciais que são facilitados pela implementação da VA em um sistema clínico de US [41].

Os RCAs (RCA, do inglês reconfigurable array) são transdutores de US matriciais reconfiguráveis bidimensionais, nos quais os elementos piezelétricos são dinamicamente conectados em grupos utilizando recursos de microeletrônica [53]. A eletrônica implementada no RCA permite a combinação dinâmica de elementos em diferentes configurações de abertura, focalização e varredura eletrônica do foco, com a vantagem de requerer um número pequeno de canais [54]. O controle da abertura fornece uma formação do feixe precisa para a varredura eletrônica do foco por um volume, nas direções de elevação, azimutal e axial. A varredura eletrônica evita o deslocamento mecânico do transdutor, o que previne a degradação da imagem causada por erros mecânicos e artefatos de movimento, bem como ruídos inerentes da varredura mecânica.

Este capítulo apresenta um estudo numérico mostrando o uso de transdutores matriciais reconfiguráveis para a formação de feixe em VA. Propõe-se a utilização do RCA na aquisição por VA para a melhoria da qualidade de imagens e aumento da viabilidade da técnica na prática clínica. Uma investigação numérica da formação do feixe 
utilizando o RCA para VA é apresentada. O RCA apresenta milhares de elementos retangulares o que demanda um longo tempo de simulação computacional. Para tanto, desenvolveu-se um algoritmo utilizando a aproximação de Fresnel, permitindo a simulação de um grande número de elementos em um tempo relativamente pequeno. Estudou-se valores ótimos para os parâmetros do $R C A$, tais como número de elementos, número de canais, varredura eletrônica, distância focal, abertura e $f$-número ou abertura relativa (relação entre distância focal e o diâmetro da abertura), de maneira a se avaliar o desempenho do $R C A$ e definir a configuração mais viável para a execução de VA. O RCA possibilita a varredura eletrônica de um volume, bem como flexibiliza a definição da abertura utilizada, permitindo a utilização de padrões anelares de abertura, o que aprimora a qualidade da imagem e diminui o tempo de aquisição da VA.

\subsubsection{Solução analítica para o campo acústico}

Aplicações clínicas de VA, tais como avaliações de tecido biológico de tireóide e mama, são realizadas em profundidades entre $10 \mathrm{e}$ $50 \mathrm{~mm}$. Para uma avaliação apropriada do uso do RCA para VA, é necessário examinar-se os efeitos da formação do feixe a partir de profundidades dessa ordem. Estudos numéricos de campos acústicos emitidos por fontes retangulares podem ser realizados por métodos temporais (métodos de resposta ao impulso) ou por métodos no domínio da frequência (métodos de espectro angular). Nos métodos temporais, os elementos são considerados como fontes independentes e suas contribuições individuais para um tempo e local específico são somadas e ponderadas pela função de apodização [55]. Pelo método de espectro angular, a transformada rápida de Fourier bidimensional, FFT ( $F F T$, do inglês Fast Fourier Transform) do potencial de velocidade $\Phi$ no plano da fonte é multiplicado pela função de transferência (do plano da fonte até o plano de interesse) e finalmente calcula-se a transformada 


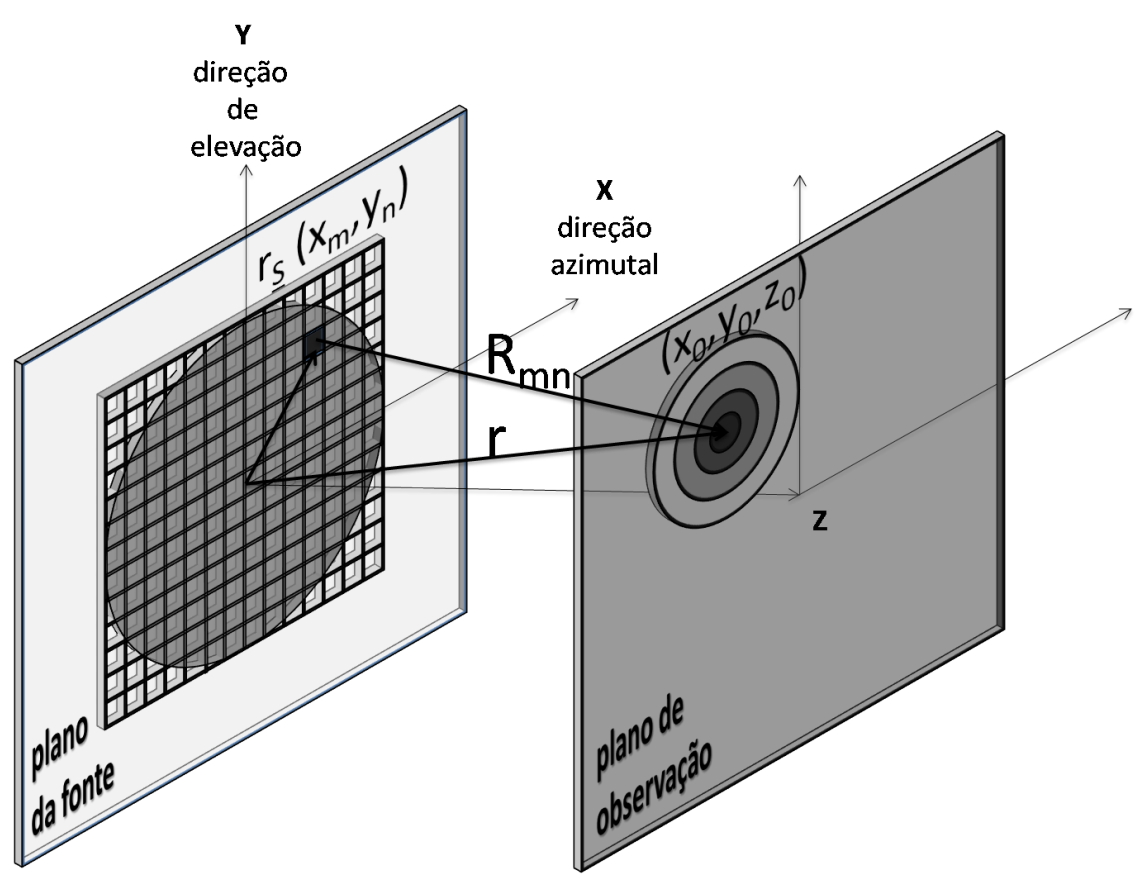

Figura 5.1: Transdutor matricial reconfigurável com fontes retangulares $\left(x_{m}, y_{n}\right)$ situadas no plano de origem e um ponto de observação em $\left(x_{0}, y_{0}, z_{0}\right)$ no plano de observação numa distância $R_{m n}$.

inversa de Fourier do resultado [56]. O fasor de pressão $p$ é dado por

$$
p=j \omega \rho_{0} \Phi
$$

sendo $\omega$ a frequência angular $(\omega=2 \pi f), \rho_{0}$ a densidade no equilíbrio, e o plano dado expresso em termos da distribuição angular das ondas planas.

O método aproximado de Fresnel é um método de espectro angular que permite soluções analíticas simples para fontes retangulares no campo-próximo [57]. Neste estudo, assume-se um transdutor matricial 2D de elementos retangulares, como mostrado na Figura 5.1, com indíces $m$ e $n$ para as direções $x$ e $y$, respectivamente. A solução analítica para a velocidade potencial calculada no tempo $t$, a uma distância $R_{m n}=\left|\vec{r}-\vec{r}_{s}\right|$ (Figura 5.1) é obtida a partir da integral de 
Rayleigh

$$
\phi_{N}(\vec{r}: t)=\iint_{S} \frac{\xi_{0} v_{0} e^{j \omega\left(t-\frac{R m n}{c_{0}}\right)}}{2 \pi R_{m n}} d S
$$

sendo $\xi_{0}$ a variação espacial relacionada à apodização, $v_{0}$ a velocidade com direção normal à superfície $S, c_{0}$ a velocidade de propagação da onda e $R_{m n}=\sqrt{\left(x_{0}-x_{m}\right)^{2}+\left(y_{0}-y_{n}\right)^{2}+z_{0}^{2}}$.

$\mathrm{Na}$ aproximação de Fresnel, a expansão de série binomial da distância $R_{m n}$, dada por

$$
R_{m n}=z_{0}\left\{1+\frac{1}{2 z_{0}^{2}}\left[\left(x_{0}^{2}+y_{0}^{2}\right)-2\left(x_{0} x_{m}+y_{0} y_{n}\right)+\left(x_{m}^{2}+y_{n}^{2}\right)\right]+\ldots\right\}
$$

é truncada no elemento de segunda ordem. Esse método permite uma rápida, fácil e relativamente precisa avaliação do campo no plano de observação desejado, quando comparado ao método de resposta ao impulso [36].

\subsubsection{Implementação numérica}

A aproximação de Fresnel foi implementada nas simulações numéricas de campo acústico emitido pelo RCA em um meio fluido homogêneo, isotrópico e não viscoso, levando em consideração os efeitos da focalização e apodização. As razões para a escolha da aproximação de Fresnel envolvem o compromisso entre custo computacional e confiabilidade dos resultados na avaliação do foco da VA.

A implementação numérica para transdutores retangulares de largura $W$ e altura $H$ pelo método de Fresnel no domínio da frequência baseou-se no produto entre as funções de apodização e abertura, dada por [36] 


$$
\begin{aligned}
p_{m n}(\vec{r}: \omega) \approx & \frac{-\omega \rho_{0} v_{0} z_{0} \lambda}{8 \pi R_{m n}} e^{-j\left(k z_{0}-\phi_{0}\right)} \\
& \left\{\operatorname{erf}\left[\sigma\left(W-2 x_{0}\right)\right]-\operatorname{erf}\left[-\sigma\left(W+2 x_{0}\right)\right]\right\} \times \\
& \left\{\operatorname{erf}\left[\sigma\left(H-2 y_{0}\right)\right]-\operatorname{erf}\left[-\sigma\left(H+2 y_{0}\right)\right]\right\}
\end{aligned}
$$

sendo $\phi_{0}=\omega R_{m n} / c$ e o termo $\sigma$ definido como

$$
\sigma=\sqrt{-j \pi /\left(4 \lambda z_{0}\right)}
$$

e erf a função erro, dada por

$$
e r f=\frac{2}{\sqrt{\pi}} \int_{0}^{z_{0}} e^{-\varsigma^{2}} d s
$$

A função erro é uma representação matemática simples da função gaussiana convoluída com a distribuição retangular dos elementos [57].

A Equação (5.4) é utilizada para calcular a pressão acústica emitida independentemente por cada elemento. Cada pixel no plano de observação corresponde à contribuição (soma) da resposta acústica de todos os elementos no plano da fonte. As respostas acústicas para as frequências $\omega_{1}$ e $\omega_{2}$ são dadas por

$$
p\left(\vec{r}: \omega_{i}\right)=\sum_{m} \sum_{n} A_{m n}\left(\omega_{i}\right) p_{m n}\left(\vec{r}: \omega_{i}\right), i=1,2
$$

sendo $A_{m n}$ a definição do canal considerando o atraso temporal e a frequência de excitação $(i=1,2)$, e $p_{m n}$ a contribuição da pressão de cada elemento no plano da fonte na coordenada $m n$. $A_{m n}$ é 1 quando um elemento é excitado com $\omega_{i}$ e 0 em caso contrário. 
Tabela 5.1: Parâmetros gerais para simulações do RCA.

\begin{tabular}{cc}
\hline \hline Parâmetros & Definições \\
\hline Abertura & Círculos concêntricos \\
Tamanho do elemento & $0,2 \times 0,2 \mathrm{~mm}^{2}$ \\
Kerf $(x$ e $y)$ & $0,001 \mathrm{~mm}$ \\
Frequência central $f_{1}$ & $5 \mathrm{MHz}$ \\
Diferença de frequência $\Delta f$ & $50 \mathrm{kHz}$ \\
Número de elementos por eixo $N_{e}$ & $50,100,150,200$ \\
Número de canais $N_{c}$ & $32,64,96,128$ \\
Distância focal $D_{f}$ & $20,30,40,50 \mathrm{~mm}$ \\
\hline
\end{tabular}

\subsection{Algoritmo}

\subsubsection{Descrição geral}

Considerou-se um RCA com 200 por 200 elementos, totalizando 40.000 elementos de dimensões $0,2 \mathrm{~mm} \times 0,2 \mathrm{~mm}$. A distância entre cada par de elementos nas direções $x$ e $y$ (kerf) foi de $0,001 \mathrm{~mm}$. A frequência central $f_{1}$ foi ajustada para $5 \mathrm{MHz}$ e a frequência gerada pela interferência das ondas incidentes $\Delta f$ foi ajustada para $50 \mathrm{kHz}$.

A influência dos parâmetros do RCA (Tabela 5.1), incluindo número de elementos, número de canais e posição do foco (deflexão eletrônica do foco nos planos azimutal e de elevação), foi avaliada de maneira a se definir a configuração ótima para geração de imagens por VA. Gerou-se os perfis de PSF e campos acústicos nas direções $x$ e $y$ para comparações quantitativas dos parâmetros. O número de canais avaliados foi de $32,64,96$ e 128 e o número de elementos por eixo foi de $50,100,150$ e 200. O desempenho da deflexão eletrônica do foco foi analisado no plano azimutal nas posições $x_{0}=0,3,6,9$ e $12 \mathrm{~mm}$. A avaliação do foco em diferentes distâncias $(20,30,40$ e $50 \mathrm{~mm}$ ) foi dada nos planos azimutal e de elevação (Figura 5.1). 


\subsubsection{Definição da abertura para o estudo numérico}

A avaliação da formação do feixe descreve duas aberturas concêntricas utilizadas como fontes de US para geração do fenômeno de interferência numa região focal comum. A implementação do tipo confocal utilizando anéis concêntricos foi adotada devido à boa resolução lateral, dependência angular e longa profundidade de campo fornecida pela simetria cilíndrica [36].

Primeiramente, para uma dada posição focal a $x_{0}, y_{0}$ e $z_{0}$, os atrasos temporais foram calculados para cada elemento da matriz. Ativou-se uma abertura circular dentro da dimensão máxima do $R C A$. Para cada um dos canais na parte ativa da matriz, distribuiu-se iguais números de elementos. Assim, dividiu-se os elementos ativos disponíveis dentro dos anéis concêntricos $N_{c}$. No RCA, cada canal pode ser excitado por diferentes sinais com um atraso temporal particular. Todos os elementos conectados a um canal receberam o mesmo sinal. Neste estudo, assume-se sinais de onda contínua com frequências fixas. Para cada canal, determinou-se um único atraso temporal para todos os elementos presentes no canal correspondente. Computou-se o valor médio dos valores de atraso temporal associados aos elementos de um determinado canal. O próximo passo foi definir os sinais transmitidos com frequências $\omega_{1}$ e $\omega_{2}$ para diferentes grupos de canais. Adotou-se números iguais de canais para os feixes excitados com frequência $\omega_{1}$ e $\omega_{2}$. Quando o ponto focal esteve fora do eixo central do transdutor, o atraso deslocou-se de maneira que o atraso mínimo foi promovido aos elementos próximos à posição do foco $\left(x_{0}, y_{0}\right)$. Os anéis concêntricos foram utilizados como em Cogan et al. [58]. Como visto na Figura 5.2(d), os anéis foram deslocados quando realizada a deflexão eletrônica do foco em $x_{0}=6 \mathrm{~mm}$. A definição da frequência de excitação a um dado elemento foi matematicamente representada por $A_{m n}\left(\omega_{1}\right)$ e $A_{m n}\left(\omega_{2}\right)$ na equação (5.7). Neste estudo, simulou-se um transdutor confocal que consiste de 2 elementos, um disco central e 
(a)

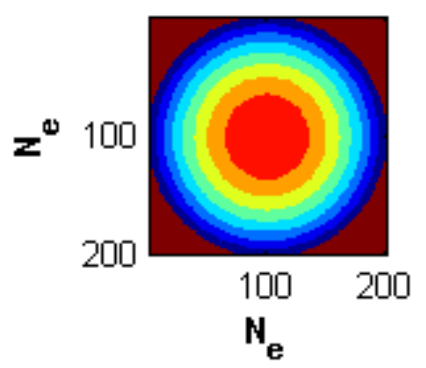

(d)

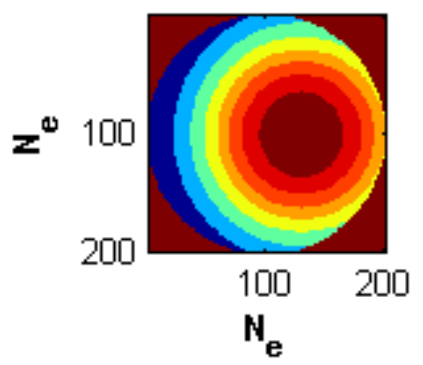

(b)

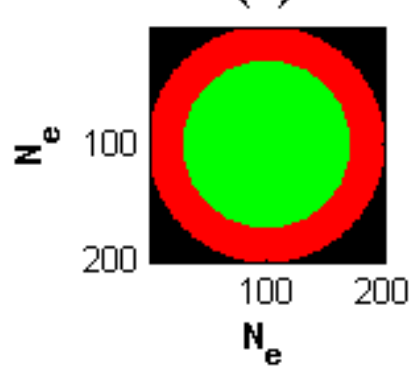

(e)

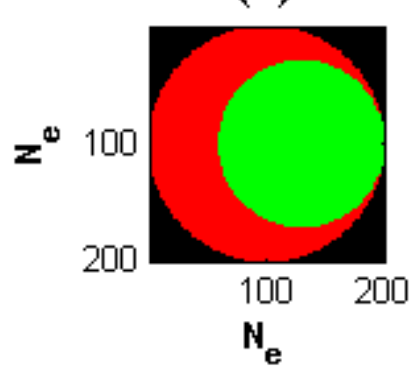

(c)

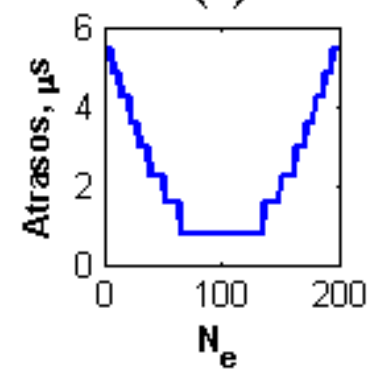

(f)

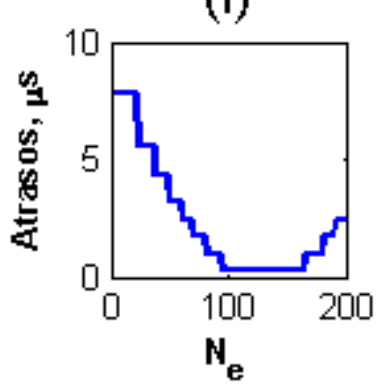

Figura 5.2: Aspectos para a definição da abertura: (a) canais, representados por iguais áreas mostrando os elementos ativados para cada canal; (b) regiões para cada frequência, áreas com frequência de excitação $\omega_{1}$ em vermelho e $\omega_{2}$ em verde; e (c) perfil de atraso temporal, no qual diferentes níveis representam atrasos na fase de ativação. As figuras (d), (e) e (f) mostram os respectivos aspectos para definição de abertura para $6 \mathrm{~mm}$ de deflexão eletrônica do foco na direção $x$. A variação no número de canais nas simulações foi de 32 à 128. Para permitir uma boa visualização foram representados apenas 8 canais neste esquema.

um anelar. Com o $R C A$, definiu-se elementos similares, porém, quando executada a deflexão eletrônica do foco, o disco central foi deslocado eletronicamente. Avaliou-se numericamente os campos de pressão para os feixes com frequência $\omega_{1}$ e $\omega_{2}$ utilizando a Equação (5.7). Para encontrar a magnitude do termo dinâmico de baixa frequência $\Delta \omega$, calculou-se o produto das distribuições espaciais dos dois feixes como na Equação (2.19). 


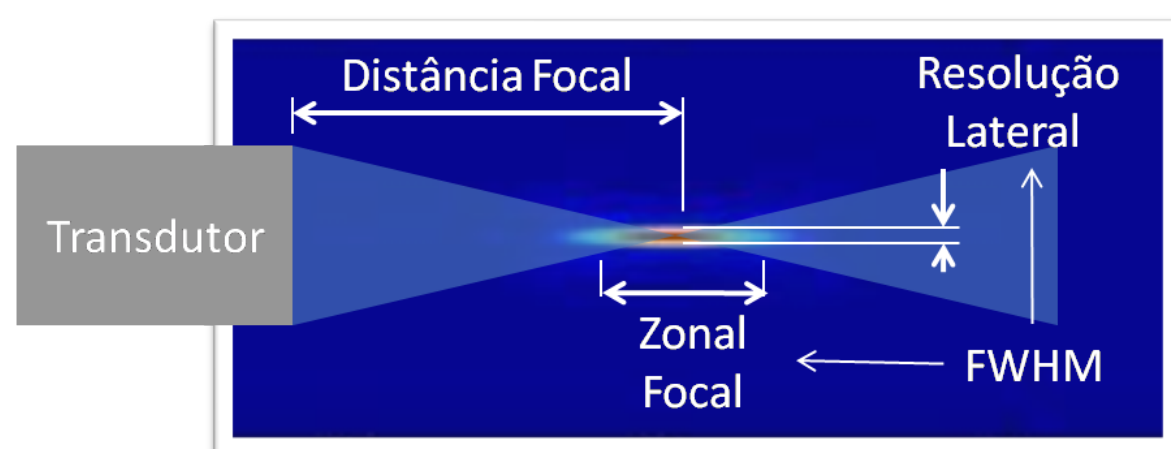

Figura 5.3: Parâmetros espaciais utilizados na avaliação do foco. A FWHM foi utilizada para definir a zona focal e a resolução lateral. A distância focal foi definida como a distância entre o transdutor e o ponto de máximo da força acústica.

\subsubsection{Análise da PSF}

A análise espacial da PSF incluiu os parâmetros: distância focal $D_{f}$, zona focal $F_{z}$ e resolução lateral $R_{l}$. Os parâmetros espaciais estão ilustrados na Figura 5.3. A distância focal $D_{f}$ foi definida como a distância entre o transdutor e o ponto de intensidade máxima da pressão ao longo do eixo central do feixe. A distância efetiva focal, medida na simulação, foi comparada ao valor esperado. A zona focal $F_{z}$ refere-se ao comprimento do foco delimitado pela largura à meia altura, FWHM (FWHM, do inglês full-width at half-maximum) da PSF ao longo do eixo do feixe. A resolução lateral $R_{l}$ foi avaliada nessa análise pela medida do comprimento da região delimitada pela FWHM na região focal ao longo da direção azimutal [59].

A análise da PSF também incluiu a força normalizada $F_{n}$ definida como a força de pico na PSF normalizada.

\subsubsection{Otimização da deflexão eletrônica do foco}

Nas simulações descritas, utilizou-se igual número de canais para a produção dos feixes de frequências $\omega_{1}$ e $\omega_{2}$. Quando o feixe é deslocado lateralmente, o ângulo de deslocamento para alguns dos elementos pode se tornar muito aberto. Esses elementos podem ficar 
muito distanciados da posição do foco e, com isso, pouco ou nada contribuirão para a formação do feixe. Essencialmente, o produto $p_{1}(r) \cdot p_{2}(r)$ na Equação (2.19) é reduzido e a magnitude da força para $\Delta \omega$ é reduzida. O produto $p_{1}(r) \cdot p_{2}(r)$ é maximizado quando as pressões nos dois feixes são iguais. A varredura do feixe cria um desbalanceamento entre as amplitudes dos dois feixes. Uma maneira de corrigir esse desbalanceamento é redirecionar o número de canais de um feixe para outro. Definiu-se $N_{c}$ como

$$
N_{c}=N_{c, 1}+N_{c, 2}
$$

sendo $N_{c, 1}$ e $N_{c, 2}$ os números de canais atribuídos aos feixes de frequências $\omega_{1}$ e $\omega_{2}$, respectivamente. Pode-se variar $N_{c, 1}$ de 1 até $N_{c}-1$ e avaliar-se a magnitude de $\Delta \omega$. Executou-se simulações com $N_{e}$ $=200, N_{c}=128$ e variou-se a posição focal de $x_{0}=1$ à $28 \mathrm{~mm}$ e $z_{0}=$ 10 à $50 \mathrm{~mm}$. Encontrou-se valores de $N_{c, 1}$ que otimizaram a magnitude de $\Delta \omega$ para cada posição focal.

\subsection{Resultados}

\subsubsection{Análise espacial do foco}

Na Figura 5.2(a) são mostrados os atrasos temporais aplicados nos canais para a formação do foco. As regiões do disco e do anel na Figura 5.2(b) representam as regiões excitadas pelas frequências $\omega_{1}$ e $\omega_{2}$. A interferência entre as frequências $\omega_{1}$ e $\omega_{2}$ gerou a diferença de frequência $\Delta \omega$ na região focal. Para permitir uma boa visualização, nas Figuras 5.2(a) à (f) são mostrados atrasos para somente 8 canais. Contudo, a variação de canais simulada foi de 32 à 128 canais.

Na Figura 5.4 é mostrada a força normalizada $F_{n}$ fornecida pelo $R C A$ no eixo do feixe, com $N_{e}=200$, para diferentes distâncias focais e números de canais. A variação de $N_{c}$ não afetou significativamente os parâmetros espaciais da PSF para uma distância focal fixa, incluindo a 

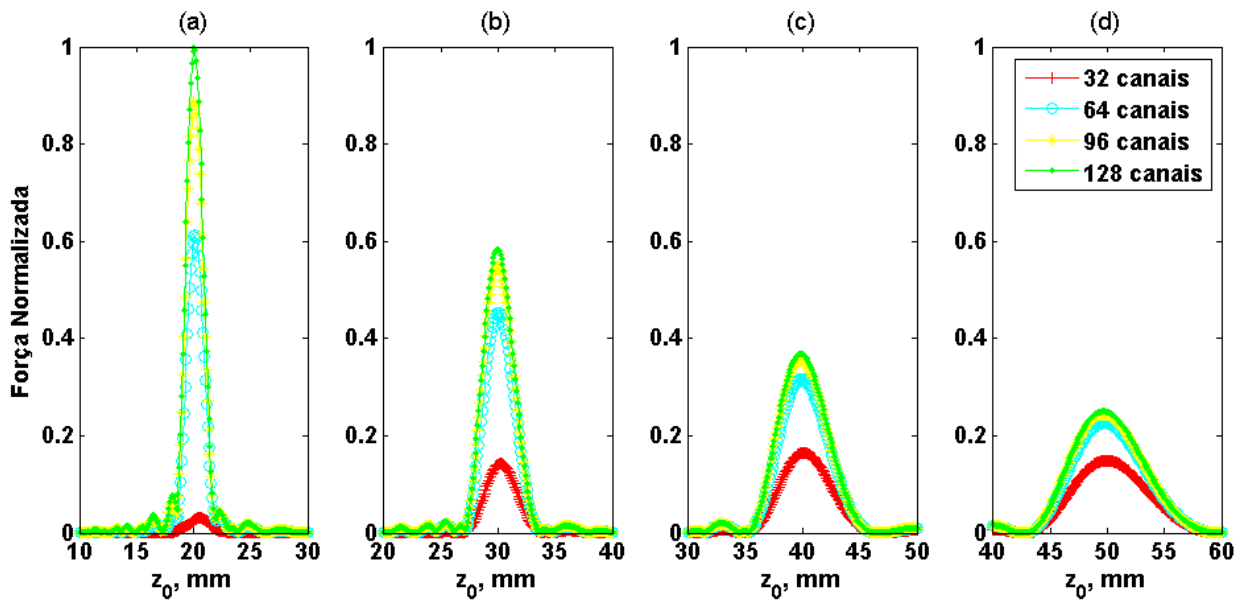

Figura 5.4: Variação da amplitude da força em relação às distâncias focais de 20, 30, 40 e $50 \mathrm{~mm}$ representadas em (a), (b), (c) e (d), respectivamente. O número de canais avaliados foram 32, 64, 96 e 128. O número de elementos foi fixado em $200 \times 200$. Todos os valores foram normalizados pelo valor máximo para todas as distâncias.

distância focal efetiva $D_{f}$, zona focal $F_{z}$ e resolução lateral $R_{l}$. Contudo, o número de canais afetou altamente a força de pico, principalmente para distâncias focais rasas. A série de gráficos na Figura 5.4 mostra o decaimento da força de pico e a diminuição da diferença entre os picos com o aumento da distância focal para diferentes números de canais. A zona focal $F_{Z}$ foi modificada somente pela variação da distância, sendo aumentada com a mesma.

A resolução lateral $R_{l}$ aumentou com a distância focal e a Figura 5.5 mostra as diferenças entre os perfis azimutais para diferentes distâncias focais e número fixo de 128 canais.

$\mathrm{Na}$ Figura 5.6 são mostrados os mapas de campo de $\vec{F}_{d}$ para diferentes números de elementos com foco localizado a $z_{0}=20 \mathrm{~mm}$. As distâncias focais efetivas foram altamente afetadas pelo número de elementos. O número mínimo de elementos para uma apropriada focalização do feixe a $20 \mathrm{~mm}$ foi de $N_{e}=100$. Além disso, a resolução lateral foi degradada pela diminuição do número de elementos. Os $f$-números para cada combinação de $N_{e}$ e distância focal $D_{f}$ são dados na Tabela 5.2. 


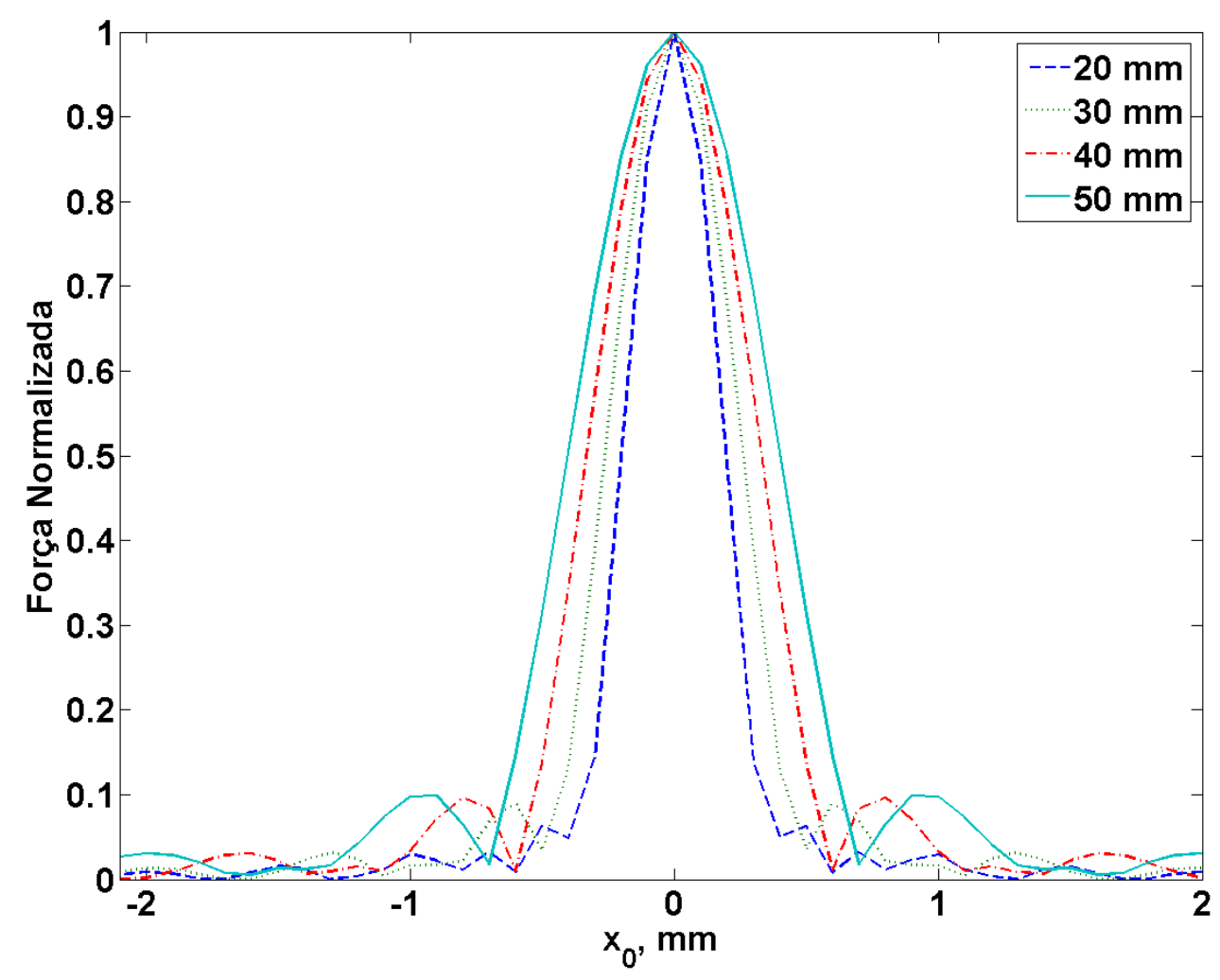

Figura 5.5: Resoluções laterais para profundidades de foco em 20, 30,40 e $50 \mathrm{~mm}$ para 128 canais e $200 \times 200$ elementos.

Na Figura 5.7 é mostrado que, devido ao emprego de poucos elementos, ocorre a dispersão do foco e diferenças na distância focal efetiva, originalmente ajustados em $20 \mathrm{~mm}$.

Os mapas de PSF, mostrados na Figura 5.8, apresentam a deflexão eletrônica do foco no plano azimutal utilizando $N_{c}=128$ e $N_{e}=$ 200 para diferentes valores de distância focal. Devido à simetria do problema, a deflexão eletrônica do foco foi avaliada somente em metade do plano. Em profundidades mais rasas, a PSF apresenta zona focal mais curta e melhor resolução espacial. Conforme a distância focal aumenta, a zona focal e a largura do feixe também aumentam.

A Figura 5.9 foi obtida tomando-se os valores máximos das magnitudes da Figura 5.8 nas distâncias $x_{0}$ (ou posições de deflexão eletrônica do foco). Observa-se que a força normalizada decresce 

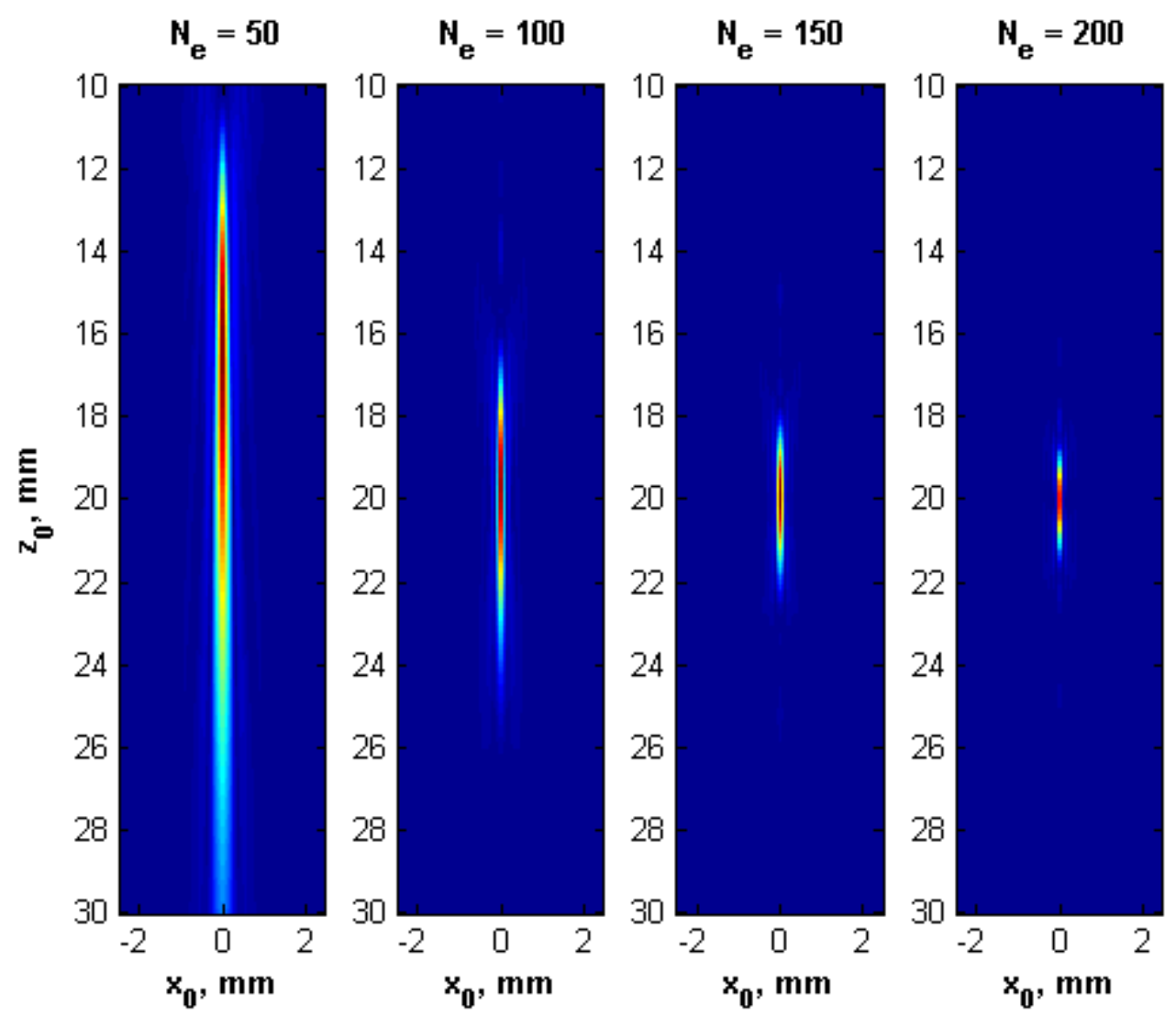

Figura 5.6: Mapas da PSF para 128 canais, distância focal ajustada para $20 \mathrm{~mm}$ e número de elementos variando de 50 x 50 à $200 \times 200$.

com a deflexão eletrônica do foco, especialmente para distâncias focais próximas ao transdutor. Para a distância focal de $20 \mathrm{~mm}$, a deflexão eletrônica do foco em $x_{0}=12 \mathrm{~mm}$ diminuiu a magnitude da força acústica em $28 \%$ do seu valor sem deflexão eletrônica do foco. Contudo, para distâncias focais superiores a $30 \mathrm{~mm}$, a magnitude diminui menos do que $50 \%$ em $x_{0}=12 \mathrm{~mm}$.

A Tabela 5.3 mostra resultados quantitativos para a distância focal efetiva, zona focal, resolução lateral e força normalizada para diferentes valores de $N_{c}, N_{e}$ e distâncias focais. A matriz de 50 x 50 elementos reduziu a distância focal efetiva em mais de $20 \%$ do valor esperado para todas as profundidades de foco avaliadas. A Tabela 5.3 mostra a necessidade de aumentar o número de elementos para profundidades maiores não somente devido à redução 


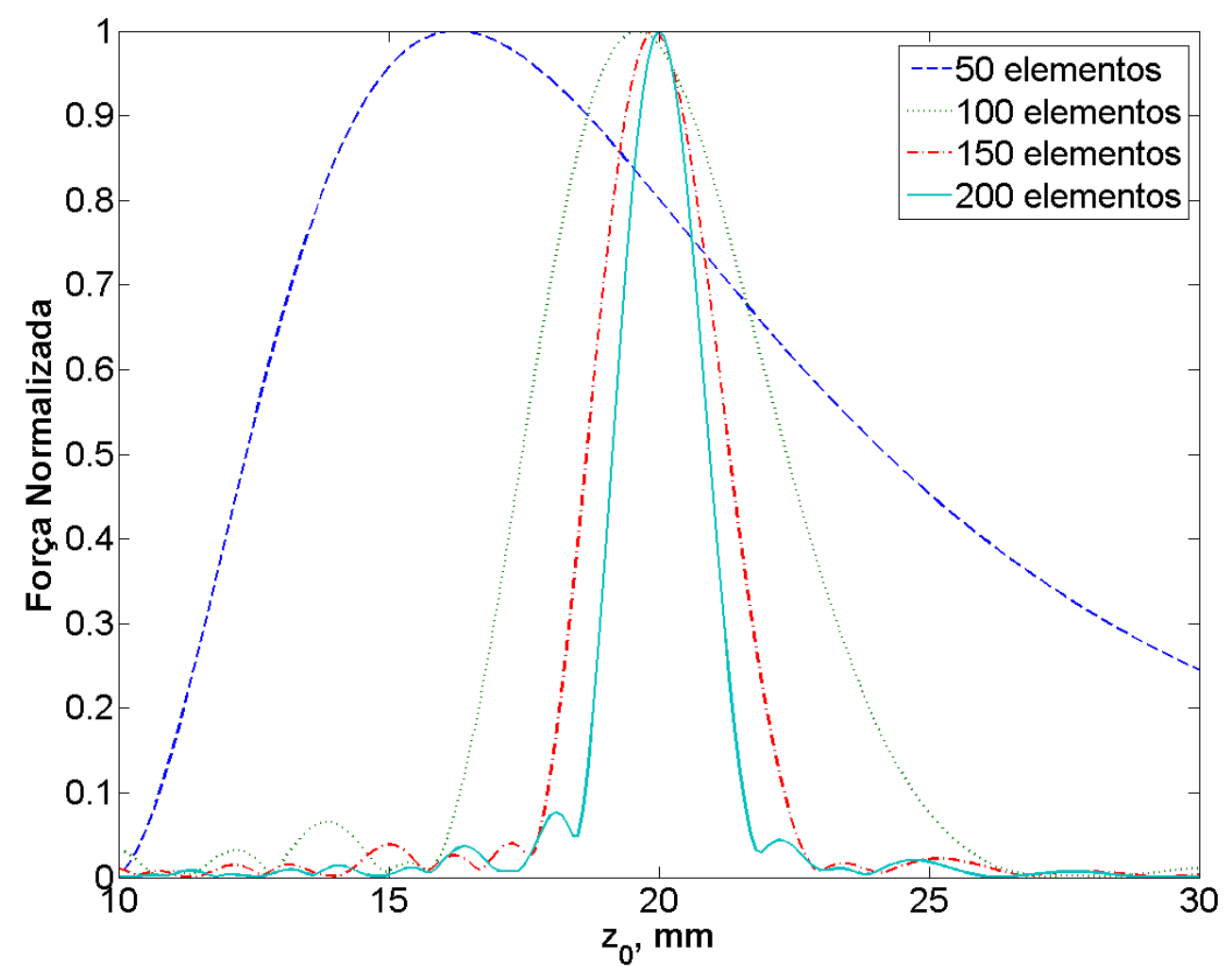

Figura 5.7: Perfil axial da PSF mostrando a distância focal efetiva para número de elementos variando de 50 × 50 à $200 \times 200$.

Tabela 5.2: f-número para aberturas e distâncias focais utilizadas nas simulações.

\begin{tabular}{c||c|c|c|c}
\hline \multicolumn{1}{c||}{} & \multicolumn{4}{c}{ Distância focal esperada } \\
$N_{e}$ & $20 \mathrm{~mm}$ & $30 \mathrm{~mm}$ & $40 \mathrm{~mm}$ & $50 \mathrm{~mm}$ \\
\hline $50 \times 50$ & 0,50 & 0,33 & 0,25 & 0,20 \\
$100 \times 100$ & 1,00 & 0,67 & 0,50 & 0,40 \\
$150 \times 150$ & 1,50 & 1,00 & 0,75 & 0,60 \\
$200 \times 200$ & 2,00 & 1,33 & 1,00 & 0,80 \\
\hline
\end{tabular}


(a)

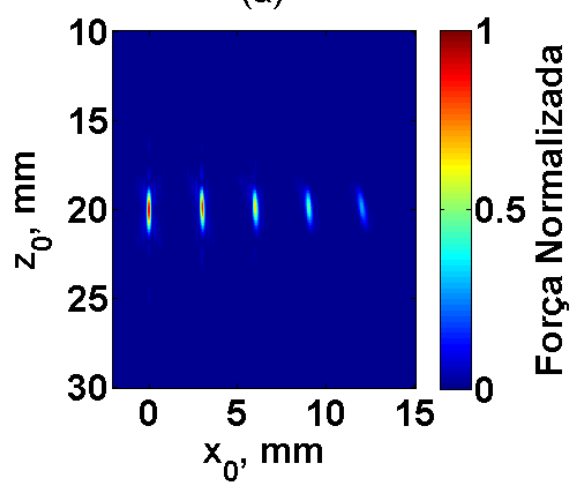

(c)

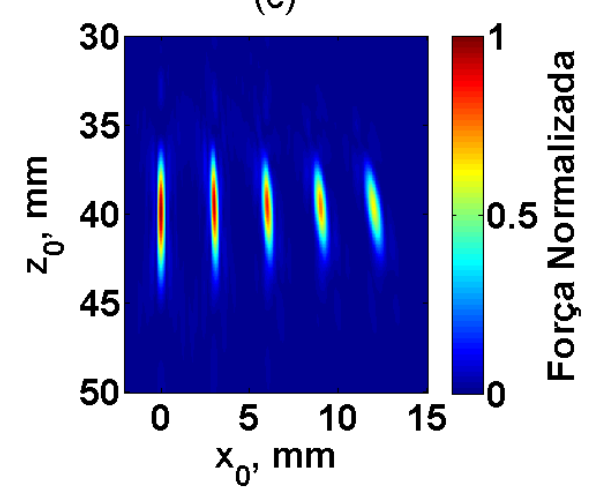

(b)

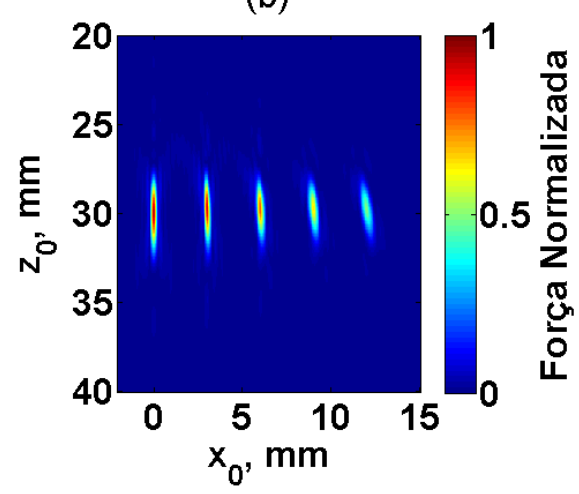

(d)

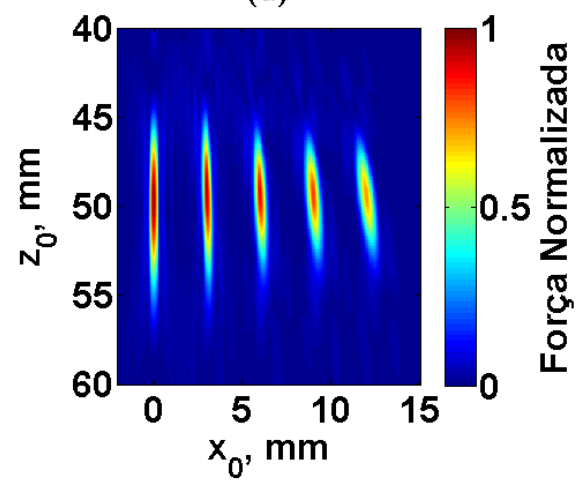

Figura 5.8: Mapas da PSF para distâncias focais de 20, 30, 40 e 50 $\mathrm{mm}$, em (a), (b), (c) e (d), respectivamente. O número de canais foi ajustado para 128 , o número de elementos para $200 \times 200$ e o feixe foi deslocado na direção azimutal para valores de $x_{0}=0,3,6,9$ e 12 $\mathrm{mm}$.

da força acústica, mas também devido ao aumento da zona focal e deterioração da resolução lateral. Para uma dada distância focal, o número de elementos afetou consideravelmente a magnitude da força acústica e a diferença entre as matrizes com 150 e 200 elementos foi de aproximadamente $60 \%$. O número de canais não alterou significativamente os resultados dos parâmetros espaciais para valores fixos de distância focal e número de elementos. Contudo, para a distância focal ajustada em $20 \mathrm{~mm}$ utilizando-se uma matriz de 100 elementos, a força acústica foi reduzida em $20 \%$ na comparação do emprego de 32 e 64 canais. Essa diferença foi ainda maior para valores maiores de $N_{e}$ para uma dada distância focal. 


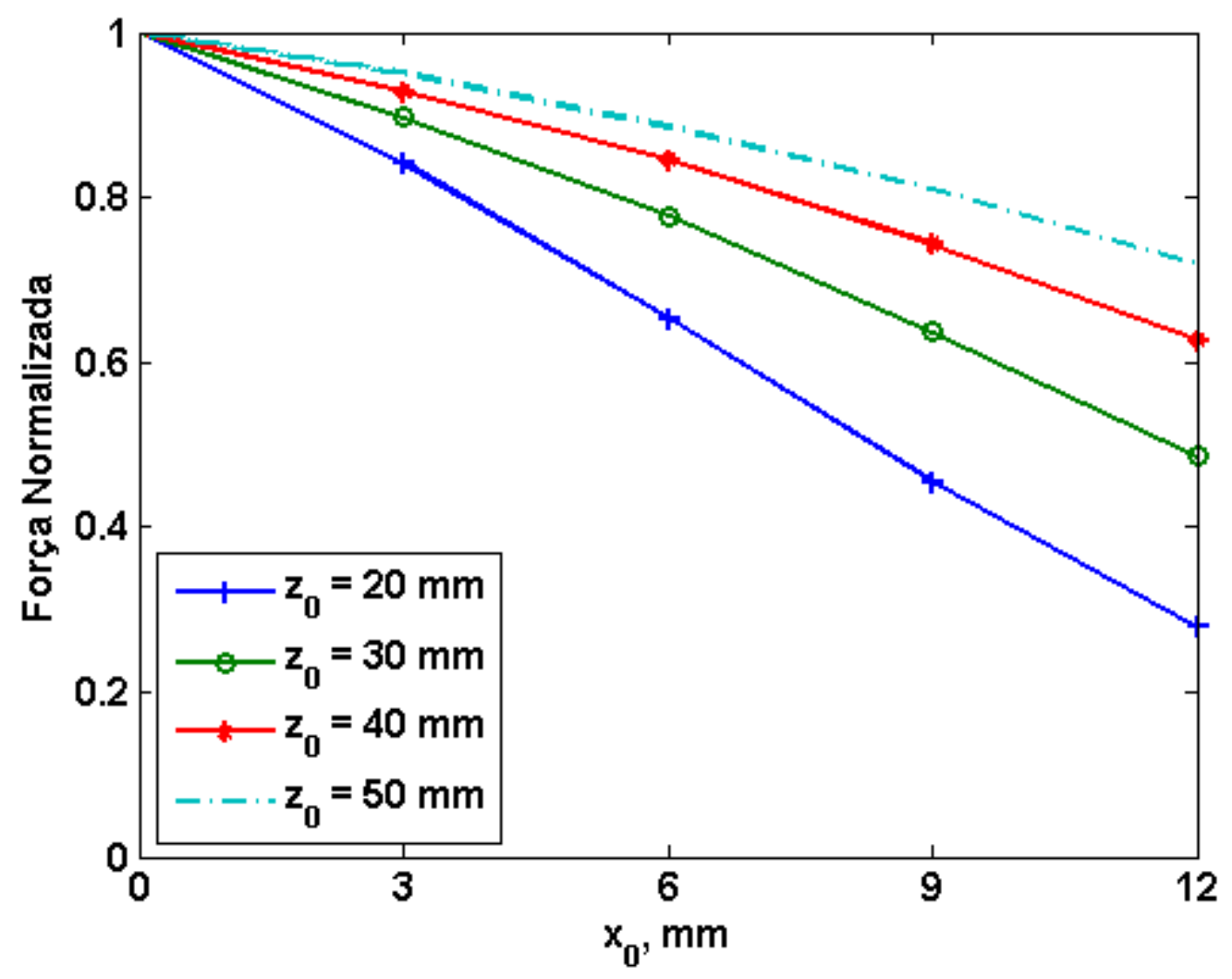

Figura 5.9: Forças máximas normalizadas extraídas dos mapas da Figura 5.8 para distâncias focais esperadas em 20, 30, 40 e $50 \mathrm{~mm}$. 

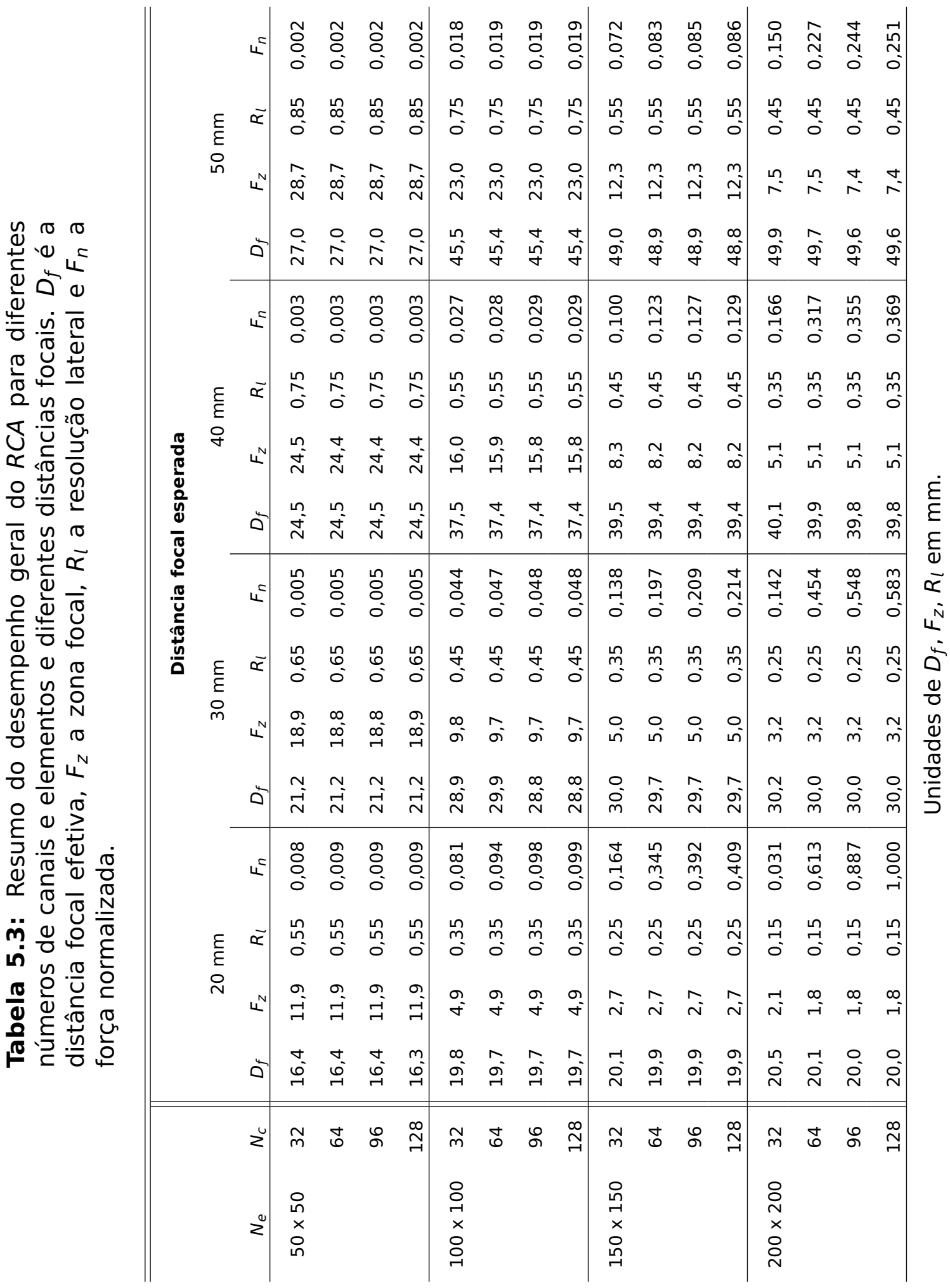


\subsubsection{Otimização da deflexão eletrônica do foco}

Variou-se o número de canais atribuídos para cada frequência de US e observou-se a existência de um número ótimo de canais dependente da localização lateral do foco (ou da deflexão eletrônica do foco). Na Figura 5.10 é mostrada a magnitude normalizada da componente $\Delta \omega$ variando-se a posição do foco em $x_{0}$. A normalização foi baseada na magnitude da componente de $\Delta \omega$ quando $N_{c, 1}=N_{c, 2}=64$. $O$ aumento na magnitude da componente de $\Delta \omega$ varia com a posição em $x_{0}$. Variou-se as posições de $x_{0}$ e $z_{0}$ e avaliou-se os valores ótimos de $N_{c, 1}$ e da magnitude normalizada da componente de $\Delta \omega$. Os resultados estão resumidos na Figura 5.11. Na Figura 5.11(a) o valor ótimo de $N_{c, 1}$ é mostrado para diferentes combinações de posições focais em $x_{0}$ e $z_{0}$. Os valores máximos de $N_{c, 1}$ foram observados em distâncias focais mais rasas. Na Figura 5.11 (b) são mostrados os ganhos na magnitude da componente de $\Delta \omega$ relativos a $N_{c, 1}=N_{c, 2}$. Por exemplo, em $z_{0}=20 \mathrm{~mm}$ e $x_{0}=15 \mathrm{~mm}$, o valor ótimo de $N_{c, 1}$ = 85 forneceu um ganho de 15,8\% sobre uma distribuição igual de canais. Utilizando-se a otimização da deflexão eletrônica do foco, as perdas relacionadas, observadas nas curvas da Figura 5.9, podem ser reduzidas. Os maiores ganhos mais uma vez foram para distâncias focais mais rasas e deflexão eletrônica do foco de aproximadamente 15 $\mathrm{mm}$. Os gráficos da magnitude normalizada da componente de $\Delta \omega$ para diferentes distâncias focais são mostrados na Figura 5.12. Aumentos de 4 à $16 \%$ na magnitude da componente de $\Delta \omega$, dependendo da distância focal, são evidentes se comparados à divisão igualitária de número de canais.

\subsection{Discussão}

Variando-se $N_{c}$, os parâmetros espaciais da PSF não foram alterados significativamente, porém a magnitude da componente de $\Delta \omega$ foi alterada. Apesar da apropriada focalização e alta resolução 


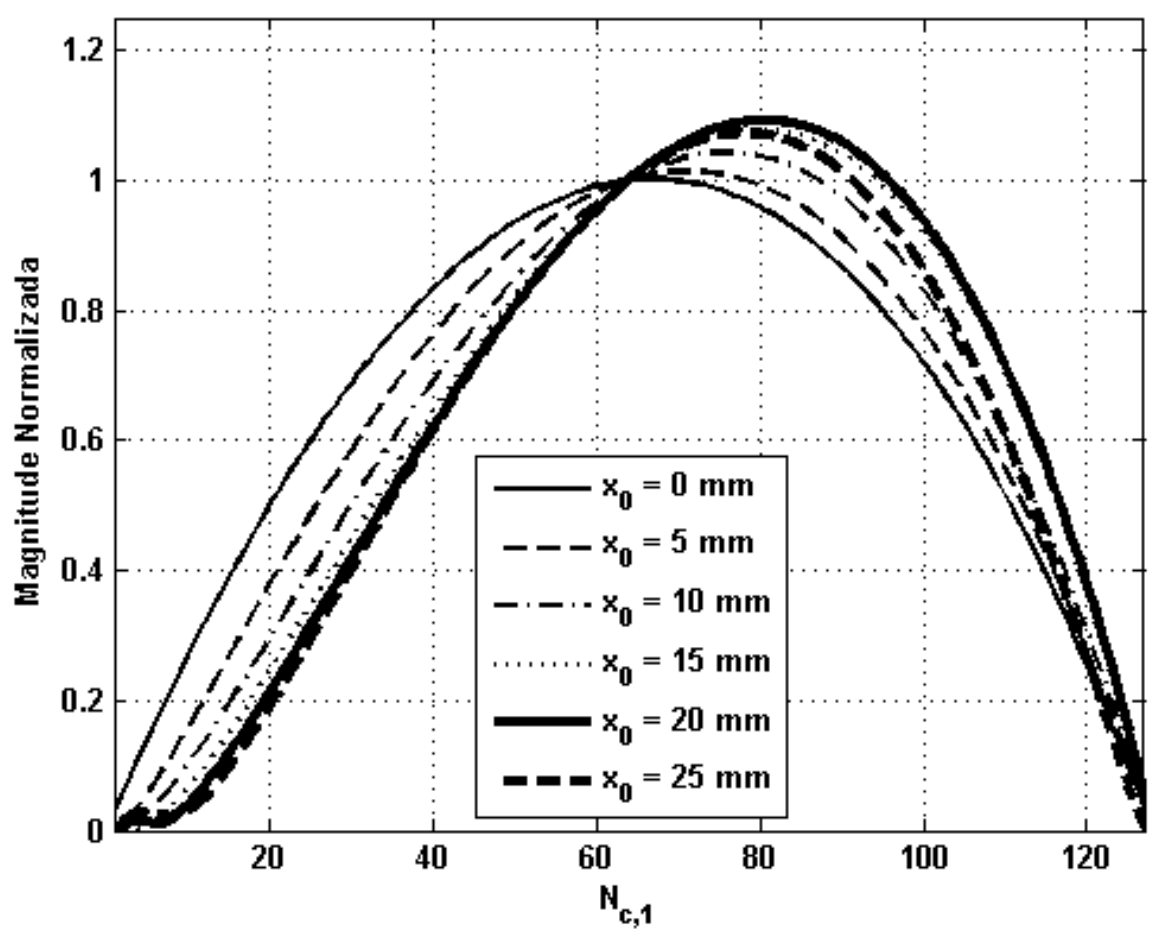

Figura 5.10: Variação da magnitude normalizada da componente de $\Delta \omega \operatorname{com} N_{c, 1}$ e localização focal variando de $x_{0}=0$ a $25 \mathrm{~mm}$ e $z_{0}=20$ $\mathrm{mm}$.

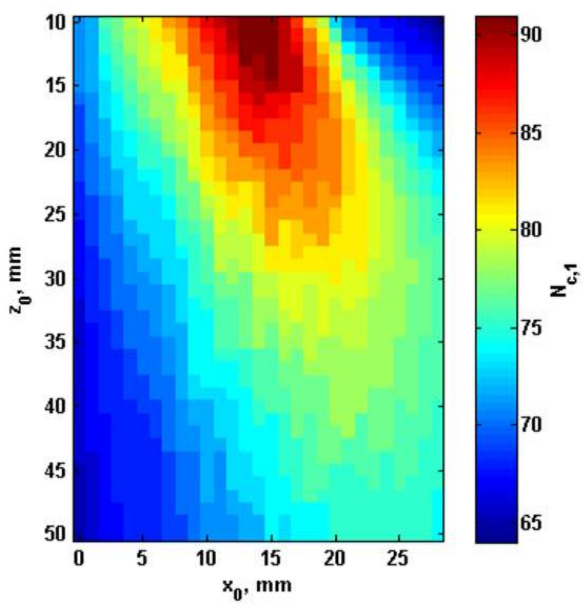

(a)

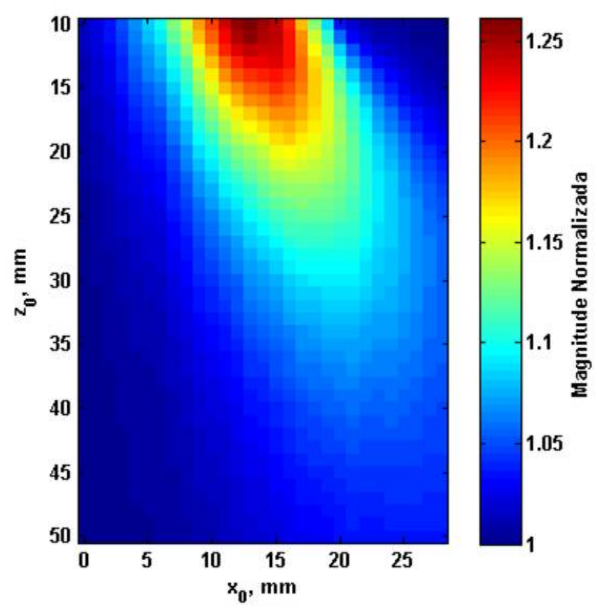

(b)

Figura 5.11: Resultados da otimização da deflexão eletrônica do foco para diferentes posições focais. (a) Valores ótimos para $N_{c, 1}$ e (b) magnitude normalizada da componente de $\Delta \omega \operatorname{com} N_{c, 1}=N_{c, 2}=64$. 


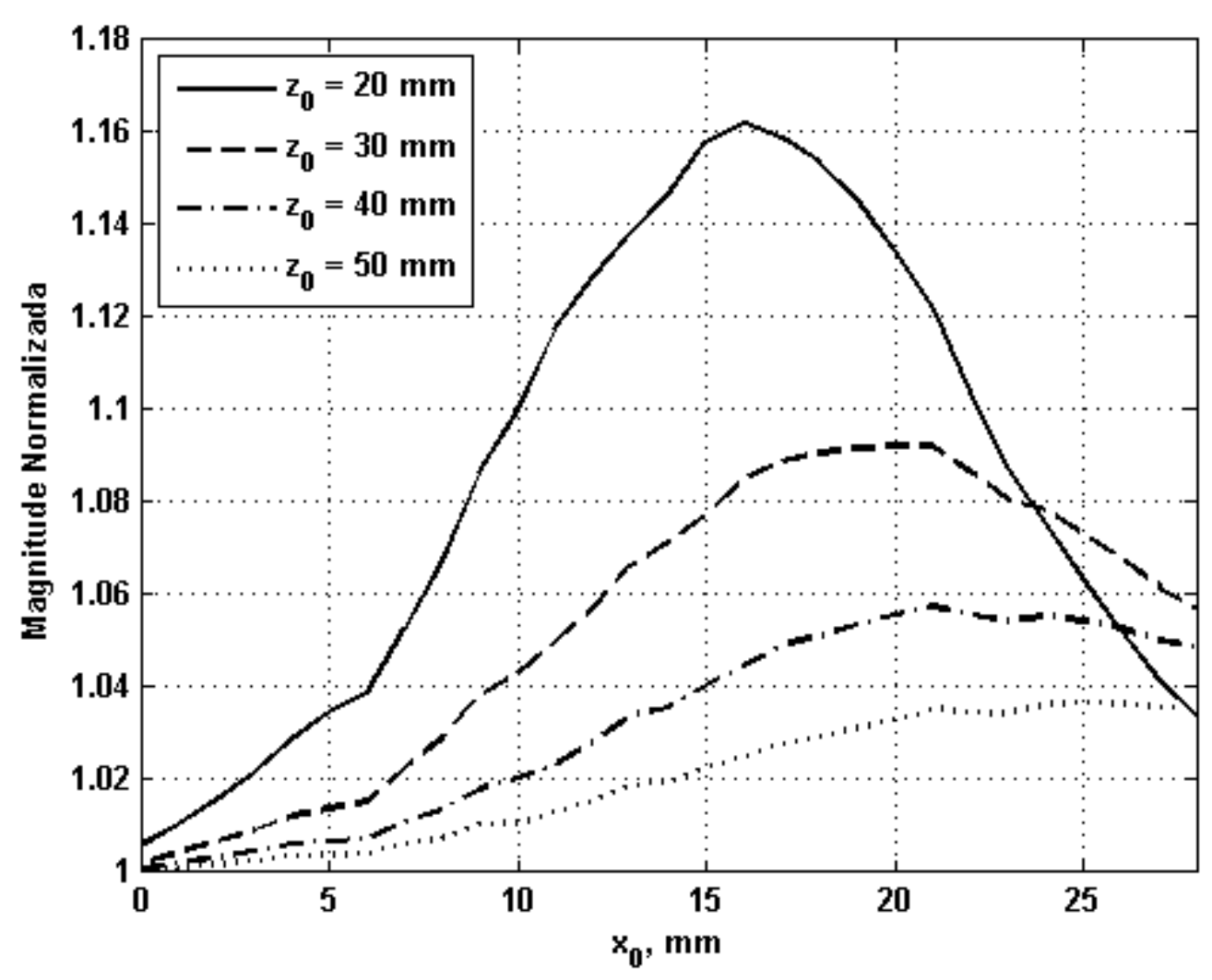

Figura 5.12: Magnitude otimizada da componente de $\Delta \omega$ para diferentes posições focais.

apresentada para a configuração de 32 canais e matriz de $200 \times 200$ elementos, a força normalizada foi de apenas $3,1 \%$ do valor máximo. Isso degradaria a imagem de VA, uma vez que a força de radiação acústica não seria suficiente para excitar o objeto-alvo. A variação da magnitude da força com o número de canais foi reduzida com o aumento da distância focal, porém os resultados encorajam o uso de maior número de canais para aberturas maiores que $100 \times 100$ elementos, uma vez que um menor número de canais não resultaria numa significativa redução do tempo de aquisição da imagem.

O aumento de $N_{e}$ tem um efeito expressivo na capacidade de focalização do feixe. O tamanho da abertura está diretamente relacionado com a focalização do feixe. Para focalizar o feixe em $z_{0}=$ 20 mm, o número mínimo de elementos necessários foi de $100 \times 100$. A 
Tabela 5.2 mostra o f-número para as diferentes aberturas e distâncias focais simuladas. Comparando-se as Tabelas 5.2 e 5.3, observa-se que a distância focal apropriada ocorre para valores de $f$-número maiores que 0,6. Utilizando-se menor número de elementos, o f-número decresce levando a uma focalização inapropriada. O aumento da zona focal para baixos números de elementos pode ser útil em determinadas aplicações. Dependendo do problema clínico, tais como geração de imagens de osso por VA [30] ou de superfícies de implantes, uma maior extensão do foco ou zona focal permite a excitação de um maior volume. Com isso, um estudo otimizado da cobertura da zona focal e resolução lateral é necessário para a definição da melhor configuração de número de elementos para diferentes aplicações.

Observou-se os efeitos da deflexão eletrônica do foco sobre a magnitude e o formato da PSF. A célula de resolução da PSF não foi alterada significativamente, porém o foco foi inclinado em relação à face do transdutor e perdeu levemente a simetria quando aplicou-se um ângulo de deflexão eletrônica do foco. A magnitude da componente de $\Delta \omega$ diminuiu quando o foco foi guiado lateralmente para fora do centro da matriz.

Uma maneira de se reduzir a perda na magnitude da componente de $\Delta \omega$ é desbalanceando o número de canais entre os dois feixes de US. Foi mostrado que a mudança de número de canais atribuídos a cada frequência otimiza a magnitude do sinal no foco para diferentes posições focais. O ganho da magnitude da componente de $\Delta \omega$ variou de 0 à $26 \%$ para $N_{c}=128$ e $N_{e}=200$. Os maiores ganhos ocorreram próximos ao transdutor com deflexão eletrônica do foco de $x_{0}=15$ $\mathrm{mm}$ e os ganhos diminuiram com a distância focal. Esse tipo de otimização pode ser facilmente implementado com o RCA devido à sua flexibilidade para mudança dinâmica do número de canais para cada feixe.

Com o transdutor confocal, a varredura mecânica do transdutor é necessária para cobrir toda a região de interesse. Com o $R C A$, é 
possível criar uma abertura menor do que a abertura total e deslocá-la eletronicamente dentro da matriz, mantendo a PSF uniforme por uma porção da imagem, como na varredura mecânica utilizando-se o transdutor confocal. Ainda, pode-se inclinar o feixe nas bordas da área coberta pela abertura, de maneira a estender a cobertura do foco. Esse processo foi utilizado similarmente com transdutores lineares como reportado por Urban et al. [41]. Para implementar esta técnica é importante encontrar o valor mínimo de $N_{e}$ que fornece uma focalização apropriada com força suficiente para obter uma adequada relação sinal-ruído na imagem resultante.

O modelo de simulação apresentado neste trabalho fornece uma plataforma muito útil para a otimização da implementação da VA utilizando-se o transdutor RCA. Baseado na aplicação e na distância focal de interesse, pode-se utilizar a simulação para encontrar a melhor combinação de $N_{e}, N_{c, 1}$ e $N_{c, 2}$.

A implementação do RCA na VA oferece algumas vantagens muito importantes. Uma vantagem bastante relevante do uso do RCA é que se pode dispensar a varredura mecânica do transdutor como no caso de transdutores confocais [19] ou lineares [41]. O tempo necessário para o deslocamento mecânico do transdutor confocal torna o tempo de varredura da região de interesse longo, sendo de até 8 minutos para imagens de $50 \times 50 \mathrm{~mm}$ com $200 \times 200$ pixeis. O tempo esperado para a varredura eletrônica utilizando-se o RCA é de aproximadamente 2 ms por pixel, que é seis vezes mais rápido do que a realizada com o confocal (480 s para 4000 pixels $=12 \mathrm{~ms} /$ pixel). O intervalo de $2 \mathrm{~ms}$ foi baseado no tempo necessário para se registrar a emissão acústica de baixas frequências por até $300 \mu \mathrm{s}$, bem como considerações sobre o tecido e aquecimento do transdutor. Com isso, subsequentes medidas não teriam interferência.

A utilização do $R C A$ proporcionaria outras linhas de implementação clínica para a VA. A resolução espacial varia com a distância focal, porém é comparável com a do transdutor confocal de tamanho 
de abertura equivalente [38]. Uma vantagem do RCA frente ao transdutor linear é que o feixe pode ser focalizado nas direções de elevação, azimutal e axial. Imagens em modo-B poderiam ser registradas subsequentemente às imagens de VA para comparações e implementações para representação tridimensional da imagem de VA. A resolução do sistema pode ser otimizada baseada nos múltiplos parâmetros discutidos neste estudo, incluindo o número de elementos e o número de canais designados para cada frequência de excitação.

A implementação da VA requer a avaliação de possível aquecimento do transdutor e bioefeitos tais como aquecimento do tecido e produção de cavitação. Com a disponibilidade do transdutor, as pressões e intensidades poderão ser avaliadas e limitadas aos limites seguros de utilização, como por exemplo os ditados pela FDA (do inglês Food and Drug Administration) [60]. O aquecimento de tecidos poderia ser avaliado por métodos numéricos baseados no estudo de Chen et al. [61].

O RCA requer hardware específico para a excitação dinâmica dos sinais, seleção de canais e atrasos temporais para deflexão eletrônica do foco, tal como o aparelho clínico da General Electric Vivid 7, já utilizado em estudos para geração de imagens de VA [41]. 


\section{Capítulo}

\section{Considerações finais}

\subsection{Conclusões}

Os resultados deste trabalho mostraram a viabilidade da VA na avaliação de implantes em ortopedia, como alternativa ao uso de técnicas de radiação ionizante para este propósito. Em técnicas baseadas em radiação ionizante, a alta densidade do osso pélvico e do implante prejudica a visualização e avaliação da estabilidade da ATQ, devido ao sobreposicionamento das regiões. Já neste trabalho, a alta densidade desses materiais é tida como grande vantagem, uma vez que essa característica permite a visualização seletiva da superfície do implante e da região óssea adjacente. Além disso, durante este trabalho foi desenvolvido um transdutor de pressão de baixo custo para avaliação da força de radiação acústica [62], para o controle de qualidade de transdutores utilizados em técnicas baseadas nesse fenômeno.

A correção analítica para representação tridimensional da imagem de VA forneceu uma avaliação quantitativa mais precisa da área da superfície descoberta do implante. A imagem de VA apresentou alto contraste e alta resolução entre as superfícies do osso e do implante, permitindo uma simples e precisa avaliação da área. A baixa sensibilidade à variação do ângulo de incidência na formação de imagem de VA é a principal vantagem em comparação com o 
modo-B. Para implantes e objetos de alta densidade com geometrias conhecidas, a imagem de VA é adequada para avaliação tridimensional da superfície, desde que uma correção da topologia seja aplicada.

O uso combinado do modo-B e VA permitiu a visualização da superfície óssea adjacente ao implante. Isso pode ser útil no diagnóstico de fissuras no acetábulo que podem prejudicar a fixação do implante. Além disso, as imagens de VA e modo-B podem ser usadas para a avaliação de objetos de alta densidade com geometrias desconhecidas.

Foi demonstrado um modelo numérico para a implementação de VA utilizando-se transdutores 2D matriciais reconfiguráveis. Estudou-se os efeitos do número de elementos, número de canais e posição do foco, sobre a PSF para forças de baixa frequência. Verificou-se que as dimensões da PSF são modificadas com a mudança do número de elementos e da posição do foco. Foi explorada ainda uma otimização do campo acústico, baseada no desbalanceamento do número de canais para cada feixe de ultrassom. As simulações fornecem uma forte base para a avaliação e otimização da VA utilizando $R C A$ para diferentes aplicações clínicas.

Por fim, a qualidade das imagens apresentadas sugere a viabilidade da VA para a avaliação de diferentes tipos de implante inseridos em regiões não profundas (menos que $7 \mathrm{~cm}$ de profundidade), tais como em membros superiores, membros inferiores e joelhos. O uso da VA pode ser principalmente útil em casos em que se deve evitar o uso de radiação ionizante, como, por exemplo, em diagnóstico de fraturas e avaliação de implantes em gestantes e em jovens [2].

\subsection{Trabalhos Futuros}

Para a validação da técnica na avaliação de ATQ seriam necessários estudos in vivo. A técnica de VA já é estudada in vivo na Mayo Clinic, MN, EUA, para casos de microcalcificações em mama, tireóide 
e próstata. Estudos futuros para a utilização do método proposto in vivo já estão sendo considerados em colaboração entre os laboratórios GIIMUS e de Ultrassom da Mayo Clinic.

O uso da técnica de VA na prática clínica ainda está em fase de estudo. Para a utilização da técnica proposta na rotina clínica de avaliação de superfície óssea e de implantes, um grande facilitador seria a utilização de transdutores comerciais com capacidade de geração de foco similar a do transdutor confocal. Com isso, a implementação do transdutor $R C A$ é fundamental para a melhoria da qualidade das imagens de VA evitando problemas de acoplamento gerados por transdutores confocais.

A implementação do $R C A$ para VA permite o controle flexível do comprimento do foco. Uma proposta seria aumentar o comprimento do foco, para diminuir o número de varreduras em diferentes profundidades e, assim, reconstruir a superfície tridimensional, como proposto neste trabalho.

Outra proposta seria a geração de imagens 3D utilizando $R C A$ somente no modo de VA. Através da diminuição do comprimento do foco para alguns milímetros seria possível a aquisição em várias profundidades de foco e posteriormente reconstruir tridimensionalmente o volume varrido, a partir apenas de imagens de VA.

A avaliação tridimensional de superfícies ósseas utilizando técnicas não-ionizantes em medicina esportiva é também de grande importância para a rotina clínica. A utilização da VA na reconstrução da superfície tridimensional da escápula facilitaria o posicionamento de sensores de movimentos em estudos de articulações em Biomecânica. Atualmente, o posicionamento dos sensores é realizado através de palpação. 


\section{Referências Bibliográficas}

[1] BROWN, T. E.; CUI, Q.; MIHALKO, W. M. Arthritis and arthroplasty: The hip. Arthritis and Arthroplasty. Philadelphia: Saunders Elsevier, 2009. 428 p. 1

[2] REYNOLDS, D.; FREEMAN, M. A. R. Osteoarthritis in the young adult hip: options for surgical management. Current problems in orthopaedics. Churchill Livingstone, 1989. 290 p. 1, 82

[3] SPANGEHL, M. J.; BERRY, D. J.; TROUSDALE, R. T.; CABANELA, M. E. Uncemented acetabular components with bulk femoral head autograft for acetabular reconstruction in developmental dysplasia of the hip: results at five to twelve years. J. Bone Jt. Surg., Needham, v. 83A, n. 10, p. 1484-1489, out. 2001. 1, 3

[4] FATEMI, M.; GREENLEAF, J. F. Ultrasound-stimulated vibro-acoustic spectrography. Science, Washington, v. 280, n. 5360, p. 82-85, abr. 1998. 1, 4, 27, 52

[5] GUARNIERO, R. Dysplasia of hip development: update. Rev. Bras. Ortopedia, São Paulo, v. 45, p. 116-121, mar. 2010. 2

[6] KAVANAGH, B. F.; ILSTRUP, D. M.; FITZGERALD, R. H. Revision total hip arthroplasty. J. Bone Jt. Surg., Needham, v. 67A, n. 4, p. 517, abr. 1985. 2

[7] ANDERSON, M. J.; HARRIS, W. H. Total hip arthroplasty with insertion of the acetabular component without cement in hips 
with total congenital dislocation or marked congenital dysplasia. J. Bone Jt. Surg., Needham, v. 81A, n. 3, p. 347-354, mar. 1999. 2

[8] HARTOFILAKIDIS, G.; GEORGIADES, G.; BABIS, G. C.; YIANNAKOPOULOS, C. K. Evaluation of two surgical techniques for acetabular reconstruction in total hip replacement for congenital hip disease - Results after a minimum ten-year follow-up. J. Bone Jt. Surg., London, v. 90B, n. 6, p. 724-730, jun. 2008. 2

[9] JASTY, M.; ANDERSON, M. J.; HARRIS, W. H. Total hip-replacement for developmental dysplasia of the hip. Clin. Orthop. Relat. Res., Philadelphia, v. 1, n. 311, p. 40-45, fev. 1995. 2

[10] KIM, Y. H.; SEO, H. S.; KIM, J. S. Outcomes after THA in patients with high hip dislocation after childhood sepsis. Clin. Orthop. Relat. Res., New York, v. 467, n. 9, p. 2371-2378, set. 2009. 2

[11] SANCHEZ-SOTELO, J.; TROUSDALE, R. T.; BERRY, D. J.; CABANELA, M. E. Surgical treatment of developmental dysplasia of the hip in adults: I. nonarthroplasty options. J. Am. Acad. Orthop. Surg., v. 10, n. 5, p. 321-333, set./out. 2002. 2

[12] BECKENBAUGH, R. D.; ILSTRUP, D. M. Total hip arthroplasty. J. Bone Jt. Surg., Needham, v. 60A, n. 3, p. 306-313, abr. 1978. 3

[13] RABELLO, B. T.; CABRAL, F. P.; FREITAS, E.; PENEDO, J.; CURY, M. B.; RINALDI, E. R.; PEIXOTO, L. Artroplastia total do quadril não cimentada em pacientes com artrite reumatóide. Rev. bras. ortop., São Paulo, v. 43, n. 8, p. 336-342, set. 2008. 3

[14] JOHNSTON, R. C.; FITZGERALD, R. H.; HARRIS, W. H.; POSS, R.; MULLER, M. E.; SLEDGE, C. B. Clinical and radiographic evaluation of total hip replacement. A standard system of terminology for reporting results. J. Bone Jt. Surg., Needham, v. 72A, n. 2, p. 161-168, fev. 1990. 3 
[15] PRINS, J.; JøRGENSEN, $\mathrm{H}$. The role of quantitative ultrasound in the assessment of bone: a review. Clinical Physiology, Oxford, v. 18, n. 1, p. 3-17, jan. 1998. 3

[16] BAUER, D. C.; GLUER, C. C.; CAULEY, J. A.; VOGT, T. M.; ENSRUD, K. E.; GENANT, H. K.; BLACK, D. M. Broadband ultrasound attenuation predicts fractures strongly and independently of densitometry in older women - A prospective study. Arch. Intern. Med., Chicago, v. 157, n. 6, p. 629-634, mar. 1997. 3

[17] LEE, M. H.; CHA, J. G.; HONG, H. S.; LEE, J. S.; PARK, S. J.; PAIK, S. H.; LEE, H. K. Comparison of high-resolution ultrasonography and computed tomography in the diagnosis of nasal fractures. J. Ultrasound Med., Laurel, v. 28, n. 6, p. 717-723, jun. 2009. 4

[18] BARRATT, D. C.; CHAN, C. S. K.; EDWARDS, P. J.; PENNEY, G. P.; SLOMCZYKOWSKI, M.; CARTER, T. J.; HAWKES, D. J. Instantiation and registration of statistical shape models of the femur and pelvis using 3D ultrasound imaging. Medical Image Analysis, Amsterdam, v. 12, n. 3, p. 358-374, jun. 2008. 4

[19] FATEMI, M.; GREENLEAF, J. F. Vibro-acoustography: An imaging modality based on ultrasound-stimulated acoustic emission. Proc. Nat. Acad. of Sci. USA, Washington, v. 96, n. 12, p. 6603-6608, jun. 1999. 4, 14, 79

[20] FATEMI, M.; MANDUCA, A.; GREENLEAF, J. F. Imaging elastic properties of biological tissues by low-frequency harmonic vibration. Proc. IEEE, Piscataway, v. 91, n. 10, p. 1503-1519, out. 2003. 4

[21] ALIZAD, A.; FATEMI, M.; WHALEY, D. H.; GREENLEAF, J. F. Application of vibro-acoustography for detection of calcified arteries in breast tissue. J. Ultrasound Med., Laurel, v. 23, n. 2, p. 267-273, fev. 2004. 4 
[22] PISLARU, C.; KANTOR, B.; KINNICK, R. R.; ANDERSON, J. L.; AUBRY, M. C.; URBAN, M. W.; FATEMI, M.; GREENLEAF, J. F. In vivo vibroacoustography of large peripheral arteries. Invest. Radiol., Philadelphia, v. 43, n. 4, p. 243-252, abr. 2008. 4

[23] FATEMI, M.; WOLD, L. E.; ALIZAD, A.; GReEnleAF, J. F. Vibro-acoustic tissue mammography. IEEE Trans. Med. Imag., lowa City, v. 21, n. 1, p. 1-8, jan. 2002. 4

[24] ALIZAD, A.; FATEMI, M.; WOLD, L. E.; GREENLEAF, J. F. Performance of vibro-acoustography in detecting microcalcifications in excised human breast tissue: A study of 74 tissue samples. IEEE Trans. Med. Imag., lowa City, v. 23, n. 3, p. 307-312, mar. 2004. 4

[25] ALIZAD, A.; MITRI, F. G.; KINNICK, R. R.; GREENLEAF, J. F.; FATEMI, M. Vibro-acoustography of thyroid. In: . ASA, c2007. v. 122 of 154th Meet. Acoust. Soc. Am. p. 3026-3026. 4

[26] MITRI, F. G.; TROMPETTE, P.; CHAPELON, J. Y. Improving the use of vibro-acoustography for brachytherapy metal seed imaging: A feasibility study. IEEE Trans. Med. Imag., lowa City, v. 23, n. 1, p. 1-6, jan. 2004. 4

[27] MITRI, F. G.; DAVIS, B. J.; ALIZAD, A.; GREENLEAF, J. F.; WILSON, T. M.; MYNDERSE, L. A.; FATEMI, M. Prostate cryotherapy monitoring using vibro-acoustography: preliminary results of an ex vivo study and technical feasibility. IEEE Trans. Biomed. Eng., Gainesville, v. 55, n. 11, p. 2584-2592, nov. 2008. 4

[28] MITRI, F. G.; DAVIS, B. J.; GREENLEAF, J. F.; FATEMI, M. In vitro comparative study of vibro-acoustography versus pulse-echo ultrasound in imaging permanent prostate brachytherapy seeds. Ultrasonics, v. 49, n. 1, p. 31-38, jan. 2009. 4

[29] MITRI, F. G.; DAVIS, B. J.; URBAN, M. W.; ALIZAD, A.; GREENLEAF, J. F.; LISCHER, G. H.; WILSON, T. M.; FATEMI, 
M. Vibro-acoustography imaging of permanent prostate brachytherapy seeds in an excised human prostate - Preliminary results and technical feasibility. Ultrasonics, v. 49, n. 3, p. 389-394, mar. 2009. 4

[30] CALlE, S.; REMENIERAS, J. P.; MATAR, O. B.; DEFONTAINE, M.; PATAT, F. Application of nonlinear phenomena induced by focused ultrasound to bone imaging. Ultr. Med. Biol., v. 29, n. 3, p. 465-472, abr. 2003. 4, 78

[31] RenAud, G.; CALle, S.; REMEnierAS, J. P.; DEFONTAINE, M. Non-linear acoustic measurements to assess crack density in trabecular bone. Internat. J. Non-Linear Mechanics, v. 43, n. 3, p. 194-200, abr. 2008. 4

[32] ALIZAD, A.; WALLCH, M.; GREENLEAF, J. F.; FATEMI, M. Vibrational characteristics of bone fracture and fracture repair: Application to excised rat femur. J. Biomech. Eng. - Trans. ASME, New York, v. 128 , n. 3, p. 300-308, jun. 2006. 4

[33] MITRI, F. G.; DAVIS, B. J.; GREENLEAF, J. F.; FATEMI, M. In vitro comparative study of vibro-acoustography versus pulse-echo ultrasound in imaging permanent prostate brachytherapy seeds. Ultrasonics, Amsterdam, v. 49, n. 1, p. 31-38, jan. 2009. 5

[34] NELSON, T. R.; PRETORIUS, D. H. Three-dimensional ultrasound imaging. Ultr. Med. Biol., v. 24, n. 9, p. 1243-1270, mai. 1998. 6, 29

[35] ODONNELL, M.; JAYNES, E. T.; MILLER, J. G. Kramers-Kronig relationship between ultrasonic attenuation and phase velocity. J. Acoust. Soc. Am., v. 69, p. 696-701, mar. 1981. 10

[36] COBBOLD, R. S. C. Foundations of biomedical ultrasound. New York: Oxford University Press, USA, 2007. 10, 11, 18, 61, 64 
[37] BAMBER, J. C. Ultrasonic properties of tissues. In: J. Ultrasound Med., Medical Science Series. IOP Publishing Ltd, 1998. Cap. 4, p. 57-88. 11

[38] CHEN, S.; FATEMI, M.; KINNICK, R. R.; GREENLEAF, J. F. Comparison of stress field forming methods for vibro-acoustography. IEEE Trans. Ultrason. Ferroelectr. Freq. Control, Aurora, v. 51, n. 3, p. 313-321, ago. 2004. 14, 16, 80

[39] JENSEN, J. A. Field: A program for simulating ultrasound systems. In: . 10th Nordic-Baltic Conf. on Biomedical Imaging, Tampere, Finlândia, Suplemento 1, parte 1, jun., 1996. 14

[40] SILVA, G. T.; GREENLEAF, J. F.; FATEMI, M. Linear arrays for vibro-acoustography: A numerical simulation study. Ultrasonic Imaging, v. 26, n. 1, p. 1-17, jan. 2004. 17

[41] URBAN, M. W.; CHALEK, C.; KINNICK, R. R.; KINTER, T. M.; HAIDER, B.; GREENLEAF, J. F.; THOMENIUS, K.; FATEMI, M. Implementation of vibro-acoustography on a clinical ultrasound system. IEEE Trans. Ultrason. Ferroelectr. Freq. Control, Aurora, No prelo. 17, $58,79,80$

[42] WILDES, D. G.; CHIAO, R. Y.; DAFT, C. M. W.; RIGBY, K. W.; SMITH, L. S.; THOMENIUS, K. E. Elevation performance of $1.25 \mathrm{~d}$ and $1.5 \mathrm{~d}$ transducer arrays. IEEE Trans. Ultrason. Ferroelectr. Freq. Control, Aurora, v. 44, n. 5, p. 1027-1037, set. 1997. 18

[43] MAST, T. D. Empirical relationships between acoustic parameters in human soft tissues. Acoustics Research Letters Online, v. 1, n. 2, p. 37-42, nov. 2000. 24

[44] MADSEN, E. L.; FRANK, G. R.; DONG, F. Liquid or solid ultrasonically tissue-mimicking materials with very low scatter. Ultr. Med. Biol., Kidlington, v. 24, n. 4, p. 535-542, mai. 1998. 24 
[45] BURGER, W.; BURGE, M. J. Digital image processing: an algorithmic introduction using Java. Springer-Verlag New York Inc, 2008. 30, 31

[46] GONZALEZ, R. C.; WOODS, R. E.; EDDINS, S. L. Digital image processing using MATLAB. Prentice Hall Upper Saddle River, NJ, 2004. 31

[47] ZILL, D. G.; WRIGHT, W. S.; CULLEN, M. R. Advanced engineering mathematics. 4. ed. Londres: Jones and Bartlett Publishers International, 2011. Cap. 7.4 Cross Product, p. 319-324. 34

[48] FENSTER, A.; DOWNEY, D. B.; CARDINAL, H. N. Three-dimensional ultrasound imaging. Physics Med. Biol., v. 46, n. 5, p. R67-R99, mai. 2001. 53

[49] TREECE, G. M.; GEE, A. H.; PRAGER, R. W.; CASH, C. J. C.; BERMAN, L. H. High-definition freehand 3-D ultrasound. Ultr. Med. Biol., v. 29, n. 4 , p. $529-546$, abr. 2003. 53

[50] ALIZAD, A.; WHALEY, D. H.; GREenLEAF, J. F.; FATEMI, M. Potential applications of vibro-acoustography in breast imaging. Tech. Canc. Res. Treat., v. 4, n. 2, p. 151-157, abr. 2005. 58

[51] ALIZAD, A.; WHALEY, D. H.; GREENLEAF, J. F.; FATEMI, M. Critical issues in breast imaging by vibro-acoustography. Ultrasonics, $\mathrm{V}$. 44, n. Suppl. 1, p. E217-E220, dez. 2006. 58

[52] HOSSEINI, H. G.; ALIZAD, A.; FATEMI, M. Integration of vibro-acoustography imaging modality with the traditional mammography. Int. J. Biomed. Imag., v. 2007, p. 8, 2007. 58

[53] FISHER, R.; THOMENIUS, K.; WODNICKI, R.; THOMAS, R.; COGAN, S.; HAZARD, C.; LEE, W.; MILLS, D.; KHURI-YAKUB, B.; ERGUN, A.; YARALIOGLU, G. Reconfigurable arrays for portable ultrasound, set. 2005. IEEE Internat. Ultr. Symp., Rotterdam, 2005. 58 
[54] HOOI, F. M.; THOMENIUS, K. E.; FISHER, R.; CARSON, P. L. Hybrid beamforming and steering with reconfigurable arrays. IEEE Trans. Ultrason. Ferroelectr. Freq. Control, Aurora, v. 57, n. 6, p. 1311-1319, jun. 2010. 58

[55] STEPANISHEN, P. R. The Time-Dependent Force and Radiation Impedance on a Piston in a Rigid Infinite Planar Baffle. J. Acoust. Soc. Am., v. 49, p. 841, 1971. 59

[56] WILLIAMS, E. G.; MAYNARD, J. D. Numerical evaluation of the Rayleigh integral for planar radiators using the FFT. J. Acoust. Soc. Am., v. 72 , p. 2020, 1982. 60

[57] MAST, T. D. Fresnel approximations for acoustic fields of rectangularly symmetric sources. J. Acoust. Soc. Am., v. 121, n. 6, p. 3311-3322, jun. 2007. 60, 62

[58] COGAN, S.; FISHER, R.; THOMENIUS, K.; WODNICKI, R. Solutions for Reconfigurable Arrays in Ultrasound. In: . IEEE Ultr. Symp. Vancouver: , c2006. p. 116-119, Vancouver, out., 2006. 64

[59] ZISKIN, M. C.; LEWIN, P. A. Ultrasonic exposimetry. Boca Raton: CRC Press, 1992. 66

[60] HERMAN, B.; HARRIS, G. Models and regulatory considerations for transient temperature rise during diagnostic ultrasound pulses. Ultr. Med. Biol., v. 28, n. 9, p. 1217-1224, set. 2002. 80

[61] CHEN, S.; AQUINO, W.; ALIZAD, A.; URBAN, M. W.; KINNICK, R. R.; GREENLEAF, J. F.; FATEMI, M. Thermal safety of vibro-acoustography using a confocal transducer. Ultr. Med. Biol., v. 36, n. 2 , p. $343-349$, fev. 2010.80

[62] KAMIMURA, H. A. S.; PAVAN, T. Z.; ALMEIDA, T. W. J.; PÁDUA, M. L. A.; BAGGIO, A. L.; FATEMI, M.; CARNEIRO, A. A. O. Pressure transducer for measuring acoustic radiation force based on a magnetic 
sensor. Measurement Science and Technology, Philadelphia, v. 22, p. 015101, jan. 2011. 81

1

\footnotetext{
${ }^{1}$ Citação de referências normalizada de acordo com a Associação Brasileira de Normas Técnicas (ABNT) - NBR 6023.
} 